WALDEN

UNIVERSITY

A higher degree. A higher purpose.

Walden University ScholarWorks

2015

\title{
Predictors of Obesity Among Nigerian Immigrants in the United States
}

Olawunmi Obisesan

Walden University

Follow this and additional works at: https://scholarworks.waldenu.edu/dissertations

Part of the Epidemiology Commons, and the Public Health Education and Promotion Commons

This Dissertation is brought to you for free and open access by the Walden Dissertations and Doctoral Studies Collection at ScholarWorks. It has been accepted for inclusion in Walden Dissertations and Doctoral Studies by an authorized administrator of ScholarWorks. For more information, please contact ScholarWorks@waldenu.edu. 


\title{
Walden University
}

\author{
College of Health Sciences
}

This is to certify that the doctoral dissertation by

\author{
Olawunmi Obisesan
}

has been found to be complete and satisfactory in all respects, and that any and all revisions required by the review committee have been made.

Review Committee

Dr. Wen-Hung Kuo, Committee Chairperson, Public Health Faculty

Dr. Michael Brunet, Committee Member, Public Health Faculty

Dr. James Rohrer, University Reviewer, Public Health Faculty

Chief Academic Officer

Eric Riedel, Ph.D.

Walden University

2015 


\begin{abstract}
Predictors of Obesity Among Nigerian Immigrants in the United States

by

Olawunmi Obisesan
\end{abstract}

MPH, Walden University, 2012

BSN, Southeast Missouri State University, 2013

BA, University of Ado Ekiti, 2001

\author{
Dissertation Submitted in Partial Fulfillment \\ of the Requirements for the Degree of \\ Doctor of Philosophy \\ Public Health
}

Walden University

May 2015 


\begin{abstract}
Obesity has been identified as a significant risk factor for chronic diseases, contributing to health disparities in minority and vulnerable populations. Though research has identified an increased risk for obesity in the Hispanic immigrant population, there is little or no research on the heterogeneity of obesity predictors in specific immigrant populations in the United States. This study examined the predictors of obesity in the Nigerian immigrant population in the United States. Guided by the social ecological model and the segmented assimilation theory, this cross-sectional study collected primary data from 205 Nigerian immigrants in the United States using the CDC's Behavioral Risk Factor Surveillance System self-administered web-based survey. Spearman's correlation and logistic regressions were used to analyze data through SPSS. The results showed no significant relationship between obesity and the factors education, socioeconomic status, length of stay, and level of physical activity. This study, however, identified a significant association between weekly consumption of alcohol and all obesity (OR 1.78, $p=.021$ ), and moderate/morbid obesity (OR 2.46, $p=.013$ ). There was also a significant association between gender and moderate/morbid obesity (OR 3.30, $p=.031)$. These findings provide strong evidence to inform the development of targeted culturallyrelevant community-based interventions for Nigerian immigrant population in the United States, including health education and targeted screenings for alcohol consumption, and other unrecognized behaviors that increase their risk for obesity. The lack of association between other well-known predictors of obesity and obesity outcomes calls for further investigation into other causes of obesity in this immigrant population.
\end{abstract}


Predictors of Obesity Among Nigerian Immigrants in the United States by

\section{Olawunmi Obisesan}

MPH, Walden University, 2012

BSN, Southeast Missouri State University, 2013

BA, University of Ado Ekiti, 2001

Dissertation Submitted in Partial Fulfillment

of the Requirements for the Degree of

Doctor of Philosophy

Public Health

Walden University

May 2015 


\section{Acknowledgments}

First of all, I thank God for his love, mercies and grace during this journey. I appreciate my committee chairperson, Dr. Wen-Hung Kuo, who always provided timely and valuable feedback, despite the distance. I thank Dr. Michael Brunet, my committee member, who was only "an email away," for his consistent and excellent contribution to my research content on obesity. I thank Dr. James E. Rohrer and Dr. Peter Anderson who made significant contributions to the success of my study.

I thank my wonderful husband, Adekunle, and my children, Tam and Moyo, for demonstrating such love and understanding during this journey. I thank my parents, Prof. and Mrs. Olaleye, who taught me the value of education from a very young age. I also appreciate my wonderful parents-in-law, Mr. and Mrs. S.A. Obisesan, whose constant phone calls and prayers gave me comfort. I thank my entire family for giving me the space to write, for understanding how important completing this degree was for me, and not holding grudges when I could not attend family or social functions.

I will like to say a special thank you to all my friends who offered words of encouragement and prayers, most especially Olusola Oloruntoba and Oluseyi Odulaja. I appreciate Olubusayo Akinola for being the perfect dissertation partner and my go-to person whenever I got stuck; the bond we created during this period is strong and for life. I appreciate my mentors, Prof. William Brieger, Dr. Oluremi Sogunro, Dr. Donna Allen, and Dr. Yvonne Commodore-Mensah, who continue to inspire me to impact my community through my public health degree. Finally, I appreciate every Nigerian immigrant who participated in my study. God bless you all! 


\section{Table of Contents}

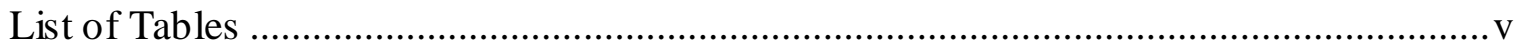

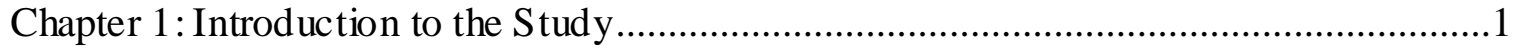

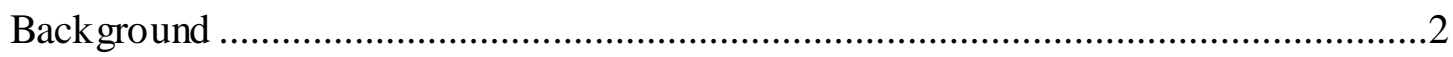

Risk Factors for Obesity Among Immigrants .......................................................

Obesity and Diet Among Immigrants ...................................................... 3

Obesity and Sedentary Lifestyles Among Immigrants ...................................... 3

Obesity and Socioeconomic Status Among Immigrants ................................... 4

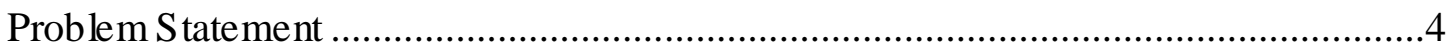

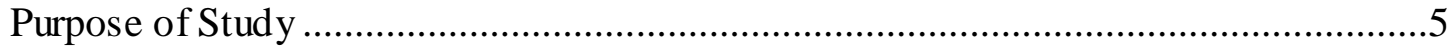

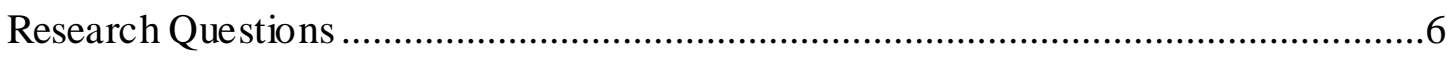

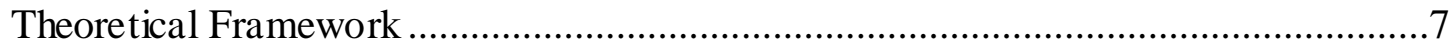

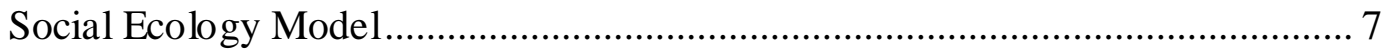

Segmented Assimilation Theory ................................................................. 8

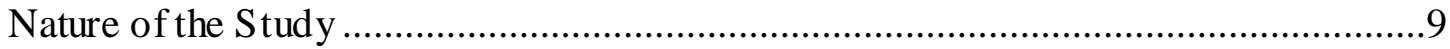

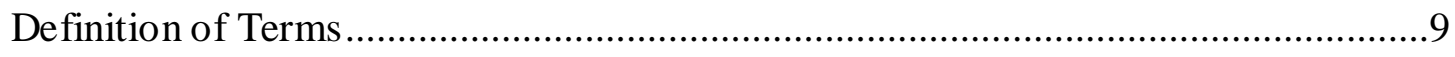

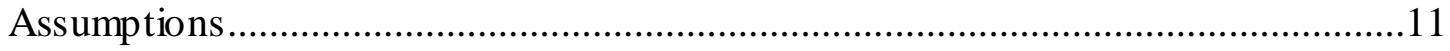

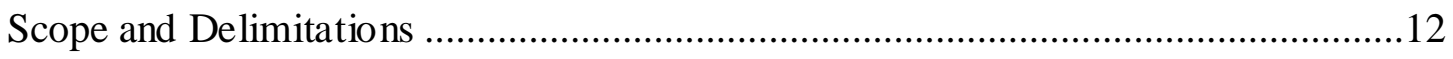

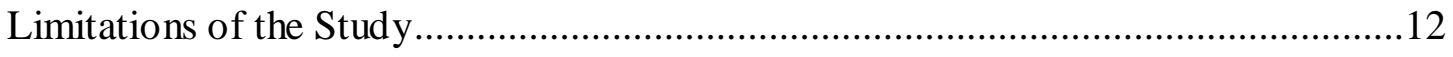

Significance and Potential for Positive Social Change .........................................13

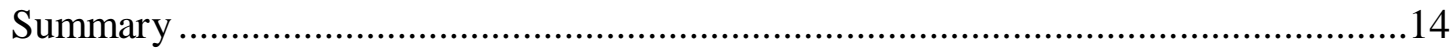

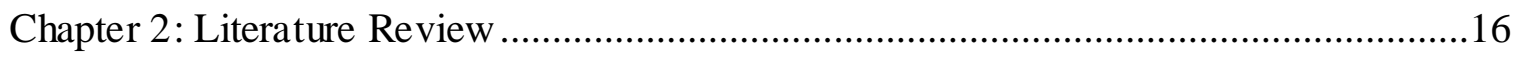

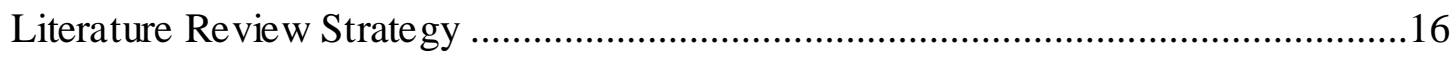




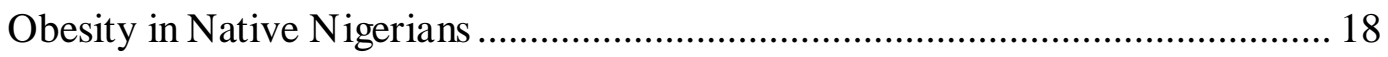

Obesity and Immigrants in the United States .......................................................23

Literature Review Related to Key Variables .........................................................26

Obesity and Diet in Immigrant Populations .................................................... 26

Obesity and Physical Activity in Immigrant Populations ..................................... 29

Gender, Socioeconomic Status, Level of Education, and Obesity in

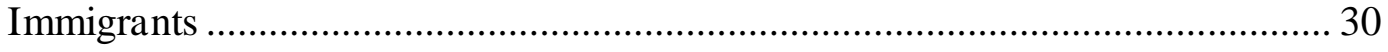

Obesity and Length of Stay in Immigrant Populations ........................................... 32

Theoretical Foundation Framework ..........................................................................33

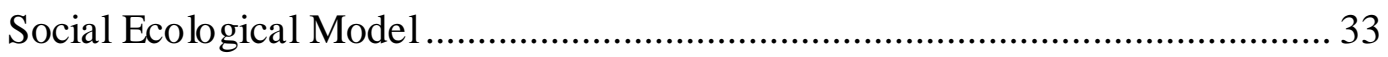

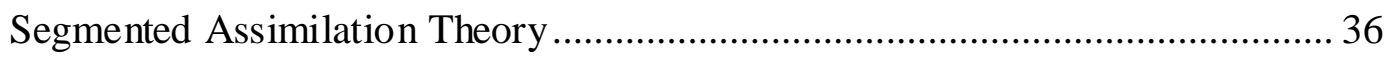

Literature Related to the Research Design and Methodology .......................................37

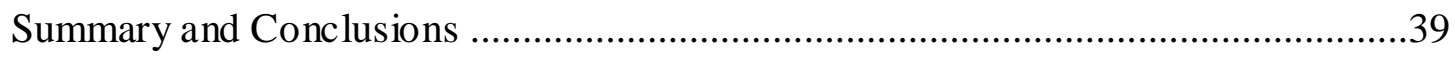

Chapter 3: Research Methods ...................................................................................41

Research Design and Approach .............................................................................4

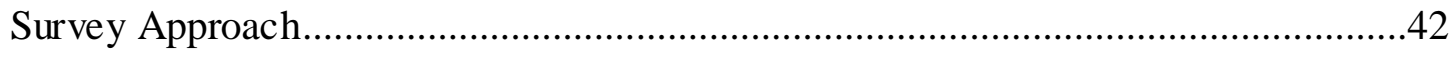

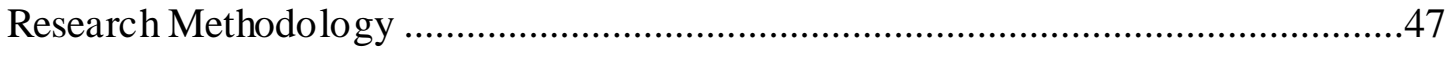

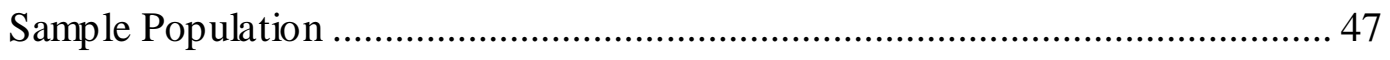

Sampling and Recruitment Procedures .............................................................. 47

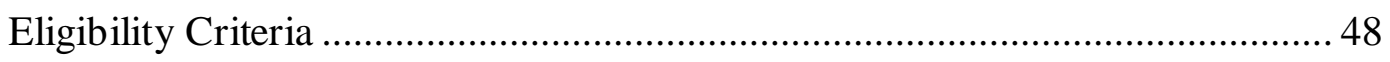

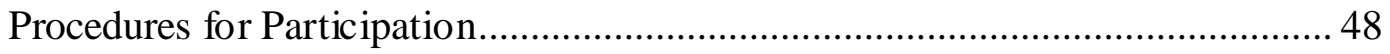




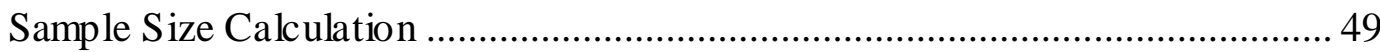

Instrumentation and Operationalization of Constructs ...............................................50

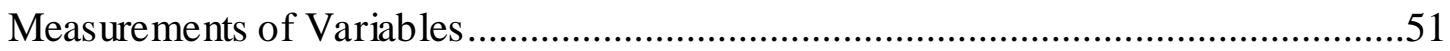

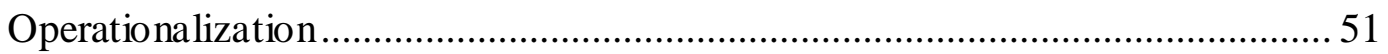

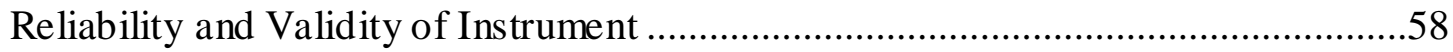

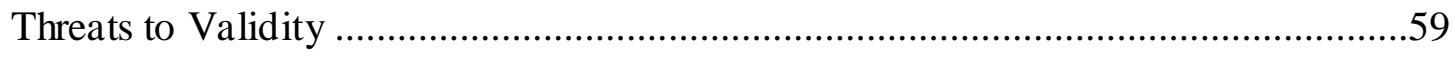

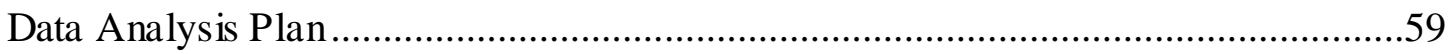

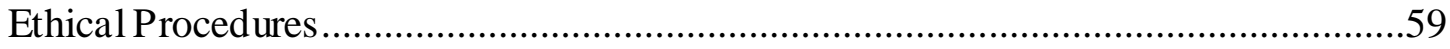

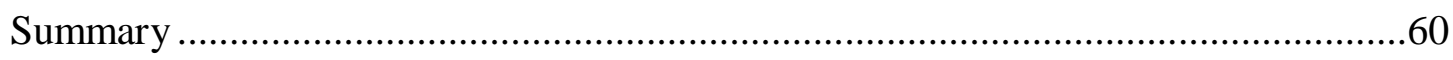

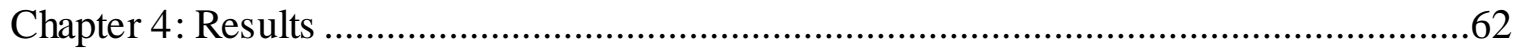

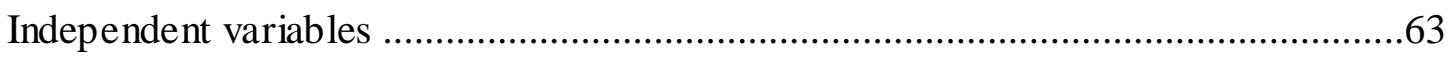

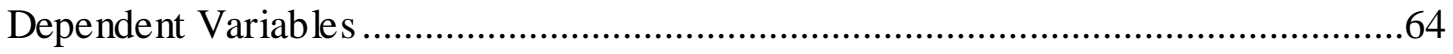

Research Questions and Hypotheses .....................................................................64

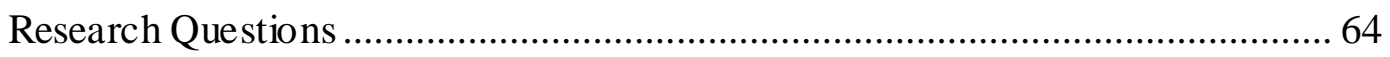

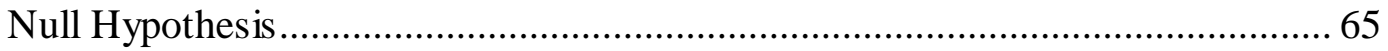

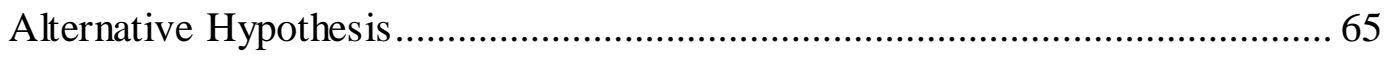

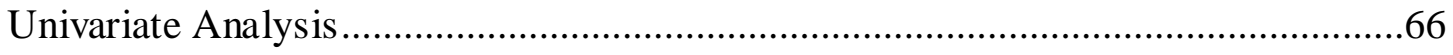

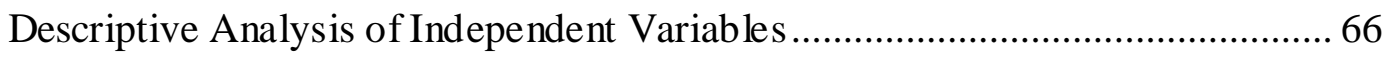

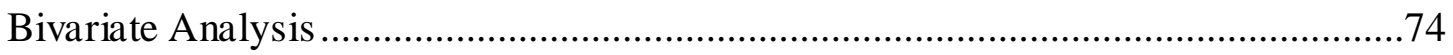

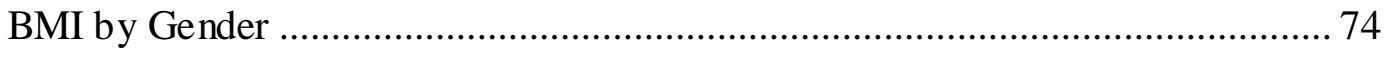

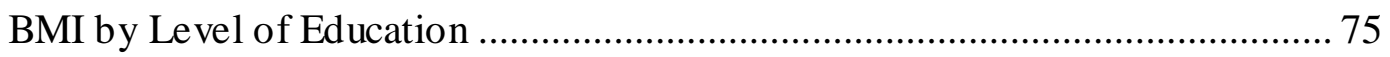

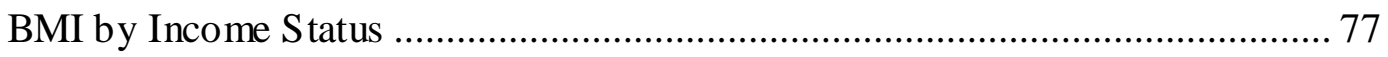

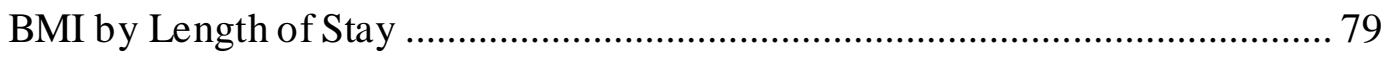




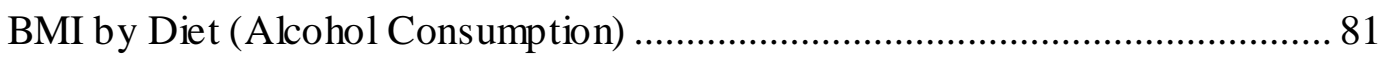

Bivariate Analysis - Logistic Regression ................................................... 95

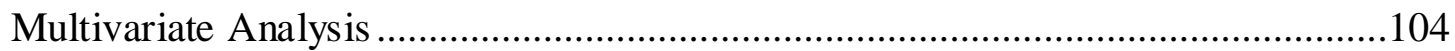

Predictors for Obesity …......................................................................... 104

Predictors for Moderate/Morbid Obesity ..................................................... 106

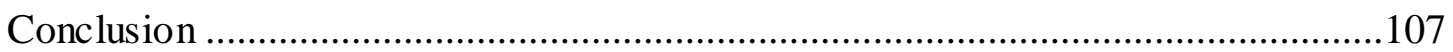

Chapter 5: Discussions, Recommendations, Conclusions and Summary......................109

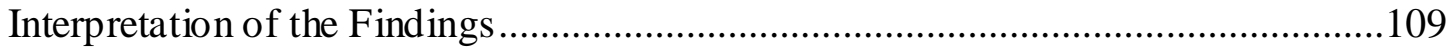

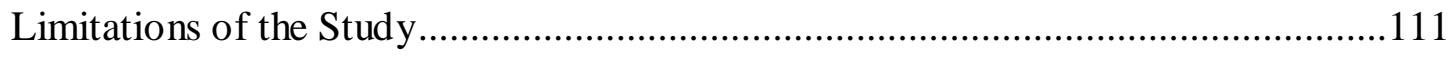

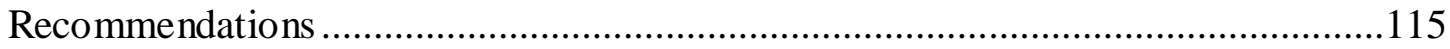

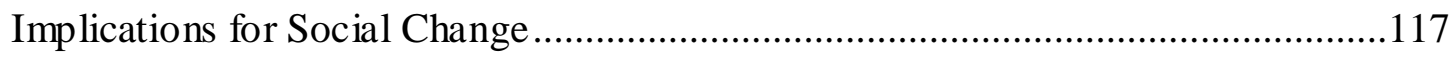

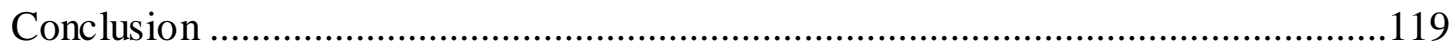

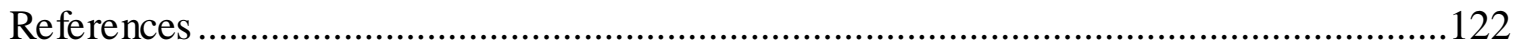

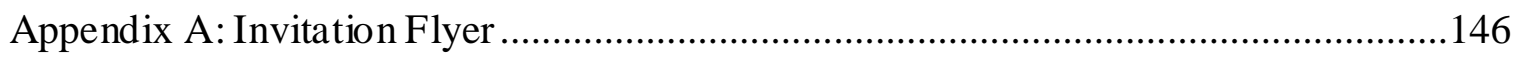

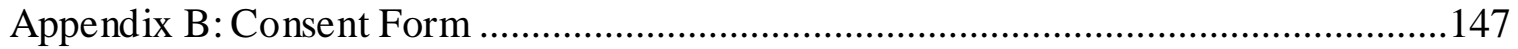

Appendix C: Modified BRFSS Questionnaire ......................................................149 
List of Tables

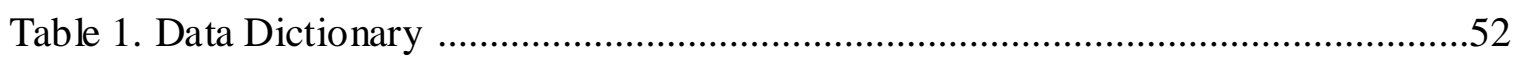

Table 2. Distribution of Gender of Study Participants ..............................................66

Table 3. Distribution of Highest Level of Education of Study Participants ....................67

Table 4. Distribution of Annual Household Income of Study Participants ....................68

Table 5. Distribution of Years in the United States of Study Participants ......................68

Table 6. Distribution of Selected Measures of Diet of Study Participants ......................70

Table 7. Physical Activity Reported by Participants ................................................. 71

Table 8. Distribution of Calculated BMI of Study Participants ....................................72

Table 9. Distribution of General BMI Category of Study Participants ..........................73

Table 10. Distribution of Obese/Not Obese BMI Category of Study Participants .........73

Table 11. Distribution of Moderate and Morbid Obesity BMI Category of Study

Participants

Table 12. Cross-Tabulation and Chi-Square Analysis of Association between Gender and

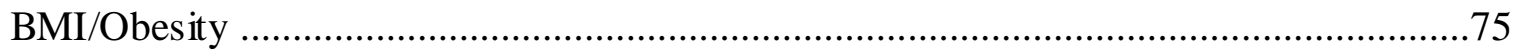

Table 13. Cross-Tabulation and Chi-Square Analysis of Association between Level of

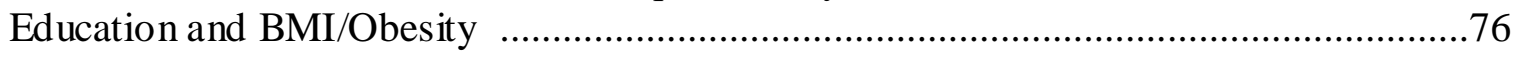

Table 14. Cross-Tabulation and Chi-Square Analysis of Association between Income

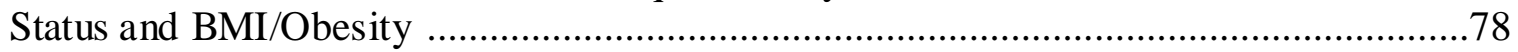

Table 15. Cross-Tabulation and Chi-Square Analysis of Association between Length of

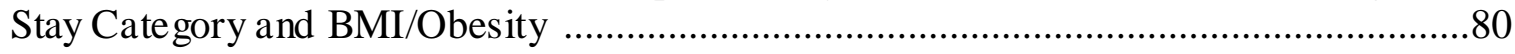

Table 16. Cross-Tabulation and Chi-Square Analysis of Association between Diet (Alcohol Consumption) Category and BMI/Obesity

Table 17. Cross-Tabulation and Chi-Square Analysis of Association between Diet (Soda Consumption) Category and BMI/Obesity .85 
Table 18. Cross-Tabulation and Chi-Square Analysis of Association between Diet (Green Vegetables Consumption) Category and BMI/Obesity

Table 19. Cross-Tabulation and Chi-Square Analysis of Association between Physical Activity Cate gory and BMI/Obesity

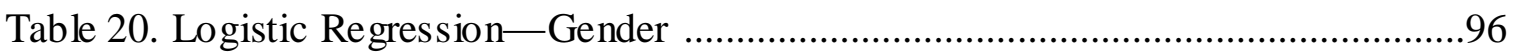

Table 21. Logistic Regression Analysis_Education ....................................................97

Table 22. Logistic Regression—Socio-economic Status ..................................................98

Table 23. Logistic Regression Analysis - Length of Stay in the United States ...............99

Table 24. Logistic Regression Analysis-Weekly Consumption of Alcohol ................100

Table 25. Logistic Regression Analysis-Monthly Consumption of Alcohol ................101

Table 26. Logistic Regression Analysis_Exercise for 20 Minutes ...............................102

Table 27. Logistic Regression Analysis-Moderate Exercise for 10 Minutes ................103

Table 28. Logistic Regression Analysis_-Vigorous Exercise for 10 Minutes ...............104

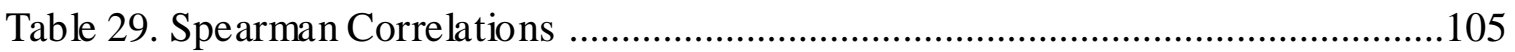

Table 30. Multivariate Logistic Regression Results -Predictors of Obesity Variables in the Equation $(\mathrm{N}=103)$

Table 31. Multivariate Logistic Regression Results-Predictors of Moderate/Morbid

Obesity Variables in the Equation $(\mathrm{N}=103)$ 
Chapter 1: Introduction to the Study

As individuals continue to exceed recommended weight standards, obesity is gradually becoming a global epidemic (World Health Organization [WHO], 2014a). The WHO recommends the use of the body mass index (BMI) to identify obesity in individuals; different levels of BMI are associated with specific weight status categories and include overweight status, defined as a BMI of $25-29.9 \mathrm{~kg} / \mathrm{m}^{2}$ and obesity status which is a BMI $\geq 30 \mathrm{~kg} / \mathrm{m}^{2}$ (Centers for Disease Control and Prevention [CDC], 2012; WHO, 2014a). The prevalence of obesity has significantly increased in the United States. In 2012, more than a third of the U.S. adult population was classified as obese; as of 2008, nearly 500 million (10\%) individuals were classified as obese worldwide (CDC, 2014; WHO, 2014b).

The increase in obesity rates has been associated with higher morbidity and mortality (CDC, 2010). Obesity has been linked to $44 \%$ of diabetes cases, $23 \%$ of coronary heart disease cases, and $7-41 \%$ of certain cancer cases; it has also been identified as the fifth leading risk for all deaths globally, with close to 2.8 million obesity-associated annual deaths in adults (WHO, 2014b). The CDC (2010) explained that not one of the 50 states and the District of Columbia was able to meet the Healthy People 2010 goal to reduce the prevalence of obesity to $15 \%$. For instance, the 2010 statistics showed that 12 states had an obesity prevalence of $30 \%$ or higher. This was unlike the year 2000 statistics with obesity prevalence rates of 15-24\% (CDC, 2010). 
In 2008, the estimated annual obesity-associated healthcare expenditure in the United States was $\$ 147$ billion, with the average medical costs for obese individuals estimated at \$1,429 more than individuals with normal weight (CDC, 2014). Using nonlinear regression models, public health experts anticipated that by year 2030, the prevalence of obesity will increase by $33 \%$ and the prevalence of severe obesity will increase by $130 \%$, resulting in an estimated annual obesity-associated healthcare expenditure of $\$ 549.5$ billion (Finkelstein et al., 2012).

\section{Background}

There is a disproportionately higher burden of obesity in nonwhite ethnic groups residing in the United States, with varying prevalence in the different ethnic groups (Office of the Surgeon General, 2010). As of 2012, about 34.9\% of adults older than 18 years of age were obese in the United States, with the highest prevalence identified in the non-Hispanic black population (47.8\%), followed closely by the Hispanic population (42.5\%), non-Hispanic white population (32.6\%), and non-Hispanic Asian population (10.8\%; CDC, 2014). Researchers have identified a possible association between obesity and immigrant status (Averett, Argys, \& Kohn, 2012). This finding is especially important since the influx of immigrants into the United States has significantly increased over the years (Caramota, 2012). As of 2011, the U.S. Census Bureau data showed there were about 50 million immigrants residing in the United States, increasing the number of ethnic groups in the United States (Caramota, 2012). 


\section{Risk Factors for Obesity Among Immigrants}

Though obesity has been described as a naturally-occurring risk, it is possible to predict obesity based on certain risk factors; the prevalence of obesity has been associated with behavioral, socioeconomic, and sociocultural factors in many populations (International Risk Governance Council, 2010).

\section{Obesity and Diet Among Immigrants}

The imbalance in energy consumed and expended is a significant contributor to obesity; when individuals consume more calories than they use, their bodies store or accumulate excess body fat (WHO, 2014). Postmigration obesity trends in immigrants may reflect dietary acculturation to a Western, calorie-dense diet (Wändell, 2013). With limited access to their cultural staple foods and few financial resources, the allure of relatively cheap, easily accessible fast foods often results in a diet change that favors obesity; some immigrants also experience dietary acculturation because of the pressure to identify with the culture of the host country (Association for Psychological Science, 2011).

\section{Obesity and Sedentary Lifestyles Among Immigrants}

There is evidence that individuals who participate in increased physical activity have reduced risks for obesity, and so the importance of physical activity in preventing obesity cannot be overstated (YoonMyung \& SoJung, 2009). The CDC (2013) recommended that adults need to engage in weekly moderate physical activity such as brisk walking, lasting about 150 minutes, or intense physical activity, such as jogging, 
lasting about 75 minutes. Unfortunately, many adults living in the United States, regardless of immigrant status, do not adhere to this recommendation. The Office of the Surgeon General of the United States reported that a quarter of U.S. adults do not engage in any form of physical activity, regardless of their job schedule or requirement (U.S. Department of Health and Human Services, n.d.).

\section{Obesity and Socioeconomic Status Among Immigrants}

Poverty is an additional risk factor for obesity, besides other well-known risk factors such as large portion control, overeating, and inactive lifestyle. Low-income individuals and populations are particularly vulnerable to obesity (Food Research and Action Center, 2010). As of 2010, about $23 \%$ (close to a quarter) of the immigrant population in the United States live at or below poverty level compared with $13.5 \%$ of U.S. citizens (Caramota, 2012). Due to the relatively high cost of healthy foods, there is a tendency for poorer people to shun healthy foods, especially fresh produce, and to lean more towards purchasing cheaper refined/processed foods that contain higher concentrations of sugar and fat (Food Research and Action Center, 2010).

\section{Problem Statement}

The prevalence of obesity in immigrant populations has become an increasingly complex issue, with significant influences from lifestyle, behavioral, sociocultural, and socioeconomic factors; the interaction between these different variables in different ethnic groups cannot be underestimated (Harvard School of Public Health, 2014). Researchers have conducted many epidemiological studies on the factors contributing to 
the prevalence of obesity in the general African American population and African immigrant population residing in the United States, with little focus on the identification of substantial heterogeneity in the predictors of obesity in different immigrant populations (Oza-Frank \& Narayan, 2008; Zheng \& Yang, 2012).

My study, therefore, addressed this gap by focusing on the specific factors of gender, level of education, length of stay, diet, socioeconomic status, and level of physical activity that may predict obesity in Nigerian immigrants residing in the United States. The collected data from the study clarified the risk factors that increase the burden of obesity in this specific population. An understanding of obesity disparities in specific ethnic populations clarifies the factors that contribute to health disparities in the prevalence of obesity-associated chronic diseases (WHO, 2014b).

\section{Purpose of Study}

In this quantitative study, I used cross-sectional survey research to investigate the prevalence of obesity in the Nigerian immigrant population in the United States; I also sought to identify the predictors of obesity in this population. Using primary data collected through a web-based, self-administered, modified Behavioral Risk Factor Surveillance System (BRFSS) questionnaire, I collected data on individual demographics and other characteristics, such as physical activity and dietary habits, that could be used to measure what exists in the Nigerian immigrant population in the United States. 


\section{Research Questions}

To guide this study on obesity among Nigerian immigrants living in the United States, two quantitative research questions were appropriate:

RQ1: What is the prevalence of obesity in Nigerian immigrants within this sample?

RQ2: Are gender, level of education, socioeconomic status, length of stay, diet, and level of physical activity predictors of obesity in Nigerian immigrants within this sample?

$H_{0} 1$ : Gender is not a predictor of obesity in Nigerian immigrants within this sample

$H_{0} 2$ : Level of education is not a predictor of obesity in Nigerian immigrants within this sample

$H_{0} 3$ : Socioeconomic status is not a predictor of obesity in Nigerian immigrants within this sample

$H_{0} 4$ : Length of stay is not a predictor of obesity in Nigerian immigrants within this sample

$H_{0} 5$ : Diet is not a predictor of obesity in Nigerian immigrants within this sample

$H_{0} 6$ : Level of physical activity is not a predictor of obesity in Nigerian immigrants within this sample

$H_{1} 1$ : Gender is a predictor of obesity in Nigerian immigrants within this sample 
$H_{1}$ 2: Level of education is a predictor of obesity in Nigerian immigrants within this sample

$H_{1} 3$ : Socioeconomic status is a predictor of obesity in Nigerian immigrants within this sample

$H_{1} 4$ : Length of stay is a predictor of obesity in Nigerian immigrants within this sample

$H_{1}$ 5: Diet is a predictor of obesity in Nigerian immigrants within this sample $H_{1} 6$ : Level of physical activity is a predictor of obesity in Nigerian immigrants within this sample

\section{Theoretical Framework}

A better understanding of the contributors to the prevalence of obesity in this population required identifying what social ecological factors influence the diet and physical activity status of this population and how various assimilation factors increase the risk for obesity.

\section{Social Ecology Model}

The social ecology model, defined by McLeroy (1988), identifies the interrelationships that exist between behaviors at the social level and health (SimonsMorten, McLeroy, \& Wendel, 2012). The social ecology model is a framework that analyzes the complex impact of social factors - the various individual factors, relationship, community, and societal factors and how they influence one another at different social levels (CDC, 2013b). The social ecological model postulates that there 
are seven levels of influence - "intrapersonal, interpersonal, organizational, community, public policy, physical environment and culture," and a dynamic interplay between these levels can determine health status (Simons-Morten et al., 2012, p. 45). To better identify and understand the predictors of obesity in this population, it is necessary to look beyond individual-level behaviors and investigate social and environmental influences that interact and impact individual behavior (National Institutes of Health [NIH], 2005).

Using this model as a theoretical framework was appropriate because it helped identify possible social and environmental risk factors that increase the vulnerability of the Nigerian immigrant population to obesity. It may also provide useful information essential to implementing strategic interventions that address these risk factors.

\section{Segmented Assimilation Theory}

Portes (as cited in Brown \& Bean, 2006) developed segmented assimilation theory in the 1900s, postulating that there may be differences among immigrants. This theory recognizes that there is a diversified and segmented U.S. society due to the growing population of immigrants, and as such immigrants' paths to assimilation are different, with consideration for existing economic and social resources; these differences may result in different outcomes for second or third generation immigrants (Brown \& Bean, 2006; Xie \& Greenman, 2005). There are three different assimilation paths for immigrants :

1. Conventional upward assimilation path-process in which there is increased integration into the middle class of the U.S. society and upward mobility. 
2. Downward assimilation path-a process in which there is increased integration into underclass and poverty, and subsequently downward mobility.

3. Selective acculturation path - a process in which immigrants consciously preserve their culture and values, while still striving for economic integration, resulting in biculturalism and upward assimilation. (Xie \& Greenman, 2005)

Using the segmented assimilation theory as a theoretical framework to guide this dissertation was appropriate because it helped identify whether socioeconomic status or sociodemographics, especially environment, contribute to the prevalence of obesity (Brown \& Bean, 2006; Waters, Tran, Kasinitz, \& Mollenkopf, 2010).

\section{Nature of the Study}

This study was cross-sectional and quantitative in nature and focused on objective, simultaneous measurements of exposure and outcome statuses using a snapshot of the population of interest at a specific period of time, following the methods explained by Frankfort-Nachmias and Nachmias (2008) and Szklo and Nieto (2014). The focus of this study was correlational, investigating and identifying the predictors of obesity and its prevalence in this defined population of Nigerian immigrants living in the United States.

\section{Definition of Terms}

Assimilation: An individual's ability to adopt the culture of another population or culture (Xie \& Greenman, 2005). 
Behavioral Risk Factor Surveillance System (BRFSS): A telephone survey system managed and used by the CDC to track public health conditions and risky behaviors in the general U.S. population (CDC, 2014).

Body mass index (BMI): A reliable indicator of body fat calculated from individual weight and height (WHO, 2014a).

Demographics: These are the quantifiable statistics of specific populations necessary to characterize and identify what variables exist in the population. These variables include age, gender, occupation, socioeconomic status, level of education, and place of residence.

Dietary acculturation: The process through which members of a foreign culture or minority groups adopt the dietary patterns of their host country (Wändell, 2013).

Health disparity: The difference in disease burden or other opportunities in a population based on race, gender, literacy, or economic status (Cohen, Chávez, \& Chehimi, 2010)

Nigerian immigrants: Individuals born in Nigeria and who have migrated to the United States as naturalized citizens, legal permanent residents, or undocumented/illegal residents.

Obesity: This is defined as a body mass index greater than $30 \mathrm{~kg} / \mathrm{m} 2$ (WHO, 2014a). 
Social change: The deliberate action to address social problems and make difference in the lives of others and within the community (Leadership Paradigms, Inc., n.d.).

Social support: The provision of a broad network of needed resources to a vulnerable community that shares the same values and lifestyle (Schneider, 2006).

Socioeconomic status: The American Psychological Association (2014) defined socioeconomic status as the social class that an individual or group belong, often measured by education, income, and occupation.

\section{Assumptions}

This research was guided by the following five assumptions:

1. I assumed that BMI is an accurate predictor of body fat in this sample population

2. I assumed that all participants would provide an accurate measurement of their height and weight to get an accurate BMI calculation.

3. I assumed that respondents were literate and able to understand the questions being asked in the survey, allowing them provide accurate and unbiased responses.

4. I assumed that respondents comprised only Nigerian immigrants, 18 years and older. This study focused on adults only. 
5. I assumed that the prevalence of obesity in this population can be calculated/estimated.

\section{Scope and Delimitations}

This study's respondents comprised only Nigerian immigrants, aged 18 years and older, who resided in the United States in order to investigate the phenomenon of obesity in the Nigerian immigrant adult population. In this study, I only examined the association between obesity and specific demographic characteristics such as gender, level of education, length of stay, diet, socioeconomic status, and level of physical activity; the associations between obesity and other variables were not examined as they were considered irrelevant for this study.

\section{Limitations of the Study}

The limitations of this study included the use of a survey instrument of measurement, which might have brought about overreporting or underreporting of data from participants, especially with regards to questions with social desirability concerns such as weight and income levels. The study was also limited to Nigerian immigrants in the United States who have access to the internet and are able to fill out the survey; this limits the generalizability of results to the general population of Nigerian immigrants. The use of a cross-sectional study limits conclusions about causal associations between variables. A future longitudinal study might be useful in addressing this limitation as it examines the association over a period of time. Although this survey intended to obtain data from Nigerian immigrants, regardless of immigration status, non-participation from 
illegal Nigerian immigrants may have resulted in selection bias, as the data provided may only include information from legal Nigerian immigrants only.

\section{Significance and Potential for Positive Social Change}

The Nigerian immigrant population is one of the fastest growing immigrant populations in the United States (American Immigration Council, 2012). As of 2010, the African immigrant population accounted for $4 \%$ of all U.S. immigrants, with Nigerian immigrants constituting $7.3 \%(219,309)$ of the total population (American Immigration Council, 2012).

Understanding the underlying causes of obesity in this population provides insight into what factors need to be addressed and whether obesity interventions are best initiated at an individual or community level (Simons-Morten, McLeroy, \& Wendel, 2012). The identification of community-level risk factors such as social norms and the physical environment could improve intervention efforts to reduce obesity disparities in the African immigrant populations, especially Nigerian immigrants (McKenzie, Neiger, \& Thackeray, 2008; Simons-Morten, McLeroy, \& Wendel, 2012). This information could be especially useful for health organizations interested in working with this community so as to tailor their interventions to target these identified predictors. For example, with the identification of obesity predictors, health professionals and health educators who work with this population can use this information to develop appropriate health education campaigns that specifically target behaviors at both individual and community levels (McKenzie et al., 2008). Since there is no existing dataset on obesity in the general 
adult Nigerian immigrant population residing in the United States, the social change significance of this study is that creating a new dataset can for future research in not just obesity but other public health issues in this population. This study could also provide information useful for the facilitation of a supportive environment necessary to improve positive health outcomes in the Nigerian immigrant population. This could ultimately reduce the risk for chronic diseases and the subsequent associated healthcare costs.

\section{Summary}

This study investigated the prevalence and predictors of obesity in Nigerian immigrants living in the United States, providing information on significant associations between specific demographic characteristics and obesity, and identifying obesity predictors that are unique to only this population. The findings of this research could inform the development of appropriate population-based interventions that focus on addressing obesity in this population. Chapter 2 focuses on a review of current literature on different predictors of obesity in other immigrant populations in the United States. This chapter uses current literature to provide insight into how both the social ecological model and segmented assimilation theory explain and predict the phenomena of obesity in the sample population and how they act as a theoretical framework for this study. Chapter 3 provides a detailed description of the research design, definition and introduction of the sample population; this chapter also identifies and describes the instrument of measurement, and methods of sampling, data collection and statistical analysis. Chapter 4 presents the research findings. Chapter 5 summarizes the meaning, 
importance, and significance of the research results, identifying how they fill the research gap and meet current research needs. This section also provides the research conclusions and recommendations, as well as implications for future research and practice. 


\section{Chapter 2: Literature Review}

Since obesity has been associated with significant morbidity and mortality in many populations, especially minority populations, examining current epidemiology research on other immigrant populations in the United States shows what other researchers have identified as the sociodemographic predictors of obesity in African American, Asian, Hispanic, Pacific Islanders, and European immigrant populations (Barrington, Baquero, Borrell, \& Crawford, 2010; Castellanos, Connell, \& Lee, 2011; Guendelman, Ritterman-Weintraub, Fernald, \& Kaufer-Horwitz, 2013; Hunte \& Williams, 2009; Jasti, Chang Hyun, \& Doak, 2011; Singh, Siahpush, Hiatt, \& Timsina, 2011; Tseng, \& Fang, 2011; Yeary et al., 2011). This review allow for a comparison of what conditions exist among the different immigrant populations residing in the United States, and more specifically, the Nigerian immigrant population; this review also helped in determining significant chronic diseases' risk factors and poor health outcomes in these populations.

\section{Literature Review Strategy}

This literature review comprised relevant and current peer-reviewed articles, published between 2009 and 2014, in the following databases: MEDLINE, Cumulative Index to Nursing and Allied Health (CINAHL), PsycARTICLES, Academic Search Complete, and ScienceDirect database. To maximize the search results, I used a twostage search approach. I used the following search strings in the first stage: immigrants AND obesity AND diet; immigrants AND obesity AND education; immigrants AND 
obesity AND socioeconomic status; immigrants AND obesity AND gender; immigrants AND obesity AND length of stay; immigrants AND obesity AND acculturation; and immigrants AND obesity AND sociodemographics. In the second stage, I carried out an expanded search of specific full key words such as: obesity in Nigerian Immigrants, obesity in Nigerian immigrants residing in the United States, obesity in Asian immigrants residing in the United States, obesity in Hispanic immigrants residing in the United States, predictors of obesity in immigrants residing in the United States, and obesity and acculturation. I also included additional obesity-related articles from federal government agencies, public health organizations, and immigrant and minority health organizations.

Forty published articles met the inclusion criteria, and I organized them according to the two theories that guided this study (social ecology model and segmented assimilation theory) and the following constructs of interest associated with obesity in immigrant populations: diet, physical activity, socioeconomic status, length of stay, level of education, and gender.

\section{Obesity}

Obesity is a health condition, and due to the increased prevalence of obesity, it has become a significant public health problem in the United States (American Heart Association, 2014). With this increase in obesity prevalence comes an increase in obesity-associated morbidities and mortality (Ogden, Carroll, Kit, \& Flegal, 2014). In industrialized countries such as the United States, the level of obesity-associated morbidities is comparable to those associated with poverty and nicotine, and is second 
only to smoking in preventable causes of mortality (Chapman, Fiscella, Duberstein, Coletta, \& Kawachi, 2009; Tekkel, Veideman, \& Rahu, 2010; Vals, Kiivet, \& Leinsalu, 2013). Mackenbach et al. (2014) explained that though genetics and an imbalance of energy consumed versus energy expended may be an underlying contributing factor to obesity, these should not be isolated from other social, behavioral, and environmental determinants that promote obesity in individuals.

\section{Obesity in Native Nigerians}

To better understand the prevalence of obesity among Nigerian immigrants residing in the United States, it is necessary to examine obesity rates and patterns in native Nigerians. The WHO's (2011) overweight/obesity survey data for Nigeria indicated that the prevalence of being overweight is $26 \%$ in men and $37 \%$ in women, and an obesity prevalence of $3 \%$ in men and $8.1 \%$ women. Several studies have consistently identified that an association between the prevalence of obesity and overweight status and the female gender, socioeconomic status, age, and urban settings exist in all three major Nigerians ethnicities; the obesity prevalence in Nigeria has been found to be comparable with that of populations of other industrialized nations (Adedoyin et al., 2010; Adefule et al., 2014; Ani, Uvere, \& Ene-Obong, 2013; Buowari, 2010; Kandala \& Stranges, 2014; Kayode, Olayinka, Sola, \& Steven, 2011; Ogunjimi, Ikorok, \& Yusuf, 2010; Wahab et al., 2011).

Olatunbosun, Kaufman, and Bella (2011) investigated the prevalence of obesity and overweight status in urban adult Nigerians. Using the socioecological model as the 
theoretical framework to investigate the roles of lifestyle and behaviors in the increase in obesity, the researchers carried out a cross-sectional screening survey on a random sample of 998 Nigerian civil servants (581 males and 417 females) residing in Ibadan, Oyo State. The authors used $t$ tests and chi-square tests to analayze demographic and biosocial data including age, income, and alcohol use. They used multivariate analysis of variance (MANOVA) to identify the variables that best predicted mean BMI, and they also used logistic regressions to determine what variables were significantly associated with obesity. The study results indicated an obesity prevalence of $8.82 \%(\mathrm{CI}=7.13 \%$, $10.75 \%)$, overweight prevalence of $17.45 \%(\mathrm{CI}=15.12 \%, 19.95 \%)$, and overweight/obesity prevalence of $26.18 \%(\mathrm{CI}=23.47 \%, 29.03 \%)$. The results also showed a higher prevalence of obesity $(17.27 \%)$ in the female population $(\mathrm{CI}=13.76 \%$, $21.24 \%)$ than in the male population $[2.75 \%(\mathrm{CI}=1.58 \%, 4.43 \%)] ; 42 \%$ of the women were considered obese or overweight compared with $15 \%$ of the men (Olatunbosun et al, 2011, p. 237). The research identified an association between obesity and higher socioeconomic status in both male and female populations; however, alcohol use of 60 $\mathrm{g} /$ week and a family history of hypertension and diabetes were also predictive factors associated with obesity prevalence in men, while a family history of hypertension was also a borderline significant predictive factor associated with obesity prevalence in women (Olatunbosun et al., 2011). The researchers concluded that the prevalence of obesity in the study population who reside in urban Nigerian communities is comparable to the rates identified in many developed/westernized nations. The strength of this study 
included the recruitment of a sample population that is nationally representative of Nigeria's three major ethnic groups, Hausa, Ibos, and Yorubas; the ability to control for multiple confounders and interactions between variables was also a significant strength of the study. This study, however, had some limitations. The sample population comprised of individuals from only one professional field; also, the criteria of diagnosing obesity were based on the international criteria for adiposity estimation used in Caucasian populations (Olatunbosun et al., 2011).

The research by Sola, Steven, Kayode, and Olayinka (2011) also investigated the prevalence of obesity based on BMI and waist circumference in adult Nigerians living in both rural and urban communities of Benue State, using the WHO criteria. The researchers carried out a cross-sectional screening survey of height, weight, and waist circumference measurements from a random sample of 435 Nigerian adults (298 males and 137 females), ages 18 to 45 . The researchers used descriptive statistics and independent sample Student's $t$ test to identify and analyze differences in mean age, BMI, and waist circumference. The results showed that while $22 \%$ of the population was overweight, only $4 \%$ of the total population was obese; the results also identified overweight/obesity prevalence in $40 \%$ of the female population who lived in urban communities and in $30 \%$ of the female population who lived in rural communities (Sola et al., 2011, p. 140). The researchers also found BMI to be higher in the female population than the male population, $p<0.05$ (Sola et al., 2011, p. 141). The researchers concluded that in young people, ages 18 to 45 , obesity was more prevalent in urban 
communities than rural communities. This study supported the results of the research by Olatunbosun et al. (2011) that there is a certain level of obesity prevalence in Nigeria just as in industrialized countries.

Akarolo-Anthony, Willett, Spiegelman, and Adebamowo (2014) also lended support to the identification of existing obesity prevalence in Nigeria. The researchers examined the demographic, socioeconomic factors, and physical activity correlates of obesity in a cross-sectional study of a random sample of 1041 adult (625 males and 416 females) residents of Abuja (the capital of Nigeria), aged 18 years and over; respondents comprised individuals from different professions, both skilled labor and blue-collar workers. Akarolo-Anthony et al. used survey instruments to collect data on the consumption frequency, pattern, and quantity of 11 main foods and seven types of beverages. The researchers used descriptive statistics, chi-square tests and $t$ tests to analyze the differences between male and female respondents, Spearman and Pearson correlation coefficients to analyze any correlation between covariates, and univariate and multivariate analyses with log-binomial regression models to analyze the relationship between the prevalence of obesity and potential correlates. The results indicated a mean age of 42 years a mean $\mathrm{BMI}$ of $27.2 \mathrm{~kg} / \mathrm{m} 2$ in overweight respondents, and a mean BMI of $33.8 \mathrm{~kg} / \mathrm{m} 2$ in obese respondents; the prevalence of overweight status was $32 \%$ of the female population, prevalence ratio $(\mathrm{PR}) 1.24(95 \% \mathrm{CI}=1.08,1.43, p=0.004)$, compared to $42 \%$ of the male population, and a prevalence of obesity was identified in $42 \%$ of the female population, PR 2.54 (95\% CI 2.08, 3.10, $p<0.0001$, and $15 \%$ of the 
male population. Overall overweight and obesity prevalence was $64 \%$, (57\% of males and $74 \%$ of females), with high likelihood of overweight, PR 1.45 (95\% CI=1.07, 1.97, $p$ $=0.002)$, or obesity, PR 8.07 (95\% CI 3.01, 21.66, $p<0.0001)$ in individuals aged 40-49 years (Akarolo-Anthony et al., 2014, p. 6). The results also indicated that compared to individuals in the low socioeconomic class, the PR for obesity was 1.39 (95\% CI 1.13, 1.72 ) and 1.24 (95\% CI 0.97, 1.59), $p=0.003$, for the middle and higher class socioeconomic statuses respectively (both genders). The researchers concluded that there is a high prevalence of obesity in Nigerians with urban, professional, high socioeconomic statuses, and older age and female gender are other significant obesity predictors in Nigerians (Akarolo-Anthony et al., 2014).

Iloh, Amadi, Nwankwo, and Ugwu (2011) also found similar results. The researchers investigated the prevalence and pattern of obesity during a screen for common comorbidities in a 12-month, cross-sectional study of 2,156 patients (625 males and 416 females) who were residents of Imo State, 18-90 years old, in a rural southeastern Nigerian hospital. The results showed that $6 \%$ (129) of the sample population was obese, 111 participants had Class I obesity (BMI 30-34.9), 15 participants had Class II obesity (BMI 35-39.9), and three participants had Class III obesity (BMI $\geq 40$ ); a higher obesity prevalence was observed in the female population (4.4\%) compared to $1.6 \%$ of the male population (Iloh et al., 215). The results also showed that of those identified as obese, $83.7 \%$ (108/129) were unaware of their obese status, $16.3 \%(21 / 129)$ admitted an awareness of their obese status, and 11.6\% (15/129) 
only knew of their obese status when informed by healthcare workers (Iloh et al., 2011, p. 216).

These studies demonstrate the prevalence of obesity in Nigerians before migration, with gender, age and socioeconomic status identified as significant predictors. The following review section will draw insight from the comparison of the predictors of obesity in Nigerian immigrants to other immigrant/minority populations in the United States and other Western nations.

\section{Obesity and Immigrants in the United States}

The diversity in the U.S. population continues to increase over the years, with experts projecting that immigrants will represent one in every five residents of the United States by year 2050 (Oza-Frank \& Narayan, 2010). This changing demography has been associated with an increase in overweight, obesity, and other related chronic diseases such as diabetes nationwide (Oza-Frank \& Narayan, 2010; Singh, Siahpush, Hiatt, \& Timsina, 2011). There is evidence that individuals who migrate from low or medium income countries to high income countries have increased susceptibility to obesity compared to their counterparts in their native countries (Delavari, Sønderlund, Swinburn, Mellor, \& Renzaho, 2013). The increase in obesity rate in immigrants is usually significant 10 to 15 years after migration, by which time it equals or becomes greater than that of the population in the host nation (Bodea, Garrow, Meyer, \& Ross, 2009; Delavari et al., 2013). Female immigrants to the United States have also been found to have a $10 \%$ 
increased likelihood of being obese at the point of migration than native-born counterparts (Averett, Argys, \& Kohn, 2012).

In a national, pooled data survey of 34,456 U.S. immigrant adults from 1997 to 2005, results indicated more than 8 million immigrants were already overweight; with adjustment for age, gender, and region of birth, the prevalence of overweight was highest in immigrants from Mexico, Central America, and the Caribbean than among any other ethnicities $(p<.05)$ while the prevalence of overweight was lowest in immigrants from Indian Subcontinent, Central Asia, and Southeast Asia $(p<.05)$ (Oza-Frank \& Narayan, 2010, p. 662). Wen, Kowaleski-Jones, and Fan (2013) investigated the association between total caloric intake and disparities in the prevalence of total and abdominal obesity in ethnic immigrants. The results indicated that in the general U.S.-born population, the prevalence of obesity is higher in the Black population, followed by the Hispanic population; the white population, however, had the highest prevalence of abdominal obesity compared to other U.S.-born populations. The results further indicated that in the general U.S. immigrant population, the prevalence of obesity was lowest in Black immigrants; in the general female population, white female immigrants had the lowest prevalence of abdominal obesity (Wen et al., 2013).

Singh, Siahpush, Hiatt, and Timsina (2011) examined the trends in the prevalence of obesity in 30 immigrant groups and different social class groups in the United States; this study especially focused on these populations who have been identified as having a high risk for obesity and increased significant obesity rates. The researchers investigated 
the role of factors such as age, race/ethnicity, marital status, gender, length of time since immigration, occupation, educational level, physical activity level, and income level in these groups, comparing obesity disparities in ethnic immigrants and socioeconomic groups. The results indicated that immigrants in the 30 ethnic groups consumed significantly less total calories/fat than individuals born in the United States, with increased consumption correlating with length of residence. The amount of total caloric and fat intake was also found to be lower in the lower socioeconomic status groups. This result revealed the existence of obesity disparities in the different immigrant populations in the United States (Singh et al., 2011).

Albrecht and Gordon-Larsen (2013) investigated the ethnic obesity differences that exist in Hispanic and Asian populations as they transition from adolescence to adulthood, with a focus on understanding the disparity that exists in these populations compared with the white population. The authors analyzed the BMI trajectory of Asian and Hispanic adolescent subgroups using data from a school-based cohort and compared it to white adolescent subgroups with focus on the roles of lifestyle behaviors, physical activity level, socioeconomic status, parental education, receipt of government welfare/assistance, and age. The results indicated that while average BMI was the same across the subgroups, Mexican and Puerto Rican Hispanic populations exhibited a significant increase in BMI that was not associated with behavioral and social factors, while the Asian population exhibited lower BMI than their white counterparts, even as they transitioned into adulthood. 


\section{Literature Review Related to Key Variables}

The health disparity of obesity has been associated with several physical, cultural,

environmental, and social health issues (Barrington, Baquero, Borrell, \& Crawford, 2010; Blanchard, 2009; McCubbin \& Antonio, 2012; Oza-Frank \& Narayan, 2010). Since there are no existing studies carried out on the Nigerian immigrant population in the United States, in the section below I will review studies that investigated key variables such as diet, physical activity, gender, socioeconomic status, level of education, and length of stay that have contributed to the increase in obesity among other immigrant and ethnic/minority populations who share common body compositions and genetic ancestry, and who live in developed/Westernized countries, especially the United States.

\section{Obesity and Diet in Immigrant Populations}

The interaction between obesity and immigration for different races and ethnicities in the United States is complex and varies according to differences in healthrelated behaviors, social, economic, and cultural backgrounds, and even the countries of origin (Averett, Argys, \& Kohn, n.d.; National Obesity Observatory, 2011; Wen, Kowaleski-Jones, \& Fan, 2013).

The environment of obesogenicity within U.S. society promotes the consumption of fast foods and unhealthy dietary habits (Harvard School of Public Health, 2014; Holsten, 2009; Lytle, 2009b). People in the United States have easy access to sugar-laden beverages and cereals, fast foods, and convenient processed foods that expand the waistline, and many researchers have identified these environmental influences as a 
significant contributor to the prevalence of obesity in immigrant populations (Holsten, 2009; Lytle, 2009; Sharkey, Johnson, \& Dean, 2011; Wen, Kowaleski-Jones, \& Fan, 2013).

The built environment, restaurants, and grocery stores in Westernized countries contribute to dietary patterns in immigrants (Lytle, 2009b). In an 18 month study carried out on the nutritional content of about 30,923 menu items served in 245 restaurants in the United States, Wu and Sturm (2013) found that $96 \%$ of the entrees served exceed the U.S. Department of Agriculture's daily nutritional limit recommendations for calories and fat/saturated fat content. This is similar to the report of the Center for Science in the Public Interest that $93 \%$ of menus, beverages, and portion sizes served to children exceed the U.S. Department of Agriculture's nutritional recommendations (Goldstein, 2009).

Castellanos, Connell, and Lee (2011) examined the role of several sociodemographic factors, depression, dietary intake, and weight gain in the lowacculturated Latino male population residing in the United States. The authors collected and analyzed demographic, socioeconomic, psychological, and nutritional variables in the population in order to identify the association that existed. The results indicated a gradual transition to a high dietary acculturation, evidenced by increased consumption of moderate/high fat diet and decreased consumption of fruits and vegetables (Castellanos et al., 2011). Depression was also found to have a significant association with low fruit and vegetable intake/overall decreased dietary intake (Castellanos et al., 2011). 
Tseng and Fang (2011) investigated the association between acculturative psychosocial stress and dietary behaviors in Chinese female immigrants residing in Philadelphia. The researchers measured migration-related stressors and life stressors, and associated these with higher dietary intake. The results showed an association between migration-related stress and increased percentage of dietary fat intake, an association between migration-related stress and decreased overall dietary intake, an association between positive life events and increased dietary intake, and an association between negative life events and decreased dietary intake. This was especially true in lessacculturated women than more-acculturated women. Thus, Tseng and Fang (2011) provided evidence that factors such as migration stress could have significant impact on dietary fat intake.

Sharkey, Johnson, and Dean (2011) found that when compared to Mexico-born Mexican women, U.S.-born Mexican women consumed a higher amount of sugarsweetened beverages (SSB) and fast-food meals (FFM). With consideration for other characteristics, there was an independent association between being born in in Mexico and a lower consumption of FFM, but no association with SSB (Sharkey et al., 2011). While nativity was associated with FFM and SSB in both groups, other characteristics, including single parenthood, having children, and age, were associated with the consumption of SSB, while single parenthood, full-time employment, and the consumption of SSB in Mexico-born Mexican women were associated with increased frequency of FFM consumption (Sharkey et al., 2011). 


\section{Obesity and Physical Activity in Immigrant Populations}

Researchers have identified unique challenges and barriers to participating in physical activity as a reason for sedentary lifestyle in immigrants (Drummond, Mizan, Burgoyne, \& Wright, 2011; Gele \& Mbalilaki, 2013; Martinez, Powell, Agne, Scarinci, \& Cherrington, 2012). Drummond et al. (2011) investigated barriers to healthy dietary habits and physical activity in West African female immigrants living in Australia. Data showed that while most of the study participants identified and recognized the benefits of physical activity, West African immigrant women did not agree that physical activity was helpful for weight control. Drummond et al. (2011) identified certain misconceptions and cultural beliefs were barriers that hinder the uptake of physical activity in this population. Such misconceptions included the belief that expensive equipment was necessary to be physically active, that physical activity was only for young people, and that for physical activities to achieve any purpose, pain had to be associated. The study also identified lack of time, fear of pain, lack of transportation or appropriate exercise clothing and equipment as barriers to the uptake of physical activity in West African female immigrants living in Australia (Drummond et al., 2011). In the Somalian female population, specific barriers included increased access to and use of public transportation, less frequent shopping, the increased use of devices that ease labor, need for childcare, safety concerns, and inexperience with physical activity involving the use of exercise equipment (Drummond et al, 2011). The researchers also found that while increase in BMI was associated with age, it had no relation to these identified barriers to physical 
activity or knowledge of nutrition or physical activity; an increase in external barriers was, however, associated with length of stay $(\mathrm{r}=0.54, p<0.001$; Drummond et al., 2011, p. 147).

The difference in climate may also be a contributory factor to obesity in immigrant populations. Rothe et al. (2010) provided evidence that change in weather could hinder the uptake of physical activities in African immigrants. The results showed gender and cultural concerns that hinged on females requiring specific clothing to participate in any outdoor physical activities or having limited interaction with men who were not their spouses; lack of transportation and limited financial and material resources were also identified as barriers to physical activities during the winter (Rothe et al., 2010).

\section{Gender, Socioeconomic Status, Level of Education, and Obesity in Immigrants}

Socioeconomic status and level of education are well-documented risk factors for obesity, with many studies identifying the association between low education and socioeconomic status and obesity, and increasing disparities associated with the prevalence of obesity in males and females (Chapman, Fiscella, Duberstein, Coletta, \& Kawachi, 2009; El-Sayed, Scarborough, \& Galea, 2012; Jasti, Chang Hyun, \& Doak, 2011). Babey, Hastert, Wolstein, and Diamant (2010) carried out a cross-sectional study on 17535 adolescents using the 2001-2007 California Health Interview Survey (CHIS); they examined the association between income levels and obesity prevalence in a diverse ethnic population of California adolescents and the role of gender in obesity disparities. 
The authors tracked and tested for obesity differential trends using the CHIS adolescents' data and measures of family income, analyzed as federal poverty level percentage. The results showed that adolescents whose family incomes fell below federal poverty line had a higher obesity prevalence rate compared with adolescents whose family incomes were $300 \%$ or more of the federal poverty level line, with significantly consistent increase identified in males than females.

Chapman et al. (2009), however, reached a different conclusion in their study, finding that regardless of level of education, females with higher household income had a lower BMI compared with females with lower household income. Salsberry and Reagan (2009) also conducted a review on the effect of socioeconomic status on obesity in Mexican American women, and compared the patterns against that of White and African American women. The researchers found that Mexican American women with disadvantaged socioeconomic status had an increased risk for midlife obesity; this pattern was found to be similar to that of White women with disadvantaged socioeconomic status but not in African American women (Salsberry \& Reagan, 2009).

Level of education has also been associated with differences in the prevalence of obesity in all populations (Bodea, Garrow, Meyer, \& Ross, 2009). There is evidence that the prevalence of obesity could be lower in individuals with college degrees or higher, compared to those who have less than high school education (Chapman, Fiscella, Duberstein, Coletta, \& Kawachi, 2009). Barrington, Baquero, Borrell, and Crawford (2010) examined and compared the obesity rates in whites, blacks, and Hispanics born in 
the United States to those of whites, blacks, and Hispanics born outside the United States, with a focus on sex, race, and education variables. The results indicated that overall, obesity prevalence is lower in white, black, and Hispanic immigrants to the United States than whites, blacks, and Hispanics born in the United States; the odds for obesity was lower in black immigrants than whites born in the United States; a twofold disparity in obesity existed between black women immigrants and white women born in the United States. Education had minimal effect on obesity rates in foreign-born Hispanics and U.S.born Hispanics; obesity disparity was identified in men with the highest levels of education and in women with the lowest level of education (Barrington et al., 2010).

\section{Obesity and Length of Stay in Immigrant Populations}

Current research examines the extent to which length of stay predicts an increase in obesity; as immigrants remain longer in the host country, there is a tendency to adopt the new dietary and physical activity patterns of the new population (Averett, Argys, \& Kohn, 2012; Barrington, Baquero, Borrell, \& Crawford, 2010; Jasti, Chang Hyun, \& Doak, 2011; Oster \& Yung, 2010; Oza-Frank \& Narayan, 2010; Torres \& Wallace, 2013; Tseng \& Fang, 2011). The study by Guendelman, Ritterman-Weintraub, Fernald, and Kaufer-Horwitz (2013) investigated body weight in Mexican female immigrants in comparison to Mexican women who lived in Mexico and Mexican American women who were born in the United States, with a focus to understand obesity/weight-related outcomes and trends in these populations. The researchers looked at factors such as place of birth, length of stay, age, acculturation, and education in these three groups in order to 
identify the existence of any disparities. The results indicated that Mexican female immigrants had an increased likelihood for a higher body mass index and obesity than Mexican women who lived in Mexico; however, when compared to Mexican American women who were born in the United States, Mexican female immigrants shared a similar likelihood to be overweight, but Mexican female immigrants had a less likelihood of being obese than Mexican American women who were born in the United States. The results also indicated that the weight-related outcomes in Mexican female immigrants who had lived in the United States for less than five years and Mexican women who lived in Mexico were similar.

\section{Theoretical Foundation Framework}

To examine the factors associated with obesity in minority and immigrant populations, there is a need to look at the social influences that contribute to obesity and also include social concepts of the community, culture, and physical environment levels from the socio-ecological model to the segmented assimilation theory.

\section{Social Ecological Model}

Over the years, researchers have used the social ecological model for understanding the phenomenon of obesity (Lytle, 2009a). In this study, the social ecological model is necessary to conceptualize the different social ecological factors that influence health-related behaviors and contribute to the prevalence of obesity in Nigerian immigrant populations living in the United States (Lytle, 2009a). Personal attributes and innate characteristics of the individual, such as taste preferences, physical activity 
limitations and disinterest, have been associated with obesity at the intrapersonal level (Ade, Rohrer, \& Rea, 2011; Chircop et al., 2013; Kellou, Sandalinas, Copin, \& Simon, 2014; Knoblock-Hahn \& LeRouge, 2014; Townsend \& Foster, 2013; Zive \& Rhee, 2014). Research has shown that support from public policies, and the interpersonal, physical, cultural, and organizational environments is essential for the prevention and control of obesity, and that health-related behavioral changes have a high likelihood of lasting if individuals and their entire environment experience these change simultaneously (Gentile et al., 2009; New Hampshire Department of Health and Human Services, 2010).

With a supportive social environment, the decision to change key obesity-related behaviors or live healthier becomes an easier choice (Gentile et al., 2009). Influences from the social environment are significant contributors to obesity; the support or lack of support from social relationships or the culture of the society in which an individual lives, has a tendency to have positive or negative influences on behaviors that contribute to obesity (Acheampong \& Haldeman, 2013; Ade, Rohrer, \& Rea, 2011; Layton, Parker, Hermann, \& Williams, 2009; Sutherland, 2013). Research carried out on samples of African American women has shown that social support and companionship is an accurate predictor of adopting and sustaining physically active lifestyle, and the prevention of obesity (Harley, 2009; Thomas, 2009). The study by Hunte and Williams (2009) identified an association between perceived discrimination and obesity in a multiracial and multiethnic sample population. Using the social ecological model as a 
theoretical framework, the researchers focused on how influences at the interpersonal level contribute to obesity in the sample population, specifically the perception of discrimination experienced during routine social/interpersonal interaction and how this contributed to increased abdominal girth and accumulation of body fat. The results indicated that multiethnic populations with perceived long-term discrimination were sixtimes more likely to experience increased abdominal girth and accumulation of body fat, compared to multiethnic populations without perceived long-term discrimination (Hunte \& Williams, 2009).

As immigrants transition from their native culture to the westernized culture, the cultural influences from the host country could heavily impact their dietary patterns, contributing to obesity (Harvard School of Public Health, 2014; Oza-Frank \& Narayan, 2010). When combined with intrapersonal influences, the socio-cultural context in which immigrants live could either increase or decrease the risk of obesity (Martinez et al., 2012; Oza-Frank \& Narayan, 2010). The research by Castellanos, Connell, and Lee (2011) also applied the social ecological model to better understand how influences at the culture level contributed to obesity in Latino males residing in Mississippi. The researchers examined the interplay between the intrapersonal and culture level factors to support their research that the introduction and continuous exposure of immigrants to the western diet and culture can shape the dietary habits of this population and subsequently contribute to obesity prevalence. The researchers explained that a change from the Latino dietary culture of increased consumption of protein, fiber, fruits, and vegetables could 
become gradually replaced with increased consumption of western diets which consist of refined foods, high in calories, salt and fat, thereby contributing to increased obesity rates in this population. The research results showed that there was an association between western dietary acculturation (evidenced by an increase in the consumption of a high fat diet) and obesity (Castellanos et al., 2011).

The study by Yeary et al. (2011) supported the contextual influences of the organizational and community levels on obesity; the researchers examined the role of community-based organizations in implementing weight loss programs for African American church/community members to participate in. The results showed that study participants (church members) experienced increased physical activity levels and increased social support from friends and family for healthy dietary habits and physical activities (Yeary et al.,2011).

\section{Segmented Assimilation Theory}

Segmented assimilation theory posits that there is a varying pattern of integration in immigration, which is based on race and other social factors (Hao \& Kim, 2009; Kershaw \& Albrecht, 2014; Piedra \& Engstrom, 2009). The environment immigrants settle into in the host country influences the pattern of assimilation (underclass, classic, and segmented assimilation) and contributes to heterogeneity observed in obesity (Florez, 2011). Many immigrants migrate to western countries to seek better lives and start new lives, socioeconomically, in most cases. This means they come in with practically nothing, and their skin color or accent is a unique identifier of their race or socio- 
economic status. Environmental and socioeconomic stressors affect immigrants. Because they have little income, many immigrants are forced to live in minority and poor neighborhoods; thus, they are susceptible to health-related behaviors that contribute to a higher prevalence of obesity as they adapt to a new culture and country (Piedra \& Engstrom, 2009; Waters et al., 2010). The study by Florez (2011) applied the segmented assimilation theory to the prevalence of obesity in Latino adults residing in the United States. Florez found that when age, ethnicity, length of time, gender, and physical activity limitations are considered, the odds of obesity are higher in individuals in the second and third generation conventional upward/classic assimilation path (middle and low socioeconomic class) compared to individuals in selective acculturation/segmented assimilation path (economically advanced class) (Florez, 2011). The path of upwardsegmented assimilation is evident in immigrants who have advanced socioeconomically and have embraced both their native culture and that of the host country. Upward segmented assimilation has been associated with positive dietary behaviors and health outcomes (Castro, Marsiglia, Kulis, \& Kellison, 2010; Florez, 2011; Waters et al., 2010).

\section{Literature Related to the Research Design and Methodology}

Many researchers have relied on logistic regression to analyze cross-sectional data containing multiple independent variables on the likelihood of obesity outcomes in immigrant populations (Ade et al., 2011; Barrington et al., 2010; Blanchard, 2009; Castellanos et al,, 2011; Florez, 2011; Jasti et al., 2011; McCubbin \& Antonio, 2012; Oza-Frank \& Narayan, 2010). Jasti et al. focused on investigating obesity predictors 
(gender, acculturation, frequency, and patterns of cultural/traditional dietary habits, and weight status) in Korean immigrants who reside in the United States. Jasti et al. carried out a cross-sectional study design on a convenience sample of 195 Korean immigrants, 18 years and older, and used 3-part survey/questionnaire instruments formatted as a 5point Likert scale, to obtain data on socioeconomic characteristics, personal characteristics, acculturation, and frequency of food consumption. Socio-economic and personal variables, such as age $(<28, \geq 28$ years), gender (male, female), marital status (married, not married), length of stay in the United States (0-7, $\geq 8$ years), education level (<college degree, $\geq$ college degree), annual household income $(<\$ 50,000, \geq \$ 50,000)$, and smoking status (never, past, current), were measured. BMI was measured using the WHO's recommendation for alternative cutoff points for Asians, which classified $\mathrm{BMI}<23$ as non-overweight/obese, and $\mathrm{BMI} \geq 23$ as overweight/obese.

Jasti et al. (2011) applied descriptive statistics (frequencies, means, and percentages) to the variables. Chi-square test was used to investigate any bivariate associations in the socioeconomic/personal characteristics acculturation levels and overweight/obese status. Independent samples $t$-test was used to investigate the existence of any differences in the mean frequency of culturally neutral foods, Korean foods and American foods as a group and as individuals (stratified by gender). Logistic regression was then used to test for any association between gender, specific American foods, acculturation, and being overweight or obese. Age, marital status, and education level were tested as confounders using odds ratios. Statistical significance for $p$ value was set 
and identified as $p<0.05$. Although no significant association was found between obesity and acculturation $(\mathrm{OR}=0.62$; $\mathrm{CI} 0.29-1.30)$ regardless of gender and age, the logistic regression results showed that overweight and obesity were associated with male gender. The likelihood of obesity was 5 times more likely in Korean male immigrants than females, OR=5.08; CI 2.37-10.90), older age, length of stay in the U.S., and former smoking status (Jasti et al., 2011). The results also indicated that the frequent consumption of 'American foods and snacks by the male Korean immigrant population increased their risk of obesity compared to female Korean immigrant population who consumed more traditional/cultural Korean staple foods (Jasti et al., 2011).

\section{Summary and Conclusions}

This extensive literature review summarizes peer-reviewed articles from experts who have researched the predictors of obesity in native Nigerians, Nigerian immigrants in the United States, and other immigrant/minority groups in both the United States and other western countries. The research in obesity continues to examine the complex associations between obesity and many variables by identifying that obesity outcomes are unique and differ by the interaction of many factors, including gender, level of education, length of stay, diet, level of physical activity, and ethnicity. Some studies have also compared the prevalence of obesity in Nigeria and developed countries, such as the United States and the United Kingdom, and found significant similarities. In this chapter, I identified a gap in literature by examining the prevalence and risk factors of obesity in Nigerian immigrants in the United States, whether it is increased or decreased after 
migration, and how these compare to other immigrant/minority populations in the United States.

In Chapter 3, I provided a description of the research methodology and statistical methods used to measure the prevalence of obesity in Nigerian immigrants and tested the association between obesity and potential factors. Chapter 3 will include a description of variables, gender, level of education, length of stay, and measures of dietary patterns and level of physical activity. This next chapter describes the sample population, sampling strategy, method of data collection and analysis, and research variables. 


\section{Chapter 3: Research Methods}

In this cross-sectional quantitative study, I used a survey to investigate the prevalence of obesity in the Nigerian immigrant population in the United States, and the potential correlates in the same population. I used a modified BRFSS questionnaire to collect information on demographics and other lifestyle characteristics, such as physical activity and dietary habits, with the purpose of measuring and estimating what exists in the Nigerian immigrant population. This chapter provides a thorough description of the research methodology used to carry out this research; I describe the research design, sample population, sampling method, data collection and analysis methods, and any issues that threaten the validity of the study.

\section{Research Design and Approach}

This study's cross-sectional research design measured obesity prevalence in Nigerian immigrants living in the United States and also whether there is a correlation between gender, level of education, socioeconomic status, length of stay, diet, and level of physical activity (independent variables) and obesity outcomes in the sample population (dependent variable). The study focused on identifying a snapshot of the demographics and lifestyle characteristics that exist in the study population at a specific timeframe, as explained by Frankfort-Nachmias and Nachmias (2008) for such a research design. With a cross-sectional study, the focus is on what association currently exists between the variables being investigated in the study population (Creswell, 2013; Frankfort-Nachmias \& Nachmias, 2008). This research design was appropriate for this 
study because it does not require any follow-up of the research participants and was only descriptive in nature. This also allowed for a quicker and less-expensive study to be conducted when compared to other epidemiologic studies, as noted by Creswell (2013) and Szklo and Nieto (2014).

Despite these study design characteristics, one significant limitation of crosssectional studies is that the results will be time-bound to the specific period being investigated, making it difficult to identify the sequence of events to that point; for this reason, a causal relationship between exposure and outcome cannot be determined (Szklo \& Nieto, 2014). Another important limitation is the possibility of prevalence-incidence bias. A cross-sectional study measures prevalence rather than incidence, and so the study participants with long-term duration of exposure to the variables being measured tend to overrepresent the degree of association with the outcome of interest while study participants with short-term duration of exposure tend to underrepresent the degree of association with outcome of interest, in this case obesity (Ocean University of China, n.d.).

\section{Survey Approach}

In this study, I used a survey research method. This technique is a descriptive and nonexperimental way of data collection, useful in measuring specific characteristics of study respondents or a specific population through responses to a series of questions that assess demographics, characteristics and other variables of interest (Creswell, 2013). I used a web-based, modified BRFSS questionnaire to collect quantitative data on gender, 
level of education, socioeconomic status, length of stay, diet, and level of physical activity to understand the predictive relationship that exists between them and obesity outcomes, measured by BMI. This collection of quantitative data allowed for quantitative data analysis in order to accurately measure the correlative/predictive relationship that exists between these variables.

Survey type research is an efficient, fast, and inexpensive way of measuring several variables in a large sample population. With a standardized set of questions, the survey method allows for consistency in the measurement of specific characteristics in a population (Lind, Marchal, \& Wathen, 2008; Trochim, 2006). This standardization of questions improves the reliability of the survey instrument (Creswell, 2013). Surveys present questions within a context, allowing individuals in the sample population to interpret and answer the questions appropriately and accurately (Frankfort-Nachmias \& Nachmias, 2008; Lind et al., 2008). Surveys are also flexible and convenient for the respondents; the flexibility of surveys allows for a tailoring of the questions to obtain a measurement of specific variables of interest (Creswell, 2013).

Direct interviews is a form of survey research which requires face-to-face interaction between the research respondents and the interviewer (Creswell, 2013). One of the strengths of direct interviews is the ability to immediately clarify the meaning of certain questions that the respondent might find complex to interpret or understand; with interviews, there is a higher response rate since the interviewer can pace the interview and ensure completion. With direct interviews, self-report can be augmented with 
physical observations of the respondents' behaviors, expressions and other physical characteristics (Frankfort-Nachmias \& Nachmias, 2008). Despite these strengths, direct interviews have their limitations. Interviewers may distort the data collected by rewording the questions on the survey, changing the meaning from what was originally intended. The completion of direct interviews is time-consuming and so is expensive to perform (Frankfort-Nachmias \& Nachmias, 2008). Since each interviewer is able to probe deeper to obtain essential information needed from respondents, the interpretation of questions and responses may differ among them. When sensitive information is involved, there is a tendency for respondents to underreport behaviors or attitudes that are being assessed because they are concerned about what the researcher may think of them (Creswell, 2013; Engel, \& Schutt, 2009; Frankfort-Nachmias \& Nachmias, 2008).

Mailed survey is a form of survey research that involves the mailing of questionnaires to target respondents so that they can self-administer the survey (Creswell, 2013). One of the strengths of mailed survey is that it can reach a larger population than other survey methods, thereby maximizing the rate of respondents' responses (FrankfortNachmias \& Nachmias, 2008). Since there is no direct interaction between respondents and interviewers, the possibility of interviewer bias is also less or even eliminated. Despite these strengths, mail surveys have its limitations. A lack of willingness or inadequate response time on the part of the respondents may hinder the surveys from being completed on time (Check \& Schutt, 2012). Respondents may also encounter questions that they do not understand, and without clarification, they may provide 
inaccurate answers. Without follow-up, the response rate in survey methods is low; respondents might require constant follow-up to complete the surveys. Without the probing experienced in direct interviews, respondents may have problems recalling the information about the details requested in the questionnaires and may report wrong information (Creswell, 2013; Engel \& Schutt, 2009; Frankfort-Nachmias \& Nachmias, 2008).

Despite the strengths of the above methods of surveys, I used a web-based survey in this study. This kind of survey allows for electronic collection of data and its immediate transformation into analyzable form (Fuller, 2004; van Gelder, Bretveld, \& Roeleveld, 2010). Web-based surveys also reduce data-entry errors; with data systems programming, prompts are in place to bring attention to missing questions or improbable responses (Fuller, 2004). Despite these strengths, web-based surveys have their limitations. In some instances, it is difficult to control who accesses the web survey and the frequency at which a single individual repeatedly submits a survey repeated, resulting in duplication of results (van Gelder et al., 2010). The fear for data safety and confidentiality issues may hinder people from completing these surveys (Fuller, 2004). Web-based surveys may exclude individuals with no Internet access and those who are technology challenged; this may lower the response rate (Fuller, 2004; van Gelder et al., 2010). However, web-based survey was most appropriate for this study because of the need to reach a large population which is scattered across the different states of the 
nation. It was also cheaper and less time-consuming compared to the direct interview survey and the mailed survey method (Fuller, 2004; van Gelder et al., 2010).

Irrespective of the delivery method, surveys have some general limitations. Surveys are not useful for tracking weight patterns in real-time or over a short period (Creswell, 2013). Just as their use in cross-sectional studies implies, with the collection of data at a specific time, surveys cannot measure changes in obesity outcomes unless subsequent surveys are carried out to measure these changes (Aschengrau \& Seage, 2008; Engel \& Schutt, 2009; Frankfort-Nachmias \& Nachmias, 2008). Another limitation of the survey method is that responses can be constrained, hindering the respondents' ability to provide answers beyond what was indicated in the questionnaires (Creswell, 2013; Frankfort-Nachmias \& Nachmias, 2008; Trochim, 2006). Since the completion of this web-based survey required self-reported data, there was also a potential for respondents to overreport or underreport information in order to maximize or minimize what was being measured; furthermore, respondents may provide misinformation based on inaccurate recollection of nutrition/physical activity behaviors, allowing for inaccurate measurement of these patterns. All these issues threaten the validity of the study (Creswell, 2013; Frankfort-Nachmias \& Nachmias, 2008; Lind, Marchal, \& Wathen, 2008). Another disadvantage of the survey research method is the difficulty in transcribing the research questions into succinct survey questions that the respondents can understand clearly and answer. The lack of understanding of the survey questions 
can result in incomplete survey submission, making it practically impossible to get accurate measurement of the situation being studied (Aschengrau \& Seage, 2008).

\section{Research Methodology}

\section{Sample Population}

The process of sampling is the selection of individual study participants that represent a much larger population; the purpose of this selection is to obtain measurements from a population in order to answer the research questions and make an inference about the population the researcher is interested in (Schutt, 2011). The sample population for this study was Nigerian immigrants, aged 18 years and older, who have been permanent resident in the United States for 2 years or more.

\section{Sampling and Recruitment Procedures}

In this study, I used convenience sampling to recruit research participants. This sampling method is also known as a sampling of opportunity because the participants are not chosen at random; instead they are chosen from a population that is easily accessible and is specifically targeted to meet unique research needs (Frankfort-Nachmias \& Nachmias, 2008; Lund Research, 2012). Convenience, nonprobability sampling is more feasible because Nigerian immigrants look like others in the broader African American population, and it is not easy to differentiate them from Blacks of other ethnicities.

Obtaining a large sample of research participants required identifying and targeting large cultural communities to which Nigerian immigrants belong; a random sampling method would have been less feasible and more time-consuming. I recruited study participants 
from selective Nigerian cultural communities, including local Nigerian social groups, Nigerian immigrant Facebook groups, and Nigerian churches in the United States.

\section{Eligibility Criteria}

This study included research participants who are Nigerian immigrants, aged 18 years and older, who after being provided adequate and accurate information, voluntarily made an informed decision to participate in the research. This study excluded Nigerian immigrants who have not lived in the United States for more than 2 years, and Black individuals who are Nigerians by marriage but not by birth.

\section{Procedures for Participation}

Participation was voluntary, and potential participants could access web link information on how to participate through the web pages of Nigerian immigrant groups' Facebook pages. Participants were assured of anonymity of participation and also had access to the researcher's number for follow-up questions. The 10-minute web-based survey, available on Survey Monkey, did not contain any personal identity information, reducing the ability to link each respondent to his or her survey. Respondents had a choice to click next at the beginning of the survey, and doing so served as the respondents' signed consent to continue to the survey section after reading the summary page of the study, indicating their willingness to participate. After completion of the survey, respondents had a choice to click the submit button to transmit their survey to the researcher for compilation with other data sources; closing the browser completed research participation. This survey was only available for 4 weeks. 


\section{Sample Size Calculation}

A minimum of 163 participants was needed to ensure the research population sample reflected the target population and to reduce any potential bias. Using an adequate sample size indicates representativeness, which increased confidence in the researchers' claim to generalization and applicability of their result (Schutt, 2011). This sample size was calculated using $\mathrm{G}^{*}$ Power analysis with inputs of alpha ( $\alpha$ err prob) - 0.05 , medium effect size -0.50 and power $(1-\beta$ err prob) -0.80 . Setting the alpha of this study to an arbitrary 0.05 allowed the researcher to identify if any difference existed. The power is what determines the viability of the null hypothesis, which allows the researcher to quantify the chance that the null hypothesis will be rightly rejected if the alternative hypothesis happens to be true (Ellis, 2010; Mudge, Baker, Edge, \& Houlahan, 2012). This allows for a conclusive result in which the audience can have the highest confidence possible; in this case, it was $80 \%$ (Mudge et al., 2012). The effect size is the degree to which what is being investigated is present in a sample population that is representative of a larger population, which detects a significant difference and allows the ability to test the null hypothesis to accept or reject it (Ellis, 2010). Effect size can be small, medium, or large. A medium effect size of 0.50 allows for the identification of average but consistent effect enough to identify and illustrate what association between variables exists in the sample population (Ellis, 2010; Mudge et al., 2012). Researchers give readers an insight into the measures of strength of both the association and correlation that exist for the variables by providing information about the effect-size and the 
statistical significance of a study (Field, 2009). To compensate for nonresponses, uncompleted questionnaires, missing data, and sampling bias, I targeted data collection from 220 respondents.

\section{Instrumentation and Operationalization of Constructs}

The BRFSS is a survey developed by the CDC in 1984 and administered nationwide. This survey comprises questions that allow researchers collect data on specific health risks and health-related behaviors that have been linked to important health conditions (National Collaborative on Childhood Obesity Research, 2010). I modified the questions in the core modules of the BRFSS to collect information on the demographics, dietary, physical activity, socioeconomic status, and lifestyle patterns of the Nigerian immigrants sample population. There is evidence that the prevalence rates detected by the BRFSS are comparable to those detected by other self-report surveys used nationally (Pierannunzi, Hu, \& Balluz, 2013). Although there are noted differences in the responses in the BRFSS surveys and other national surveys such as the National Health Interview Study (NHIS), National Health And Nutrition Examination Survey (NHANES), and Current Population Survey (CPS), with the BRFSS identifying lesser prevalence rates than surveys that combine self-reported data with physical measures, there is evidence that supports BRFSS validity (Pierannunzi et al., 2013). 


\section{Measurements of Variables}

\section{Operationalization}

Operationalization refers to the ability to connect the research concepts to its observations. Operationalization describes what is measured, how it is measured, and what rules are used to assign different values to the observables and the interpretation of these values (Check, \& Schutt, 2012). Theoretical frameworks based on segmented assimilation and social ecology guided the identification of factors, which contributed to the prevalence of obesity in Nigerian immigrants in the United States. This study hypothesized that obesity outcomes in Nigerian immigrants in the United States would vary based on gender, level of education, socio-economic status, length of stay, diet, and level of physical activity. This study measured concepts of four levels of social influence

of social ecology: (a) intrapersonal (gender and dietary and physical activity preferences), (b) interpersonal (social support), (c) community (education), and (d) physical environment (diet, physical activity). This allowed for the examination of the relationship between these influences and the prevalence of obesity in the sample population. This study measured socioeconomic status (income level) as a concept of segmented assimilation theory, which examined if a relationship exists between this variable and obesity outcomes. 
Table 1.

Data Dictionary

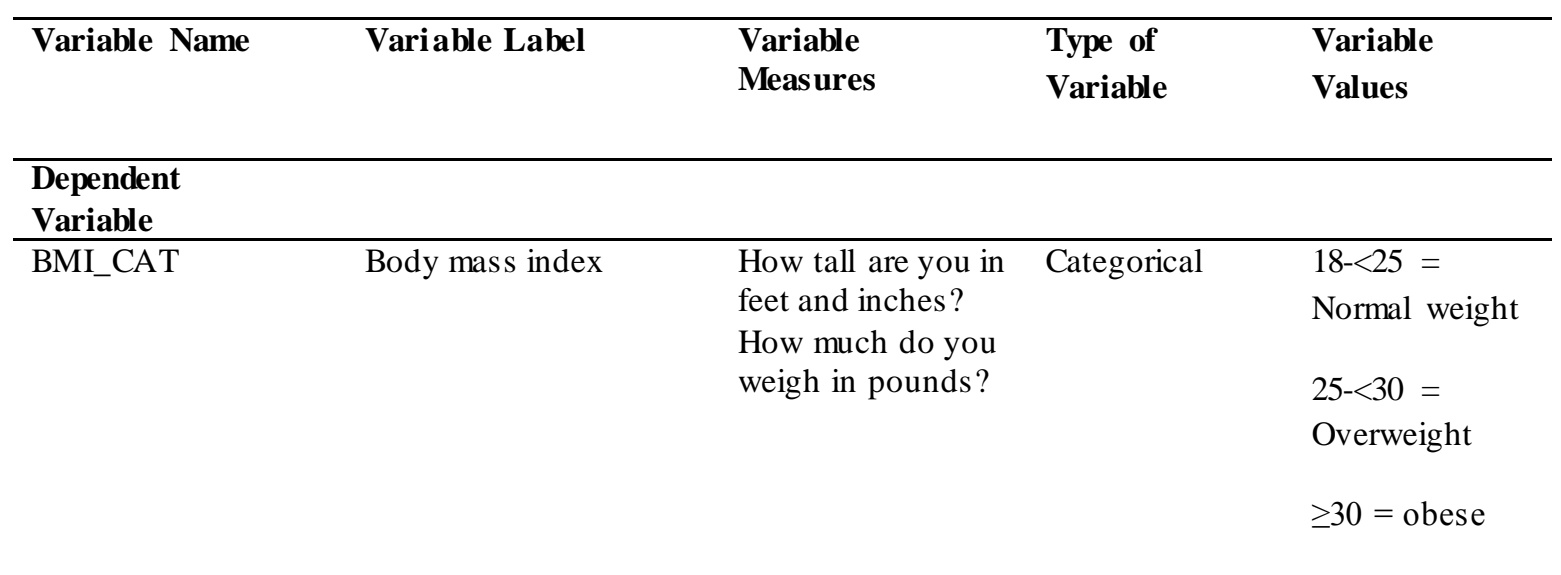

\section{Independent \\ Variables Data}

GENDER

EDUCA

RESPONDENTS SEX
EDUCATION LEVEL

female?

What is the highest Categorical

grade or year of

schoolyou

completed?

Table continues

1=male
$2=$ female
1 Never
attended school
or only
attended
kindergarten
2 Grades 1
through 8
(Elementary)
3 Grades 9
through 11
(Some high
school)
4 Grade 12 or
GED (High
school
graduate)
5 College 1
year to 3 years
(Some college
or technical
school)
6 College 4
years or more
(College
graduate)




\begin{tabular}{|c|c|c|c|c|}
\hline Variable Name & Variable Label & $\begin{array}{l}\text { Variable } \\
\text { Measures }\end{array}$ & $\begin{array}{l}\text { Type of } \\
\text { Variable }\end{array}$ & $\begin{array}{l}\text { Variable } \\
\text { Values }\end{array}$ \\
\hline EMPLOY & $\begin{array}{l}\text { EMPLOYMENT } \\
\text { STATUS }\end{array}$ & Are you currently? & Categorical & $\begin{array}{l}1 \text { Employed for } \\
\text { wages } \\
2 \text { Self - } \\
\text { employed } \\
3 \text { Out of work } \\
\text { for } 1 \text { year or } \\
\text { more } \\
4 \text { Out of work } \\
\text { for less than } 1 \\
\text { year } \\
5 \text { A } \\
\text { Homemaker } \\
6 \text { A Student } \\
7 \text { Retired } \\
8 \text { Unable to } \\
\text { work }\end{array}$ \\
\hline AGE & $\begin{array}{l}\text { REPORTED AGE IN } \\
\text { YEARS }\end{array}$ & What is your age? & Continuous & -- \\
\hline IMMIG_STATUS & $\begin{array}{l}\text { IMMIGRANT } \\
\text { STATUS }\end{array}$ & $\begin{array}{l}\text { Are you a Nigerian } \\
\text { immigrant? }\end{array}$ & Categorical & $\begin{array}{l}\text { Yes } \\
\text { No }\end{array}$ \\
\hline $\begin{array}{l}\text { LENGTH } \\
\text { _RESIDENCE }\end{array}$ & $\begin{array}{l}\text { LENGTH OF } \\
\text { RESIDENCE }\end{array}$ & $\begin{array}{l}\text { How long have } \\
\text { you lived in the } \\
\text { United States? }\end{array}$ & Continuous & $\begin{array}{l}\text { Months } \\
\text { Years }\end{array}$ \\
\hline Table continues & INCOME STATUS & $\begin{array}{l}\text { Is your annual } \\
\text { household income } \\
\text { from all sources }\end{array}$ & Categorical & $\begin{array}{l}\$ 20,000 \text { to less } \\
\text { than } \$ 25,000 \text {, } \\
\$ 15,000 \text { to less } \\
\text { than } \$ 20,000 \text {, } \\
\$ 10,000 \text { to less } \\
\text { than } \$ 15,000 \text {, } \\
\$ 25,000 \text { to les s } \\
\text { than } \$ 35,000 \text {, } \\
\$ 35,000 \text { to les s } \\
\text { than } \$ 50,000 \text {, } \\
\$ 50,000 \text { to less } \\
\text { than } \$ 75,000 \text {, } \\
\$ 75,000 \text { or } \\
\text { more. }\end{array}$ \\
\hline
\end{tabular}




\begin{tabular}{|c|c|c|c|c|}
\hline Variable Name & Variable Label & $\begin{array}{l}\text { Variable } \\
\text { Measures }\end{array}$ & $\begin{array}{l}\text { Type of } \\
\text { Variable }\end{array}$ & $\begin{array}{l}\text { Variable } \\
\text { Values }\end{array}$ \\
\hline OWN_RENT & HOME OWNERSHIP & $\begin{array}{l}\text { Do you own or } \\
\text { rent your home? }\end{array}$ & Categorical & $\begin{array}{l}1 \text { Own } \\
2 \text { Rent } \\
3 \text { Other } \\
\text { arrangement } \\
7 \text { Don't know / } \\
\text { Not sure }\end{array}$ \\
\hline STRESS_FOOD & $\begin{array}{l}\text { STRESS FOR FOOD } \\
\text { PURCHASE }\end{array}$ & $\begin{array}{l}\text { How often in the } \\
\text { past } 12 \text { months } \\
\text { would you say you } \\
\text { were worried or } \\
\text { stressed about } \\
\text { having enough } \\
\text { money to buy } \\
\text { nutritious meals? } \\
\text { Would you say } \\
\text { you were worried } \\
\text { or } \\
\text { stressed: }\end{array}$ & Categorical & $\begin{array}{l}1 \text { Always } \\
2 \text { Usually } \\
3 \text { Sometimes } \\
4 \text { Rarely } \\
5 \text { Never }\end{array}$ \\
\hline SUPPORT & SOCIAL_SUPPORT & $\begin{array}{l}\text { How often do you } \\
\text { get the social and } \\
\text { emotional support } \\
\text { you need from any } \\
\text { source? }\end{array}$ & Categorical & $\begin{array}{l}\text { 1Always } \\
2 \text { Usually } \\
3 \text { Sometimes } \\
4 \text { Rarely } \\
5 \text { Never }\end{array}$ \\
\hline BEV_SODA & $\begin{array}{l}\text { SODA } \\
\text { CONSUMPTION }\end{array}$ & $\begin{array}{l}\text { During the past } 30 \\
\text { days, how often } \\
\text { did you drink } \\
\text { regular soda or pop } \\
\text { that contains } \\
\text { sugar? Do not } \\
\text { include diet soda } \\
\text { or diet pop. }\end{array}$ & $\begin{array}{l}\text { Categorical } \\
\text { (tables) }\end{array}$ & $\begin{array}{l}1_{-} \text {_ Times per } \\
\text { day } \\
2 \ldots \text { Times per } \\
\text { week } \\
3 \ldots \text { Times per } \\
\text { month } \\
777 \text { Don't } \\
\text { know / Not } \\
\text { sure }\end{array}$ \\
\hline
\end{tabular}

Table continues 


\begin{tabular}{|c|c|c|c|c|}
\hline Variable Name & Variable Label & $\begin{array}{l}\text { Variable } \\
\text { Measures }\end{array}$ & $\begin{array}{l}\text { Type of } \\
\text { Variable }\end{array}$ & $\begin{array}{l}\text { Variable } \\
\text { Values }\end{array}$ \\
\hline BEV_FRUIT & $\begin{array}{l}\text { SUGAR FRUIT } \\
\text { DRINK } \\
\text { CONSUMPTION }\end{array}$ & $\begin{array}{l}\text { During the past } 30 \\
\text { days, how often } \\
\text { did you drink } \\
\text { sugar-s weetened } \\
\text { fruit drinks (such } \\
\text { as Kool-aid and } \\
\text { lemonade), sweet } \\
\text { tea, and sports or } \\
\text { energy drinks } \\
\text { (such as Gatorade } \\
\text { and Red Bull)? Do } \\
\text { not include 100\% } \\
\text { fruit juice, diet } \\
\text { drinks, or } \\
\text { artificially } \\
\text { sweetened drinks. }\end{array}$ & $\begin{array}{l}\text { Categorical } \\
\text { (tables) }\end{array}$ & $\begin{array}{l}1_{-}{ }_{-} \text {Times per } \\
\text { day } \\
2 \_- \text {Times per } \\
\text { week } \\
3_{-} \text {- Times per } \\
\text { month } \\
777 \text { Don't } \\
\text { know / Not } \\
\text { sure }\end{array}$ \\
\hline PHY_ACT20 & $\begin{array}{l}\text { PHYSICAL } \\
\text { ACTIVITY } 20 \text { MINS }\end{array}$ & $\begin{array}{l}\text { In the last week, } \\
\text { how many times } \\
\text { did you exercise at } \\
\text { least } 20 \text { minutes } \\
\text { hard enough to } \\
\text { breathe fast, speed } \\
\text { up yourheart rate, } \\
\text { or work up a } \\
\text { sweat? }\end{array}$ & Continuous & $\begin{array}{l}\text {-_-_-_-_ times } \\
\text { in the last week }\end{array}$ \\
\hline PHY_ACTWORK & $\begin{array}{l}\text { PHYSICAL } \\
\text { ACTIVITY AT WORK }\end{array}$ & $\begin{array}{l}\text { When you are at } \\
\text { work, which of the } \\
\text { following best } \\
\text { describes what you } \\
\text { do? Would you } \\
\text { say: }\end{array}$ & Categorical & $\begin{array}{l}1 \text { Mostly sitting } \\
\text { or standing } \\
2 \text { Mostly } \\
\text { walking } \\
3 \text { Mostly heavy } \\
\text { labor or } \\
\text { physically } \\
\text { demanding } \\
\text { work }\end{array}$ \\
\hline
\end{tabular}

Table continues 


\begin{tabular}{|c|c|c|c|c|}
\hline Variable Name & Variable Label & $\begin{array}{l}\text { Variable } \\
\text { Measures }\end{array}$ & $\begin{array}{l}\text { Type of } \\
\text { Variable }\end{array}$ & $\begin{array}{l}\text { Variable } \\
\text { Values }\end{array}$ \\
\hline ACTIVITY_MOD & $\begin{array}{l}\text { MODERATE } \\
\text { PHYSICAL } \\
\text { ACTIVITY }\end{array}$ & $\begin{array}{l}\text { Now, thinking } \\
\text { about the moderate } \\
\text { activities you do, } \\
\text { when you are not } \\
\text { working, in a usual } \\
\text { week, do you do } \\
\text { moderate activities } \\
\text { for at least } 10 \\
\text { minutes at a time, } \\
\text { such as brisk } \\
\text { walking, bicycling, } \\
\text { vacuuming, } \\
\text { gardening, or } \\
\text { anything else that } \\
\text { causes some } \\
\text { increase in } \\
\text { breathing or heart } \\
\text { rate? }\end{array}$ & $\begin{array}{l}\text { Categorical } \\
\text { (tables) }\end{array}$ & $\begin{array}{l}\text { Yes } \\
2 \text { No } \\
\text { 7Don't know / } \\
\text { Not sure }\end{array}$ \\
\hline ACTIVITY_VIG & $\begin{array}{l}\text { VIGOROUS } \\
\text { PHYSICAL } \\
\text { ACTIVITY }\end{array}$ & $\begin{array}{l}\text { Now, thinking } \\
\text { about the vigorous } \\
\text { activities you do, } \\
\text { when you are not } \\
\text { working, in a usual } \\
\text { week, do you do } \\
\text { vigorous activities } \\
\text { for at least } 10 \\
\text { minutes at a time, } \\
\text { such as running, } \\
\text { aerobics, heavy } \\
\text { yard work, or } \\
\text { anything else that } \\
\text { causes large } \\
\text { increases in } \\
\text { breathing or heart } \\
\text { rate? }\end{array}$ & $\begin{array}{l}\text { Categorical } \\
\text { (tables) }\end{array}$ & $\begin{array}{l}1 \text { Yes } \\
2 \text { No } \\
7 \text { Don't know / } \\
\text { Not sure }\end{array}$ \\
\hline Table continues & $\begin{array}{l}\text { ALCOHOL } \\
\text { CONSUMPTION }\end{array}$ & $\begin{array}{l}\text { During the past } 30 \\
\text { days, how many } \\
\text { days per week or } \\
\text { per month did you } \\
\text { have at least one } \\
\text { drink of any } \\
\text { alcoholic beverage } \\
\text { such as beer, wine, } \\
\text { a malt beverage or } \\
\text { liquor? }\end{array}$ & $\begin{array}{l}\text { Categorical } \\
\text { (tables) }\end{array}$ & $\begin{array}{l}1_{\text {_eek }} \text { Days per } \\
\text { week } \\
2 \text { _- Days in } \\
\text { past } 30 \text { days } \\
888 \text { No drinks } \\
\text { in past } 30 \text { days } \\
777 \text { Don't } \\
\text { know / Not } \\
\text { sure }\end{array}$ \\
\hline
\end{tabular}




\begin{tabular}{|c|c|c|c|c|}
\hline Variable Name & Variable Label & $\begin{array}{l}\text { Variable } \\
\text { Measures }\end{array}$ & $\begin{array}{l}\text { Type of } \\
\text { Variable }\end{array}$ & $\begin{array}{l}\text { Variable } \\
\text { Values }\end{array}$ \\
\hline FRUIT JUICE & $\begin{array}{l}\text { FRUIT JUICE } \\
\text { CONSUMPTION }\end{array}$ & $\begin{array}{l}\text { During the past } \\
\text { month, how many } \\
\text { times per day, } \\
\text { week or month did } \\
\text { you drink } 100 \% \\
\text { PURE fruit juices? } \\
\text { Do not include } \\
\text { fruit-flavored } \\
\text { drinks with added } \\
\text { sugar or fruit juice } \\
\text { you made at home } \\
\text { and added sugar } \\
\text { to. Only include } \\
\text { 100\% juice. }\end{array}$ & $\begin{array}{l}\text { Categorical } \\
\text { (tables) }\end{array}$ & $\begin{array}{l}1 \text { __Per day } \\
2 \_ \text {Per week } \\
3{ }_{-}{ }_{-} \text {Per } \\
\text { month } \\
555 \text { Never } \\
777 \text { Don't } \\
\text { know / Not } \\
\text { sure }\end{array}$ \\
\hline DIET_FRUIT & $\begin{array}{l}\text { CONSUMPTION OF } \\
\text { FRUITS }\end{array}$ & $\begin{array}{l}\text { During the past } \\
\text { month, not } \\
\text { counting juice, } \\
\text { how many times } \\
\text { per day, week, or } \\
\text { month did you eat } \\
\text { fruit? Count fresh, } \\
\text { frozen, or canned } \\
\text { fruit }\end{array}$ & $\begin{array}{l}\text { Categorical } \\
\text { (tables) }\end{array}$ & $\begin{array}{l}1 \text { __Per day } \\
2 \_ \text {Per week } \\
3{ }_{-}-\text {Per } \\
\text { month } \\
555 \text { Never } \\
777 \text { Don't } \\
\text { know / Not } \\
\text { sure }\end{array}$ \\
\hline DIET_VEG & $\begin{array}{l}\text { CONSUMPTION OF } \\
\text { VEGETABLES }\end{array}$ & $\begin{array}{l}\text { During the past } \\
\text { month, how many } \\
\text { times per day, } \\
\text { week, or month } \\
\text { did you eat dark } \\
\text { green vegetables } \\
\text { for example } \\
\text { broccoli or dark } \\
\text { leafy greens } \\
\text { including romaine, } \\
\text { chard, collard } \\
\text { greens or spinach? }\end{array}$ & $\begin{array}{l}\text { Categorical } \\
\text { (tables) }\end{array}$ & $\begin{array}{l}1 \text { __ Per day } \\
2 \_ \text {Per week } \\
3{ }_{-}{ }_{-} \text {Per } \\
\text { month } \\
555 \text { Never } \\
777 \text { Don't } \\
\text { know / Not } \\
\text { sure }\end{array}$ \\
\hline
\end{tabular}




\section{Reliability and Validity of Instrument}

Reliability has been described as the consistency with which the measurement tool achieves consistent results. Validity refers to the extent to which the measurement tool is accurate in its measurements (Creswell, 2013; Frankfort-Nachmias \& Nachmias, 2008). The BRFSS has been used in many populations in the United States, and researchers have found the module questions to be fairly or moderately valid and reliable in measuring and predicting associations between independent and dependent variables (Evenson \& McGinn, 2005; Mokdad, 2009; Pan, Freedman, Gillespie, Park, \& Sherry, 2011). Yore et al. (2007) carried out a nine-day BRFSS Physical Activity Study (BPAS) using questions from the physical activity module to measure moderate or vigorous activities in research participants. Yore et al.'s purpose was to examine whether there was adherence to the Healthy People 2010's objectives of physical activity. The results indicated test-retest reliability (Kappa statistics) of $0.35-0.53$ for moderate activity and $0.80-0.86$ for vigorous activity. The test for validity also showed a $0.40-0.52$ value for using the survey to measure recommended activity using physical activity log (Yore et al., 2007). The use of self-reported data in estimating the prevalence of health conditions, such as obesity, has been identified as a possible limitation and potential source of bias for the BRFSS. As such, this tool could benefit from the use of physical measurements to correlate and validate self-report data (Mokdad, 2009). According to Landis and Koch's standard of strength of agreement in reliability using Kappa statistics ( $\leq 0=$ poor, .01$.20=$ slight, $.21-.40=$ fair, $.41-.60=$ moderate, $.61-.80=$ substantial, and $.81-1=$ almost 
perfect), the test-retest reliability of the BRFSS is moderate to substantial (Sim \& Wright, 2005).

\section{Threats to Validity}

No identified external validity threats existed in this study. This study used weighting to address non-response if they were found potentially to threaten the internal validity of the study. Weighted estimates can identify unbiased estimates of specific parameters of the sample population. Weighted estimates are also appropriate for addressing high nonresponses rates, which could result in inaccurate results (Kish, 1990; Korn \& Graubard, 2011).

\section{Data Analysis Plan}

Descriptive statistics was used to summarize the characteristics of the sample population. The percentage distribution, frequency distribution, central tendencies, and distribution in histogram shape were computed (Gerstman, 2008). By providing a summary of all the information collected, the quantitative observations of the type of data provided an initial picture of what exists in the sample population.

This study used statistical correlation to answer the research questions and hypotheses. This statistical method was to analyze the association between the independent variables (gender, level of education, socio-economic status, length of stay, diet, and level of physical activity) and obesity (Burns \& Grove, 2007). A positive correlation between any two variables means they vary together. As one variable increases, so does the other. A negative correlation between two variables means they do 
not vary together. As one variable increases, the other decreases, and vice versa (Burns \& Grove, 2007; Creswell, 2013).

This study used binomial logistic regressions to examine the relationship that exists between possible predictors of obesity (gender, level of education, socio-economic status, and length of stay) and obesity outcomes. Because the outcome variable, obesity, was measured as dichotomous categorical variable (BMI $\geq 30, \mathrm{BMI}<30$ ), logistic regression was the most appropriate statistical model. A supposed causal relationship can be identified between specific independent variables and obesity outcomes by measuring the odds ratio (Bewick, Cheek, \& Ball, 2005; Field, 2009).

\section{Ethical Procedures}

This cross-sectional study used a web-based survey (modified BRFSS) as its data collection tool. An approval of the Walden University's Institutional Review Board (IRB) was obtained to protect the rights of human research participants before and after the research data collection (approval number 11-26-14-0160632) with an expiration date of November 25, 2015. Data collected and final research findings excluded any identifying information related to research participants. Research data were transmitted electronically and stored on a password protected computer.

\section{Summary}

Chapter 3 described the research methodology for investigating the prevalence of obesity and potential correlates (gender, level of education, socio-economic status, length of stay, diet, and level of physical activity) in the Nigerian immigrant population in the 
United States. Sampling plan, participant recruitment, and estimated sample size were described. The study used a reliable and valid modified BRFSS survey instrument to measure the variables of interest. Statistical analysis included the use of descriptive statistics, correlation coefficients, and multiple logistic regressions. This chapter also described the steps for ensuring ethical procedures. 


\section{Chapter 4: Results}

In this chapter, I present the results of the data analysis on demographic, dietary, and physical activity factors and their association with obesity outcomes in the population of interest. I posted an invitation flyer introducing the research, its purpose, and its significance to the health of Nigerian immigrants in the United States on Nigerian immigrants' community Facebook groups; this flyer also contained an active link to the BRFSS survey that was made available for 4 weeks, in December 2015. Data were collected from a convenience sample of 205 Nigerian immigrants living in the United States and analyzed to identify the prevalence of obesity and associated obesity predictors (gender, level of education, socioeconomic status, length of stay, diet, and level of physical activity) in the sample population. A total of 219 respondents filled the survey; $205(93.6 \%)$ respondents submitted the survey, of which only $181(88.2 \%)$ reported knowing both their height and weight measurements, six $(2.7 \%)$ respondents did not complete the survey, and eight (3.6\%) respondents were disqualified because they were not born in Nigeria. Data were exported from Survey Monkey to SPSS for data analysis. Participants were recruited from Nigerian immigrants' community Facebook groups through invitation flyers and personal invitations that directed them to an active link to the BRFSS survey; this sample population comprised Nigerians who lived in the 50 states of the United States but who come under an umbrella to socialize. The aim of this data analysis was to generate new knowledge about what obesity predictors exist in the Nigerian immigrant population and how these predictors compare to what is already 
known about other immigrant population and ethnicities. Data analysis was run using SPSS $®$ version 21.

\section{Independent variables}

The sample population included 205 Nigerian immigrants who were born in Nigeria and had lived in the United States for approximately 2 years or more.

Demographic variables measured included the following: (a) gender (male or female), (b) level of education (never attended school, elementary, some high school, high school graduate, some college or technical school, or college graduate), (c) income level ( $\$ 10,000$ to less than $\$ 15,000, \$ 15,000$ to less than $\$ 20,000, \$ 20,000$ to less than $\$ 25,000, \$ 25,000$ to less than $\$ 35,000, \$ 35,000$ to less than $\$ 50,000, \$ 50,000$ to less than $\$ 75,000$, or $\$ 75,000$ or more), and (d) length of stay (number of years in the United States).

Social and behavioristic variables measured included the following: (e) dietary patterns - consumption of alcohol and sugar-sweetened fruit drinks/soda, fruits, and vegetables (number per day, week, month, never, don't know/not sure, refused), and, (f) pattern and frequency of moderate and vigorous physical activities (exercise for at least 20 minutes - times in the last week; workplace physical activity-mostly sitting or standing, mostly walking or mostly heavy labor or physically demanding work; moderate activities_-yes or no or don't know/not sure; days per week of 10 minutes or more of moderate activities - number of days per week, or no moderate physical activity, or don't know/not sure; vigorous activities-yes or no or don't know/not sure; days per week of 
10 minutes or more of vigorous activities — number of days per week, or no moderate physical activity, or don't know/not sure; muscle strengthening activity — number of times per week, month, never, or don't know/not sure).

\section{Dependent Variables}

Using respondents' self-reported weight and height data, I calculated BMI using the WHO's recommendation of weight in kilograms divided by height in meters squared. I then recoded and recategorized BMI into three different variables: BMI Category 1 included respondents with BMI $<25$ (normal weight), BMI between 25 and 29.99 (overweight), BMI between 30 and 34.99 (obese), BMI between 35 and 39.99 (moderately obese), and BMI $\geq 40$ (morbidly obese). BMI Category 2 included respondents with $\mathrm{BMI}<30$ (not obese) and $\mathrm{BMI} \geq 30$ (obese). BMI Category 3 included respondents with $\mathrm{BMI}<40$ (not moderately/morbidly obese) and BMI $\geq 40$ (moderately/morbidly obese).

\section{Research Questions and Hypotheses}

To accurately generate this information, the following research questions and hypotheses were used to guide this study:

\section{Research Questions}

Research Question 1: What is the prevalence of obesity in Nigerian immigrants within this sample?

Research Question 2: Are gender, levels of education, length of stay, diet, and level of physical activity predictors of obesity in Nigerian immigrants within this sample? 


\section{Null Hypothesis}

$H_{0} 1$ : Gender is not a predictor of obesity in Nigerian immigrants within this sample.

$H_{0} 2$ : Level of education is not a predictor of obesity in Nigerian immigrants within this sample.

$H_{0} 3$ : Socioeconomic status is not a predictor of obesity in Nigerian immigrants within this sample.

$H_{0} 4$ : Length of stay is not a predictor of obesity in Nigerian immigrants within this sample.

$H_{0} 5$ : Diet is not a predictor of obesity in Nigerian immigrants within this sample.

$H_{0} 6$ : Level of physical activity is not a predictor of obesity in Nigerian immigrants within this sample.

\section{Altemative Hypothesis}

$H_{1} 1$ : Gender is a predictor of obesity in Nigerian immigrants within this sample.

$H_{1}$ 2: Level of education is a predictor of obesity in Nigerian immigrants within this sample.

$H_{1} 3$ : Socioeconomic status is a predictor of obesity in Nigerian immigrants within this sample. 
$H_{1} 4$ : Length of stay is a predictor of obesity in Nigerian immigrants within this sample.

$H_{1}$ 5: Diet is a predictor of obesity in Nigerian immigrants within this sample.

$H_{1} 6$ : Level of physical activity is a predictor of obesity in Nigerian immigrants within this sample.

This study examined the association between these six independent variables: (a) gender, (b) level of education, (c) socioeconomic status, (d) length of stay, (e) diet, and (f) level of physical activity, and two sets of dichotomized dependent variables, (a) not obese $(\mathrm{BMI}<30)$ vs. obese $(\mathrm{BMI} \geq 30)$, and (b) not moderate/morbid obesity $(\mathrm{BMI}<35)$ vs. moderate/morbid obesity $(\mathrm{BMI} \geq 35)$.

\section{Univariate Analysis}

\section{Descriptive Analysis of Independent Variables}

Table 2 shows the sample population comprised of disproportionate number of males $(23.9 \%)$ and females $(76.1 \%)$.

\section{Table 2}

Distribution of Gender of Study Participants

\begin{tabular}{llcccc}
\hline & Frequency & Percent & $\begin{array}{c}\text { Valid } \\
\text { Percent }\end{array}$ & Cumulative Percent \\
\hline \multirow{3}{*}{ Valid } & Male & 49 & 23.9 & 23.9 & 23.9 \\
& Female & 156 & 76.1 & 76.1 & 100.0 \\
& Total & 205 & 100.0 & 100.0 & \\
\hline
\end{tabular}

Table 3 shows that one person $(.5 \%)$ had only elementary school level education, two persons $(1 \%)$ were high school graduate level education, 11 persons $(5.4 \%)$ had some 
college or technical school level education, and $189(92.2 \%)$ were college graduates. After excluding the missing value (2), the valid percentage of those who were college graduates was $93.1 \%$.

Table 3

Distribution of Highest Level of Education of Study Participants

\begin{tabular}{|c|c|c|c|c|c|}
\hline & & Frequency & Percent & $\begin{array}{l}\text { Valid } \\
\text { Percent }\end{array}$ & $\begin{array}{l}\text { Cumulative } \\
\text { Percent }\end{array}$ \\
\hline \multirow{5}{*}{ Valid } & $\begin{array}{l}\text { Grades } 1 \text { through } 8 \\
\text { (Elementary) }\end{array}$ & 1 & .5 & .5 & .5 \\
\hline & $\begin{array}{l}\text { Grade } 12 \text { or GED (High school } \\
\text { graduate) }\end{array}$ & 2 & 1.0 & 1.0 & 1.5 \\
\hline & $\begin{array}{l}\text { College } 1 \text { year to } 3 \text { years } \\
\text { (Some college or technical } \\
\text { school) }\end{array}$ & 11 & 5.4 & 5.4 & 6.9 \\
\hline & $\begin{array}{l}\text { College } 4 \text { years or more } \\
\text { (College graduate) }\end{array}$ & 189 & 92.2 & 93.1 & 100.0 \\
\hline & Total & 203 & 99.0 & 100.0 & \\
\hline Missing & System & 2 & 1.0 & & \\
\hline Total & & 205 & 100.0 & & \\
\hline
\end{tabular}

Table 4 presents the income breakdown of participants. Eight persons (3.9\%) were in the income category $\$ 10,000$ to less than $\$ 15,000$, five persons $(3.4 \%)$ were in the income category $\$ 15,000$ to less than $\$ 20,000,14$ persons $(6.8 \%)$ were in the income category $\$ 20,000$ to less than $\$ 25,000$. In addition, seven persons $(3.4 \%)$ were in the income category $\$ 25,000$ to less than $\$ 35,000,25$ persons $(12.2 \%)$ were in the income category $\$ 35,000$ to less than $\$ 50,000,35$ persons $(17.1 \%)$ were in the income category 
$\$ 50,000$ to less than $\$ 75,000$, and, 111 persons $(54.1 \%)$ were in the income category $\$ 75,000$ or more.

\section{Table 4}

Distribution of Annual Household Income of Study Participants

\begin{tabular}{llllll}
\hline & $\begin{array}{l}\text { Frequenc } \\
\text { y }\end{array}$ & Percent & $\begin{array}{l}\text { Valid } \\
\text { Percent }\end{array}$ & $\begin{array}{l}\text { Cumulative } \\
\text { Percent }\end{array}$ \\
\hline \$20,000 to less than $\$ 25,000$ & 14 & 6.8 & 6.8 & 6.8 \\
$\$ 15,000$ to less than $\$ 20,000$ & 5 & 2.4 & 2.4 & 9.3 \\
Valid $\$ 10,000$ to less than $\$ 15,000$ & 8 & 3.9 & 3.9 & 13.2 \\
$\$ 25,000$ to less than $\$ 35,000$ & 7 & 3.4 & 3.4 & 16.6 \\
$\$ 35,000$ to less than $\$ 50,000$ & 25 & 12.2 & 12.2 & 28.8 \\
$\$ 50,000$ to less than $\$ 75,000$ & 35 & 17.1 & 17.1 & 45.9 \\
$\$ 75,000$ or more & 111 & 54.1 & 54.1 & 100.0 \\
Total & 205 & 100.0 & 100.0 & \\
\hline
\end{tabular}

Table 5 shows that participants reported having lived in the United States between 2 to 43 years $($ Mean=12, Median $=11, \mathrm{SD}=7.563)$.

Table 5

Distribution of Years in the United States of Study Participants

\begin{tabular}{lc}
\hline \multicolumn{1}{c}{ Valid } & \\
& 176 \\
Mean & 12.00 \\
Median & 11.00 \\
Mode & 10 \\
Std. Deviation & 7.563 \\
Variance & 57.200 \\
Range & 42 \\
Minimum & 2 \\
Maximum & 43 \\
\hline
\end{tabular}


Table 6 shows that 111 participants reported consuming alcohol per week, ranging from 0-21 drinks (Mean=3.91, Median =3, SD=3.85). Sixty-nine participants reported consuming alcohol per month, ranging from 0-105 drinks (Mean=3.85, Median $=12, \mathrm{SD}=18.81$ ). Seventy-two participants reported consuming soda per day, ranging from 0-12 drinks (Mean=.7083, Median =0, SD=1.81). Eighty-nine participants reported consuming soda per week, ranging from 0-35 drinks (Mean=2.31, Median =1, $\mathrm{SD}=1.81$ ). Ninety-two participants reported consuming soda per month, ranging from 0-140 drinks (Mean=6.80, Median =2, SD=1.81). Fifty-four participants reported consuming green vegetables per week, ranging from 0-20 servings (Mean=1.74, Median $=1, \mathrm{SD}=3.38$ ). One hundred-fourteen participants reported consuming green vegetables per week, ranging from 0-21 servings (Mean=3.91, Median =3, SD=3.38). Sixty-nine participants reported consuming green vegetables per month, ranging from 0-105 servings (Mean=3.91, Median =12, SD=15.67). Eighty-one participants reported consuming green vegetables per month, ranging from 0-25 servings (Mean=1.62, Median =1, $\mathrm{SD}=2.80$ ). Ninety participants reported consuming green vegetables per month, ranging from 0-20 servings, $($ Mean=3.80, Median $=3, \mathrm{SD}=3.31$ ). Fifty-seven participants reported consuming green vegetables per month, ranging from 0-100 servings (Mean=15.04, Median $=10, \mathrm{SD}=17.16$ ). 


\section{Table 6}

Distribution of Selected Measures of Diet of Study Participants

\begin{tabular}{lcccccc}
\hline Variable & $\mathrm{n}$ & Median & Mean & SD & Low & High \\
\hline Alcohol-Days in past week & 111 & 3.00 & 3.91 & 3.85 & 0.00 & 21.00 \\
Alcohol-Days in past month & 69 & 12.00 & 3.85 & 18.81 & 0.00 & 105.00 \\
Soda-Times per day & 72 & 0.00 & .7083 & 1.81 & 0.00 & 12.00 \\
Soda-Times per week & 89 & 1.00 & 2.31 & 1.81 & 0.00 & 35.00 \\
Soda-Times per month & 92 & 2.00 & 6.80 & 1.81 & 0.00 & 140.00 \\
Green Vegetables per day & 54 & 1.00 & 1.74 & 3.38 & 0.00 & 20.00 \\
Green Vegetables per week & 114 & 3.00 & 3.91 & 3.38 & 0.00 & 21.00 \\
Green Vegetables per month & 69 & 12.00 & 3.91 & 15.67 & 0.00 & 105.00 \\
\hline
\end{tabular}

Table 7 shows that of 176 participants, 134 participants (65.4\%), reported that they participating in moderate activity for 10 minutes each week. Thirty-eight participants $(18.5 \%)$ reported that they did not participation in moderate activity for 10 minutes. Four participants $(2 \%)$ reported that they were unsure of their participation in moderate activity. After excluding the missing value (29), the valid percentage of those who reported participating in moderate activity for 10 minutes each week was $76.1 \%$. The percent of those who reported that they did not participate in moderate activity for 10 minutes each week was $21.6 \%$. The percent of those who reported that they were unsure of their participation in moderate activity was $2.3 \%$. Table 7 also shows that of 175 participants, 83 participants (40.5\%) reported participating in vigorous activity for 10 minutes each week. Eighty-two participants (40\%) reported no participation in vigorous activity for 10 minutes. Ten participants $(4.9 \%)$ reported that they were unsure of their participation in vigorous activity. After excluding the missing value (30), the valid percentage of those who reported participating in vigorous activity for 10 minutes each 
week was $47.4 \%$. Those who reported not participating in vigorous activity for 10 minutes each week was $46.9 \%$. The percent of those participants who stated that they were unsure of their participation in vigorous activity was $5.7 \%$. Table 8 further showed that 147 participants reported participating in 20 minute exercises per week, ranging from 0-15 times $($ Mean=1.88, Median $=1, \mathrm{SD}=2.04911)$.

Table 7

Physical Activity Reported by Participants

\begin{tabular}{|c|c|c|c|c|c|}
\hline & & & Frequency & Percent & Valid Percent \\
\hline & \multicolumn{2}{|l|}{ Yes } & 134 & 65.4 & 76.1 \\
\hline Mod. & \multicolumn{2}{|l|}{ No } & 38 & 18.5 & 21.6 \\
\hline \multirow[t]{2}{*}{ Act. } & \multicolumn{2}{|c|}{ Don't know / Not sure } & 4 & 2.0 & 2.3 \\
\hline & \multicolumn{2}{|l|}{ Total } & 176 & 85.9 & 100.0 \\
\hline \multirow{3}{*}{$\begin{array}{l}\text { Missing } \\
\text { Total }\end{array}$} & \multicolumn{2}{|l|}{ System } & 29 & 14.1 & \\
\hline & & & 205 & 100.0 & \\
\hline & & & Frequency & Percent & Valid Percent \\
\hline \multirow{4}{*}{$\begin{array}{l}\text { Vig. } \\
\text { Act. }\end{array}$} & \multicolumn{2}{|l|}{ Yes } & 83 & 40.5 & 47.4 \\
\hline & \multicolumn{2}{|l|}{ No } & 82 & 40.0 & 46.9 \\
\hline & \multicolumn{2}{|c|}{ Don't know / Not sure } & 10 & 4.9 & 5.7 \\
\hline & \multicolumn{2}{|l|}{ Total } & 175 & 85.4 & 100.0 \\
\hline Missing & \multicolumn{2}{|l|}{ System } & 30 & 14.6 & \\
\hline \multicolumn{3}{|l|}{ Total } & 205 & 100.0 & \\
\hline \multicolumn{6}{|c|}{20 Min Exercise Category/Week } \\
\hline \multicolumn{3}{|c|}{ Valid } & & & \\
\hline \multicolumn{2}{|l|}{ Mean } & 1.8844 & & & \\
\hline \multicolumn{2}{|l|}{ Median } & 1.0000 & & & \\
\hline Std. D & Deviation & 2.04911 & & & \\
\hline \multicolumn{2}{|l|}{ Minimum } & .00 & & & \\
\hline \multicolumn{2}{|l|}{ Maximum } & 15.00 & & & \\
\hline
\end{tabular}


Descriptive Analysis of Dependent Variable

Table 8 shows that calculated BMI from self-reported weight and height measurements ranged from 17.48 to 65.75, $($ Mean=29.1881, Median =27.4961, $\mathrm{SD}=7.25511$ ). BMI was missing in 24 cases.

Table 8

Distribution of Calculated BMI of Study Participants

\begin{tabular}{lc}
\hline $\mathrm{N} \quad$ Valid & 181 \\
Mean & 29.1881 \\
Median & 27.4961 \\
Mode & 35.23 \\
Std. Deviation & 7.25511 \\
Variance & 52.637 \\
Range & 48.26 \\
Minimum & 17.48 \\
Maximum & 65.75 \\
\hline
\end{tabular}

Table 9 shows that 60 respondents $(29.3 \%)$ were normal weight, 52 respondents (25.4\%) were overweight, 37 respondents (18\%) were obese, 19 respondents $(9.3 \%)$ were moderately obese, and 13 respondents $(6.3 \%)$ were morbidly obese; the prevalence of obesity in this population was $33.6 \%$. After excluding the missing value, $33.1 \%$ of this population was normal weight, $28.7 \%$ of this population was overweight, $20.4 \%$ of this population was obese, $10.5 \%$ of this population was moderately obese, and $7.2 \%$ of this population was morbidly obese (Table 9). 
Table 9

Distribution of General BMI Category of Study Participants

\begin{tabular}{llllll}
\hline & & Frequenc & Percent & $\begin{array}{l}\text { Valid } \\
\text { Percent }\end{array}$ & $\begin{array}{l}\text { Cumulative } \\
\text { Percent }\end{array}$ \\
\hline \multirow{4}{*}{ Valid } & (25 normal weight & 60 & 29.3 & 33.1 & 33.1 \\
& 25-29.99 overweight & 52 & 25.4 & 28.7 & 61.9 \\
& 30-34.99 obese & 37 & 18.0 & 20.4 & 82.3 \\
& 35-39.99 moderate obesity & 19 & 9.3 & 10.5 & 92.8 \\
\multirow{2}{*}{$\begin{array}{l}\text { Missin } \\
\text { g }\end{array}$} & Total morbid obesity & 13 & 6.3 & 7.2 & 100.0 \\
Total & System & 181 & 88.3 & 100.0 & \\
\hline
\end{tabular}

Table 10 shows that when categorized as obese or not obese, 112 respondents $(54.6 \%)$ were not obese while 69 respondents $(33.7 \%)$ were obese; 24 cases $(11.7 \%)$ are missing. After excluding the missing value, $61.9 \%$ of this population is not obese while $38.1 \%$ of this population is obese. This finding answers Research Question 1 which seeks to identify the prevalence of obesity in Nigerian immigrants within the sample population.

Table 10

Distribution of Obese/Not Obese BMI Category of Study Participants

\begin{tabular}{llcccc}
\hline & & Frequency & Percent & $\begin{array}{l}\text { Valid } \\
\text { Percent }\end{array}$ & $\begin{array}{l}\text { Cumulative } \\
\text { Percent }\end{array}$ \\
\hline \multirow{3}{*}{ Valid } & $<30$ not obese & 112 & 54.6 & 61.9 & 61.9 \\
& $\geq 30$ obese & 69 & 33.7 & 38.1 & 100.0 \\
& Total & 181 & 88.3 & 100.0 & \\
Missing & System & 24 & 11.7 & & \\
Total & & 205 & 100.0 & & \\
\hline
\end{tabular}


Table 11 shows that when categorized as moderate/morbid obese or not moderate/morbid obese, 149 respondents $(72.7 \%)$ were not moderately/morbidly obese while 32 respondents (15.6\%) were moderately/morbidly obese. After excluding the missing value, $82.3 \%$ of this population was not moderately/morbidly obese while $17.7 \%$ of this population is moderately/morbidly obese.

Table 11

Distribution of Moderate and Morbid Obesity BMI Category of Study Participants

\begin{tabular}{llcccc}
\hline & & Frequency & Percent & $\begin{array}{l}\text { Valid } \\
\text { Percent }\end{array}$ & $\begin{array}{c}\text { Cumulative } \\
\text { Percent }\end{array}$ \\
\hline \multirow{3}{*}{ Valid } & $<35$ not moderate/morbid obese & 149 & 72.7 & 82.3 & 82.3 \\
& $\begin{array}{l}\text { >35 moderate/morbid obese } \\
\text { Total }\end{array}$ & 32 & 15.6 & 17.7 & 100.0 \\
& & 181 & 88.3 & 100.0 & \\
Missing & System & 24 & 11.7 & & \\
\multirow{2}{*}{ Total } & & 205 & 100.0 & & \\
\hline
\end{tabular}

\section{Bivariate Analysis}

\section{BMI by Gender}

Of the 134 female participants, 48 participants (35.8\%) were normal weight, 32 participants $(23.9 \%)$ were overweight, 25 participants (18.7\%) were obese, 18 participants $(13.4 \%)$ were moderately obese, and 11 participants $(8.2 \%)$ were morbidly obese (see Table 13). Of the 47 male participants, 12 participants $(25.5 \%)$ were normal 
weight, 20 participants $(42.6 \%)$ were overweight, 12 participants $(25.5 \%)$ were obese, one participant $(2.1 \%)$ was moderately obese, and two participants $(4.3 \%)$ were morbidly obese. Female participants were significantly more likely to be obese than were the males $(\mathrm{p}<0.05)$

Table 12

Cross-Tabulation and Chi-Square Analysis of Association between Gender and BMI

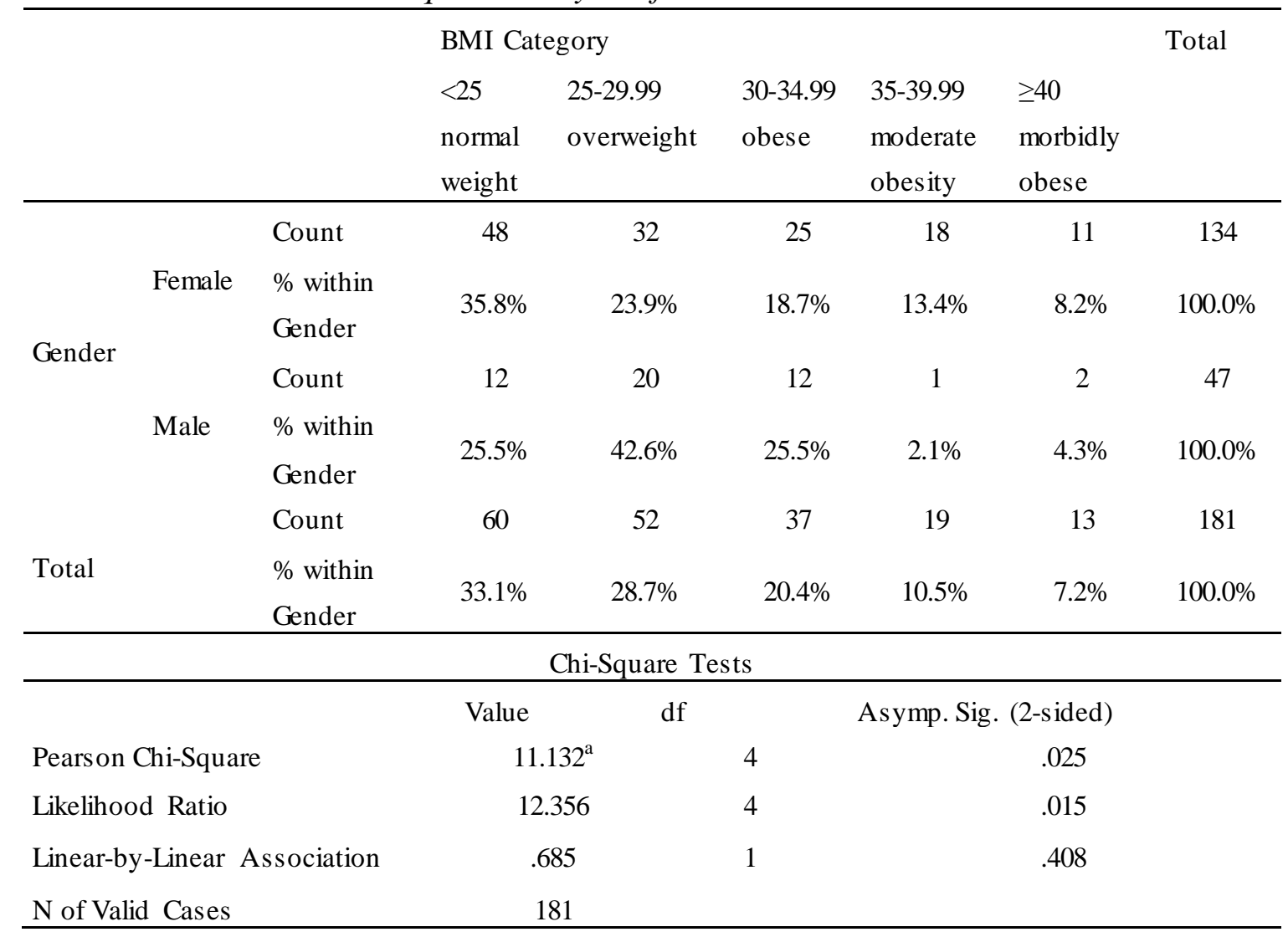

\section{BMI by Level of Education}

Table 13 shows that among participants with elementary school level education (1), $100 \%$ was normal weight, $0 \%$ was overweight, $0 \%$ was obese, $0 \%$ was moderately obese, and 0\% was morbidly obese. Among participants with high school graduate level 
education (2), $50 \%$ was normal weight, $0 \%$ was overweight, $0 \%$ was obese, $50 \%$ was moderately obese, and $0 \%$ was morbidly obese. Among participants with some college or technical school level education (9), $0 \%$ was normal weight, 33.3\% was overweight, $22.2 \%$ was obese, $11.1 \%$ was moderately obese, and $33.3 \%$ was morbidly obese. Among participants who were college graduates (167), 34.1\% was normal weight, $28.0 \%$ was overweight, $21.0 \%$ was obese, $10.2 \%$ was moderately obese, and $6.0 \%$ was morbidly obese. There is no significant association between BMI/obesity and level of education.

Table 13

Cross-Tabulation and Chi-Square Analysis of Association between Level of Education and BMI/Obesity

\begin{tabular}{|c|c|c|c|c|c|c|c|c|}
\hline & & & \multicolumn{5}{|c|}{ BMI Category } & \multirow{2}{*}{ Total } \\
\hline & & & $\begin{array}{l}<25 \text { normal } \\
\text { weight }\end{array}$ & $\begin{array}{l}25-29.99 \\
\text { over } \\
\text { weight }\end{array}$ & $\begin{array}{l}30-34.99 \\
\text { obese }\end{array}$ & $\begin{array}{l}35-39.99 \\
\text { moderate } \\
\text { obesity }\end{array}$ & $\begin{array}{l}\geq 40 \\
\text { morbidly } \\
\text { obese }\end{array}$ & \\
\hline \multirow{16}{*}{$\begin{array}{l}\text { What is the } \\
\text { highest grade or } \\
\text { year of school you } \\
\text { completed? }\end{array}$} & \multirow{5}{*}{$\begin{array}{l}\text { Grades } 1 \text { through } 8 \\
\text { (Elementary) }\end{array}$} & Count & 1 & 0 & 0 & 0 & 0 & 1 \\
\hline & & Expected Count & .3 & .3 & .2 & .1 & .1 & 1.0 \\
\hline & & $\%$ within highest grade & $100.0 \%$ & $0.0 \%$ & $0.0 \%$ & $0.0 \%$ & $0.0 \%$ & $100.0 \%$ \\
\hline & & $\%$ within BMI Cat egory & $1.7 \%$ & $0.0 \%$ & $0.0 \%$ & $0.0 \%$ & $0.0 \%$ & $0.6 \%$ \\
\hline & & Count & 1 & 0 & 0 & 1 & 0 & 2 \\
\hline & \multirow{3}{*}{$\begin{array}{l}\text { Grade } 12 \text { or GED } \\
\text { (High school graduate) }\end{array}$} & Expected Count & .7 & .6 & .4 & .2 & .1 & 2.0 \\
\hline & & $\%$ within highest grade & $50.0 \%$ & $0.0 \%$ & $0.0 \%$ & $50.0 \%$ & $0.0 \%$ & $100.0 \%$ \\
\hline & & $\%$ within BMI Category & $1.7 \%$ & $0.0 \%$ & $0.0 \%$ & $5.3 \%$ & $0.0 \%$ & $1.1 \%$ \\
\hline & \multirow{4}{*}{$\begin{array}{l}\text { College } 1 \text { year to } 3 \\
\text { years (Some college or } \\
\text { technical school) }\end{array}$} & Count & 0 & 3 & 2 & 1 & 3 & 9 \\
\hline & & Expected Count & 3.0 & 2.6 & 1.9 & 1.0 & .7 & 9.0 \\
\hline & & $\%$ within highest grade & $0.0 \%$ & $33.3 \%$ & $22.2 \%$ & $11.1 \%$ & $33.3 \%$ & $100.0 \%$ \\
\hline & & $\%$ within BMI Category & $0.0 \%$ & $5.9 \%$ & $5.4 \%$ & $5.3 \%$ & $23.1 \%$ & $5.0 \%$ \\
\hline & \multirow{4}{*}{$\begin{array}{l}\text { College } 4 \text { years or } \\
\text { more (College } \\
\text { graduate) }\end{array}$} & Count & 57 & 48 & 35 & 17 & 10 & 167 \\
\hline & & Expected Count & 55.0 & 47.6 & 34.5 & 17.7 & 12.1 & 167.0 \\
\hline & & $\%$ within highest grade & $34.1 \%$ & $28.7 \%$ & $21.0 \%$ & $10.2 \%$ & $6.0 \%$ & $100.0 \%$ \\
\hline & & $\%$ within BMI Category & $96.6 \%$ & $94.1 \%$ & $94.6 \%$ & $89.5 \%$ & $76.9 \%$ & $93.3 \%$ \\
\hline \multirow{4}{*}{ Total } & & Count & 59 & 51 & 37 & 19 & 13 & 179 \\
\hline & & Expected Count & 59.0 & 51.0 & 37.0 & 19.0 & 13.0 & 179.0 \\
\hline & & $\%$ within highest grade & $33.0 \%$ & $28.5 \%$ & $20.7 \%$ & $10.6 \%$ & $7.3 \%$ & $100.0 \%$ \\
\hline & & $\%$ within BMI Category & $100.0 \%$ & $100.0 \%$ & $100.0 \%$ & $100.0 \%$ & $100.0 \%$ & $100.0 \%$ \\
\hline
\end{tabular}

Table continues 


\begin{tabular}{llll}
\hline & Value & df & $\begin{array}{c}\text { Asymp. Sig. (2- } \\
\text { sided) }\end{array}$ \\
\hline Pearson Chi-Square & $18.220^{\mathrm{a}}$ & 12 & .109 \\
Likelihood Ratio & 17.125 & 12 & .145 \\
Linear-by-Linear & .695 & 1 & .404 \\
Association & 179 & & \\
N of Valid Cases & &
\end{tabular}

\section{BMI by Income Status}

Table 14 shows that among participants in the income category $\$ 10,000$ to less than $\$ 15,000$ (5), 20\% was normal weight, $40 \%$ was overweight, $20 \%$ was obese, $20 \%$ was moderately obese, and $0 \%$ was morbidly obese. Among participants in the income category $\$ 15,000$ to less than $\$ 20,000$ (4), 50\% was normal weight, $0 \%$ was overweight, $0 \%$ was obese, $50 \%$ was moderately obese and $0 \%$ was morbidly obese. Among participants in the income category $\$ 20,000$ to less than $\$ 25,000(10), 50 \%$ was normal weight, $10 \%$ was overweight, $20 \%$ was obese, $10 \%$ was moderately obese and $10 \%$ was

morbidly obese. Among participants in the income category $\$ 25,000$ to less than $\$ 35,000$ (6), $66.7 \%$ was normal weight, $0 \%$ was overweight, $0 \%$ was obese, $16.7 \%$ was moderately obese, and $16.7 \%$ was morbidly obese. Among participants in the income category $\$ 35,000$ to less than $\$ 50,000$ (19), $47.4 \%$ was normal weight, $10.5 \%$ was overweight, $21.1 \%$ was obese, $10.5 \%$ was moderately obese and $10.5 \%$ was morbidly obese. Among participants in the income category $\$ 50,000$ to less than $\$ 75,000$ (33), $21.2 \%$ was normal weight, $33.3 \%$ was overweight, $30.3 \%$ was obese, $9.1 \%$ was moderately obese and $6.1 \%$ was morbidly obese. Among participants in the income 
category $\$ 75,000$ or more (104), 30.8\% was normal weight, $34.6 \%$ was overweight, $19.2 \%$ was obese, $8.7 \%$ was moderately obese and $6.7 \%$ was morbidly obese. There is no significant association between BMI/Obesity and income status.

Table 14

Cross-Tabulation and Chi-Square Analysis of Association between Income Status and BMI/Obesity

Is your annual household income from all sources?

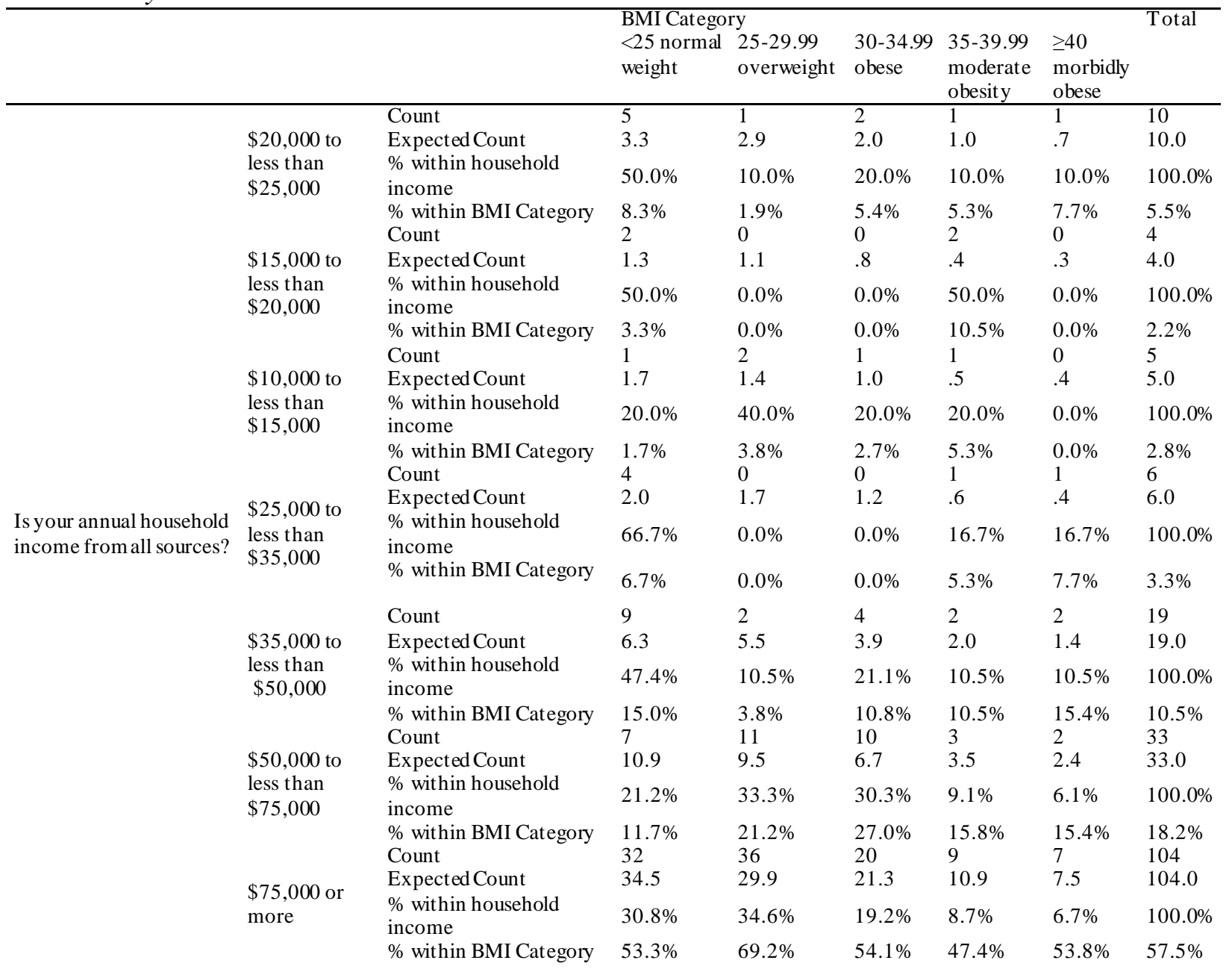

Table continues 


\begin{tabular}{|c|c|c|c|c|c|c|c|}
\hline \multirow{4}{*}{ Total } & \multirow{3}{*}{$\begin{array}{l}\text { Count } \\
\text { Expected Count } \\
\% \text { within household } \\
\text { income }\end{array}$} & 60 & 52 & 37 & 19 & 13 & 181 \\
\hline & & 60.0 & 52.0 & 37.0 & 19.0 & 13.0 & 181.0 \\
\hline & & $33.1 \%$ & $28.7 \%$ & $20.4 \%$ & $10.5 \%$ & $7.2 \%$ & $100.0 \%$ \\
\hline & $\%$ within BMI Category & $100.0 \%$ & $100.0 \%$ & $100.0 \%$ & $100.0 \%$ & $100.0 \%$ & $100.0 \%$ \\
\hline
\end{tabular}

\begin{tabular}{llll} 
Chi-Square Tests & & & \\
\hline & Value & df & $\begin{array}{l}\text { Asymp. Sig. (2- } \\
\text { sided) }\end{array}$ \\
\hline Pearson Chi-Square & $26.833^{\mathrm{a}}$ & 24 & .312 \\
Likelihood Ratio & 29.479 & 24 & .203 \\
Linear-by-Linear & .003 & 1 & .954 \\
Association & & & \\
N of Valid Cases & 181 & & \\
\hline
\end{tabular}

\section{BMI by Length of Stay}

Table 15 shows that among participants who have lived in the United States for less than 10 years (63), 30.2\% was normal weight, $30.2 \%$ was overweight, $22.2 \%$ was obese, $11.1 \%$ was moderately obese, and $6.3 \%$ was morbidly obese. Among participants who have lived in the United States between 10-20 years (85), 36.5\% was normal weight, $30.6 \%$ was overweight, $14.1 \%$ was obese, $11.8 \%$ was moderately obese, and $7.1 \%$ was morbidly obese. Among participants who have lived in the United States between 21-30 years (12), $33.3 \%$ was normal weight, $25 \%$ was overweight, $41.7 \%$ was obese, $0 \%$ was moderately obese, and $0 \%$ was morbidly obese. Among participants who have lived in the United States between 31-50 years (4), 0\% was normal weight, 25\% was overweight, $25 \%$ was obese, $25 \%$ was moderately obese, and $25 \%$ was morbidly obese. There is no significant association between BMI/obesity and length of stay. 
Table 15

Cross-Tabulation and Chi-Square Analysis of Association between Length of Stay Category and BMI/Obesity

\begin{tabular}{|c|c|c|c|c|c|c|c|c|}
\hline & & & \multicolumn{5}{|c|}{ BMI Cat egory } & \multirow[t]{2}{*}{ Total } \\
\hline & & & $\begin{array}{l}<25 \text { normal } \\
\text { weight }\end{array}$ & $\begin{array}{l}25-29.99 \\
\text { overweight }\end{array}$ & $\begin{array}{l}30-34.99 \\
\text { obese }\end{array}$ & $\begin{array}{l}35-39.99 \\
\text { moderate } \\
\text { obesity }\end{array}$ & $\begin{array}{l}\geq 40 \\
\text { morbidly } \\
\text { obese }\end{array}$ & \\
\hline \multirow{16}{*}{$\begin{array}{l}\text { Length of Stay } \\
\text { Category }\end{array}$} & \multirow{4}{*}{$<10$} & Count & 19 & 19 & 14 & 7 & 4 & 63 \\
\hline & & Expected Count & 20.7 & 18.8 & 12.3 & 6.9 & 4.2 & 63.0 \\
\hline & & $\begin{array}{l}\% \text { within Length of Stay } \\
\text { Category }\end{array}$ & $30.2 \%$ & $30.2 \%$ & $22.2 \%$ & $11.1 \%$ & $6.3 \%$ & $100.0 \%$ \\
\hline & & $\%$ within BMI Category & $35.2 \%$ & $38.8 \%$ & $43.8 \%$ & $38.9 \%$ & $36.4 \%$ & $38.4 \%$ \\
\hline & \multirow{3}{*}{$\begin{array}{l}10- \\
20\end{array}$} & Count & 31 & 26 & 12 & 10 & 6 & 85 \\
\hline & & Expected Count & 28.0 & 25.4 & 16.6 & 9.3 & 5.7 & 85.0 \\
\hline & & $\begin{array}{l}\% \text { within Length of Stay } \\
\text { Category }\end{array}$ & $36.5 \%$ & $30.6 \%$ & $14.1 \%$ & $11.8 \%$ & $7.1 \%$ & $100.0 \%$ \\
\hline & \multirow{5}{*}{$\begin{array}{l}21- \\
30\end{array}$} & $\%$ within BMI Category & $57.4 \%$ & $53.1 \%$ & $37.5 \%$ & $55.6 \%$ & $54.5 \%$ & $51.8 \%$ \\
\hline & & Count & 4 & 3 & 5 & 0 & 0 & 12 \\
\hline & & Expected Count & 4.0 & 3.6 & 2.3 & 1.3 & .8 & 12.0 \\
\hline & & $\begin{array}{l}\% \text { within Length of Stay } \\
\text { Category }\end{array}$ & $33.3 \%$ & $25.0 \%$ & $41.7 \%$ & $0.0 \%$ & $0.0 \%$ & $100.0 \%$ \\
\hline & & $\%$ within BMI Category & $7.4 \%$ & $6.1 \%$ & $15.6 \%$ & $0.0 \%$ & $0.0 \%$ & $7.3 \%$ \\
\hline & \multirow{8}{*}{$\begin{array}{l}31- \\
50\end{array}$} & Count & 0 & 1 & 1 & 1 & 1 & 4 \\
\hline & & Expected Count & 1.3 & 1.2 & .8 & .4 & .3 & 4.0 \\
\hline & & $\begin{array}{l}\% \text { within Length of Stay } \\
\text { Category }\end{array}$ & $0.0 \%$ & $25.0 \%$ & $25.0 \%$ & $25.0 \%$ & $25.0 \%$ & $100.0 \%$ \\
\hline & & $\%$ within BMI Category & $0.0 \%$ & $2.0 \%$ & $3.1 \%$ & $5.6 \%$ & $9.1 \%$ & $2.4 \%$ \\
\hline \multirow{4}{*}{ Total } & & Count & 54 & 49 & 32 & 18 & 11 & 164 \\
\hline & & Expected Count & 54.0 & 49.0 & 32.0 & 18.0 & 11.0 & 164.0 \\
\hline & & $\begin{array}{l}\% \text { within Length of Stay } \\
\text { Category }\end{array}$ & $32.9 \%$ & $29.9 \%$ & $19.5 \%$ & $11.0 \%$ & $6.7 \%$ & $100.0 \%$ \\
\hline & & $\%$ within BMI Category & $100.0 \%$ & $100.0 \%$ & $100.0 \%$ & $100.0 \%$ & $100.0 \%$ & $100.0 \%$ \\
\hline
\end{tabular}

Chi-Square Tests

\begin{tabular}{llll}
\hline & Value & df & Asymp. Sig. (2-sided) \\
\hline Pearson Chi-Square & $10.340^{\mathrm{a}}$ & 12 & .586 \\
Likelihood Ratio & 10.109 & 12 & .606 \\
Linear-by-Linear Association & .027 & 1 & .869 \\
N of Valid Cases & 160 & & \\
\hline
\end{tabular}




\section{BMI by Diet (Alcohol Consumption)}

Table 16 shows that among participants who consumed zero alcoholic beverages a day (102), 35.3\% was normal weight, $32.4 \%$ was overweight, $20.6 \%$ was obese, $5.9 \%$ was moderately obese, and $5.9 \%$ was morbidly obese. Among participants who consumed one to two alcoholic beverages a day (17), $17.6 \%$ was normal weight, $29.4 \%$ was overweight, $17.6 \%$ was obese, $17.6 \%$ was moderately obese, and $17.6 \%$ was morbidly obese. Among participants who consumed three to six alcoholic beverages a day (7), $0 \%$ was normal weight, $28.6 \%$ was overweight, $28.6 \%$ was obese, $28.6 \%$ was moderately obese, and $14.3 \%$ was morbidly obese. Among participants who consumed zero alcoholic beverages a week (90), 36.7\% was normal weight, 33.3\% was overweight, $20 \%$ was obese, $3.3 \%$ was moderately obese, and $6.7 \%$ was morbidly obese. Among participants who consumed one to five alcoholic beverages a week (30), 30\% was normal weight, $30 \%$ was overweight, $13.3 \%$ was obese, $15.3 \%$ was moderately obese, and $13.3 \%$ was morbidly obese. Among participants who consumed 6 to 10 alcoholic beverages a day (11), $45.5 \%$ was normal weight, $27.3 \%$ was overweight, $9.1 \%$ was obese, $9.1 \%$ was moderately obese, and $9.1 \%$ was morbidly obese. Among participants who consumed 11 to 20 alcoholic beverages a day (8), $12.5 \%$ was normal weight, $25 \%$ was overweight, $37.5 \%$ was obese, $25 \%$ was moderately obese, and $0 \%$ was morbidly obese. Among participants who consumed more than 20 alcoholic beverages a day (4), $25 \%$ was normal weight, $50 \%$ was overweight, $25 \%$ was obese, $0 \%$ was moderately obese, and $0 \%$ was morbidly obese. 
Table 16

Cross-Tabulation and Chi-Square Analysis of Association between Diet (Alcohol Consumption) Category and BMI/Obesity

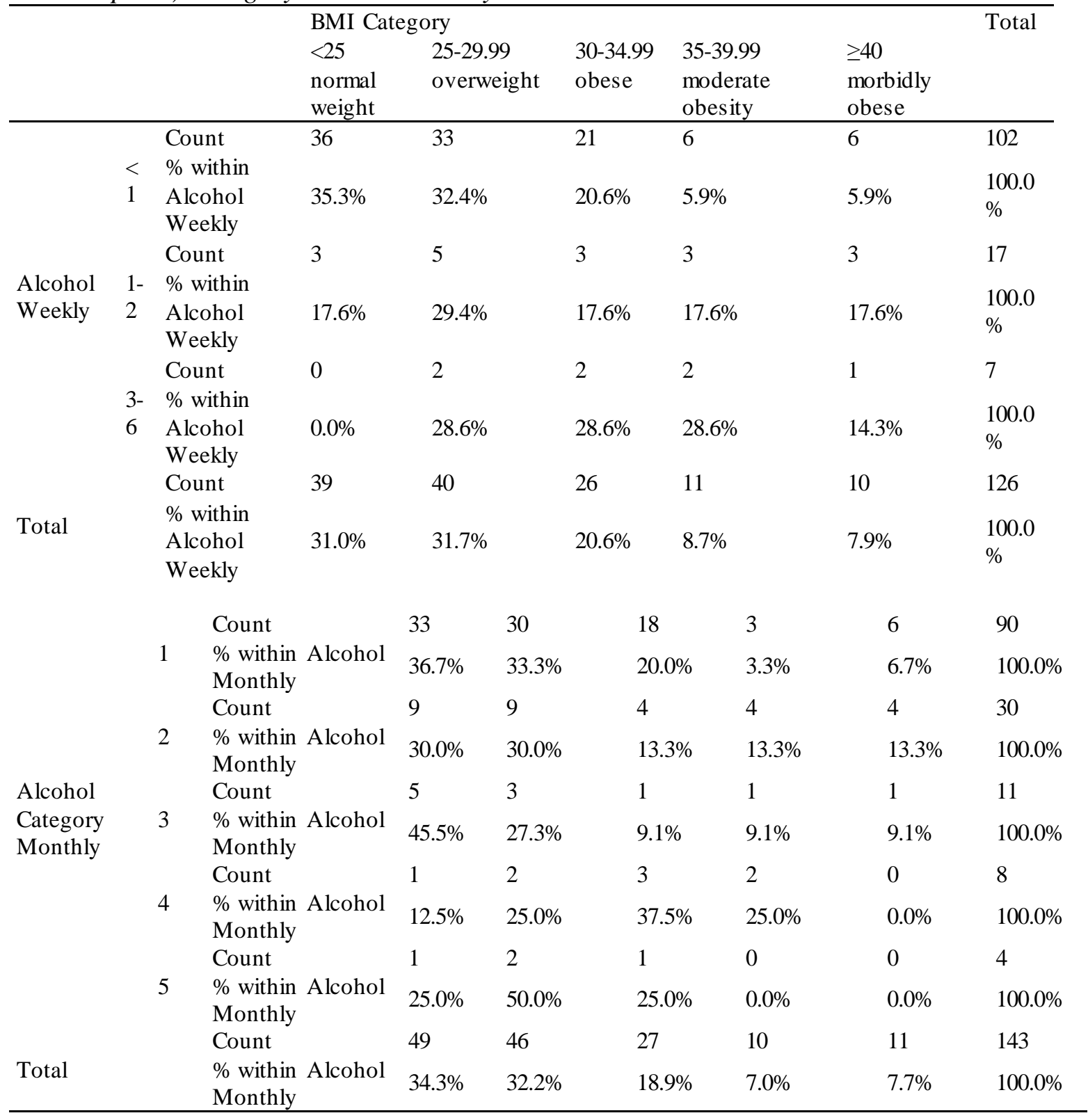

Table continues 


\begin{tabular}{|c|c|c|c|}
\hline & Value & $\mathrm{df}$ & $\begin{array}{l}\text { Asymp. Sig. } \\
\text { (2-sided) }\end{array}$ \\
\hline Pearson Chi-Square & $\begin{array}{l}16.408 \\
\text { a }\end{array}$ & 12 & .173 \\
\hline Likelihood Ratio & 15.985 & 12 & .192 \\
\hline $\begin{array}{l}\text { Linear-by-Linear } \\
\text { As sociation }\end{array}$ & 8.518 & 1 & .004 \\
\hline $\mathrm{N}$ of Valid Cases & 126 & & \\
\hline \multicolumn{4}{|c|}{ Chi-Square Tests Alcohol Monthly } \\
\hline & Value & $\mathrm{df}$ & $\begin{array}{l}\text { Asymp. Sig. } \\
\text { (2-sided) }\end{array}$ \\
\hline Pearson Chi-Square & $\begin{array}{l}15.083 \\
\text { a }\end{array}$ & 16 & .519 \\
\hline Likelihood Ratio & 14.761 & 16 & .542 \\
\hline $\begin{array}{l}\text { Linear-by-Linear } \\
\text { Association }\end{array}$ & 1.025 & 1 & .311 \\
\hline $\mathrm{N}$ of Valid Cases & 143 & & \\
\hline
\end{tabular}

\section{BMI by Diet (Soda Consumption)}

Table 17 shows that among participants who consumed zero soda beverages a day (40), $27.5 \%$ was normal weight, $40 \%$ was overweight, $15 \%$ was obese, $15 \%$ was moderately obese, and $2.5 \%$ was morbidly obese. Among participants who consumed one to two soda beverages a day (21), $23.8 \%$ was normal weight, $14.3 \%$ was overweight, $47.6 \%$ was obese, $4.3 \%$ was moderately obese, and $0 \%$ was morbidly obese. Among participants who consumed three to five soda beverages a day (3), 33.3\% was normal weight, $0 \%$ was overweight, $33.3 \%$ was obese, $33.3 \%$ was moderately obese, and $0 \%$ was morbidly obese. Among participants who consumed more than five soda beverages a 
day (1), 100\% was normal weight, $0 \%$ was overweight, $0 \%$ was obese, $0 \%$ was moderately obese, and $0 \%$ was morbidly obese. Among participants who consumed zero soda beverages a week (25), 20\% was normal weight, $48 \%$ was overweight, $20 \%$ was obese, $8 \%$ was moderately obese, and $4 \%$ was morbidly obese. Among participants who consumed one to two soda beverages a week (31), 29\% was normal weight, $29 \%$ was overweight, $19.4 \%$ was obese, $6.5 \%$ was moderately obese, and $16.1 \%$ was morbidly obese. Among participants who consumed three to five soda beverages a week (21), 19\% was normal weight, $33.3 \%$ was overweight, $28.6 \%$ was obese, $4.8 \%$ was moderately obese, and $14.3 \%$ was morbidly obese. Among participants who consumed more than five soda beverages a week (5), $60 \%$ was normal weight, $0 \%$ was overweight, $20 \%$ was obese, $20 \%$ was moderately obese, and $0 \%$ was morbidly obese.

Table 17 shows that among participants who consumed zero soda beverages a month (18), $22.2 \%$ was normal weight, $44.4 \%$ was overweight, $22.2 \%$ was obese, $5.6 \%$ was moderately obese, and 5.6\% was morbidly obese. Among participants who consumed one to two soda beverages a month (34), $44.1 \%$ was normal weight, $32.4 \%$ was overweight, $14.7 \%$ was obese, $8.8 \%$ was moderately obese, and $0 \%$ was morbidly obese. Among participants who consumed three to five soda beverages a month (18), $38.9 \%$ was normal weight, $38.9 \%$ was overweight, $22.2 \%$ was obese, $0 \%$ was moderately obese, and $0 \%$ was morbidly obese. Among participants who consumed more than five soda beverages a month (15), $20 \%$ was normal weight, $26.7 \%$ was overweight, $33.3 \%$ 
was obese, $13.3 \%$ was moderately obese, and $6.7 \%$ was morbidly obese. Statistically, there is no significant association between BMI/obesity and soda consumption.

Table 17

Cross-Tabulation and Chi-Square Analysis of Association between Diet (Soda Consumption) Category and BMI/Obesity

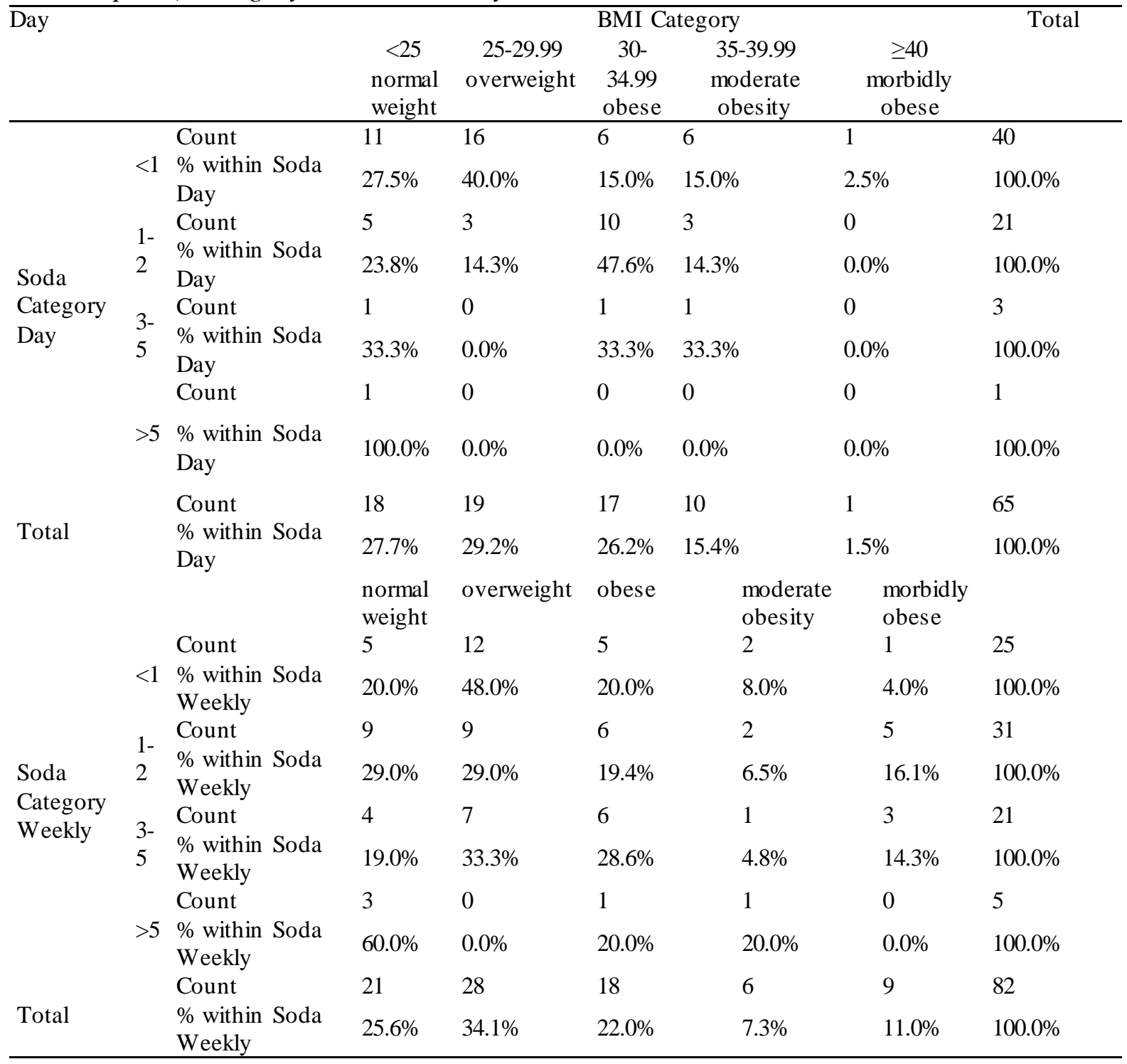




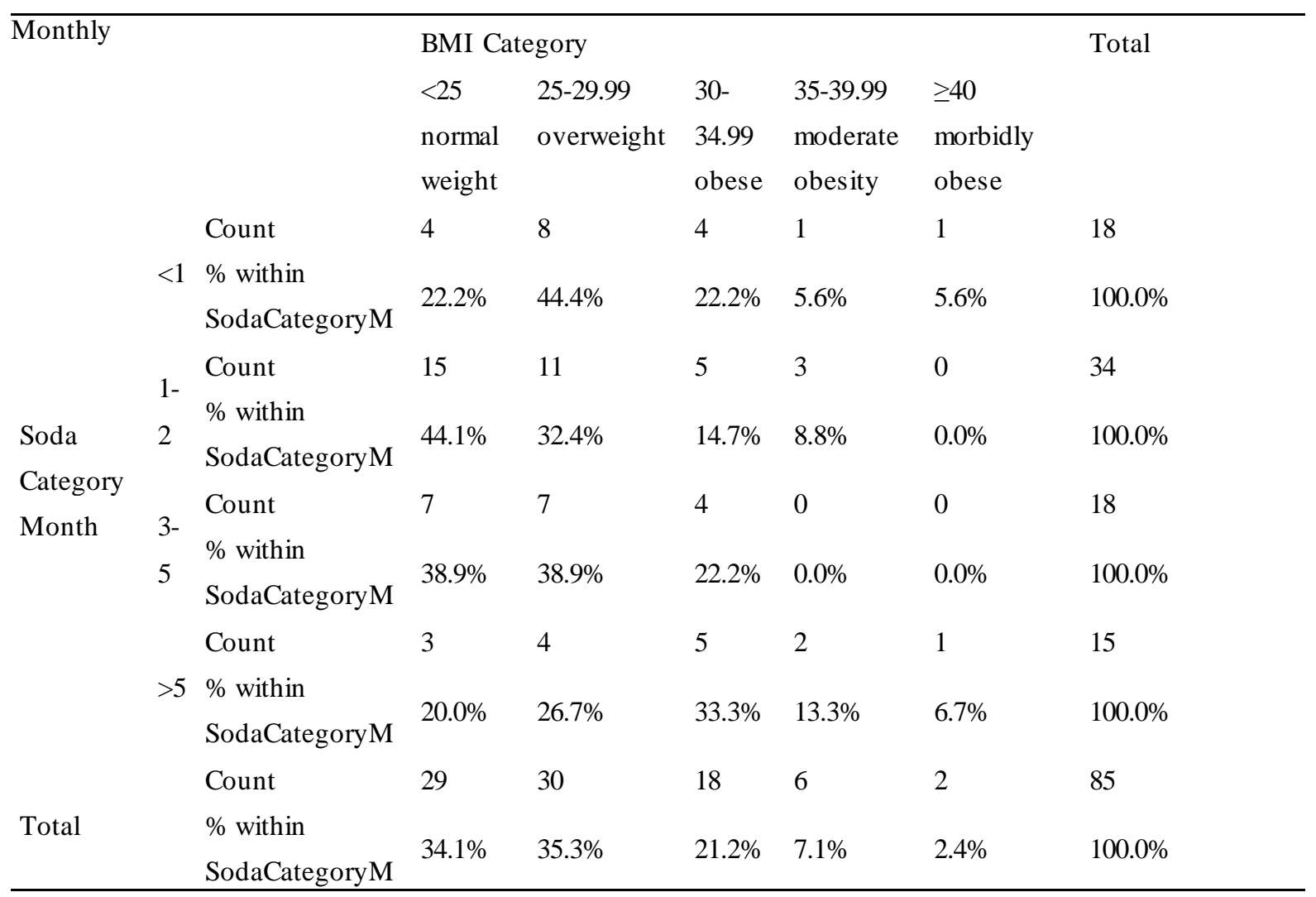

Chi-Square Tests Soda Category Day

\begin{tabular}{llcc}
\hline & \multicolumn{1}{c}{ Value } & df & $\begin{array}{c}\text { Asymp. } \\
\text { Sig. (2- } \\
\text { sided) }\end{array}$ \\
\hline $\begin{array}{l}\text { Pearson Chi- } \\
\text { Square }\end{array}$ & $13.749^{\mathrm{a}}$ & 12 & .317 \\
$\begin{array}{l}\text { Likelihood } \\
\text { Ratio }\end{array}$ & 14.584 & 12 & .265 \\
$\begin{array}{l}\text { Linear-by- } \\
\text { Linear }\end{array}$ & .101 & & \\
$\begin{array}{l}\text { Association } \\
\text { N of Valid }\end{array}$ & & 1 & .750 \\
Cases & 65 & & \\
\hline
\end{tabular}

Table continues 
Chi-Square Tests Soda Category Week

\begin{tabular}{|c|c|c|c|}
\hline & Value & df & $\begin{array}{l}\text { Asymp. Sig. } \\
\text { (2-sided) } \\
\end{array}$ \\
\hline Pearson Chi-Square & $\begin{array}{l}10.983 \\
\mathrm{a}\end{array}$ & 12 & .530 \\
\hline Likelihood Ratio & 12.394 & 12 & .415 \\
\hline $\begin{array}{l}\text { Linear-by-Linear } \\
\text { Association }\end{array}$ & .109 & 1 & .741 \\
\hline $\mathrm{N}$ of Valid Cases & 82 & & \\
\hline \multicolumn{4}{|c|}{ Chi-Square Tests Soda Category Month } \\
\hline & Value & $\mathrm{df}$ & $\begin{array}{l}\text { Asymp. Sig. } \\
\text { (2-sided) }\end{array}$ \\
\hline Pearson Chi-Square & $\begin{array}{l}10.879 \\
\text { a }\end{array}$ & 12 & .539 \\
\hline Likelihood Ratio & 12.666 & 12 & .394 \\
\hline $\begin{array}{l}\text { Linear-by-Linear } \\
\text { Association }\end{array}$ & .631 & 1 & .427 \\
\hline $\mathrm{N}$ of Valid Cases & 85 & & \\
\hline
\end{tabular}

\section{BMI by Diet (Green Vegetables Consumption)}

Table 18 shows that among participants who consumed zero servings of vegetables a day (7), 57.1\% was normal weight, $14.3 \%$ was overweight, $14.3 \%$ was obese, $0 \%$ was moderately obese, and $14.3 \%$ was morbidly obese. Among participants who consumed one to two servings of vegetables a day (35), 25.7\% was normal weight, $28.6 \%$ was overweight, $28.6 \%$ was obese, $11.4 \%$ was moderately obese, and $5.7 \%$ was morbidly obese. Among participants who consumed three to five servings of vegetables a day (5), $40 \%$ was normal weight, $20 \%$ was overweight, $20 \%$ was obese, $20 \%$ was moderately obese, and $0 \%$ was morbidly obese. Among participants who consumed more than five servings of vegetables a day (1), $0 \%$ was normal weight, $0 \%$ was overweight, 
$0 \%$ was obese, $100 \%$ was moderately obese, and $0 \%$ was morbidly obese. Table 19 shows that among participants who consumed zero servings of vegetables a week (6), $66.7 \%$ was normal weight, $16.7 \%$ was overweight, $0 \%$ was obese, $0 \%$ was moderately obese, and $16.7 \%$ was morbidly obese. Among participants who consumed one to two servings of vegetables a week (32), $37.5 \%$ was normal weight, $25 \%$ was overweight, $21.9 \%$ was obese, $9.4 \%$ was moderately obese, and $6.3 \%$ was morbidly obese. Among participants who consumed three to five servings of vegetables a week (52), 21.2\% was normal weight, $40.4 \%$ was overweight, $26.9 \%$ was obese, $5.8 \%$ was moderately obese, and $5.8 \%$ was morbidly obese. Among participants who consumed more than five servings of vegetables a week (15), $46.7 \%$ was normal weight, $13.3 \%$ was overweight, $26.7 \%$ was obese, $13.3 \%$ was moderately obese, and $0 \%$ was morbidly obese.

Table 18 shows that among participants who consumed zero servings of vegetables a month (6), 50\% was normal weight, $16.7 \%$ was overweight, $0 \%$ was obese, 0\% was moderately obese, and $33.3 \%$ was morbidly obese. Among participants who consumed one to two servings of vegetables a month (6), $50 \%$ was normal weight, $33.3 \%$ was overweight, $0 \%$ was obese, $0 \%$ was moderately obese, and $16.7 \%$ was morbidly obese. Among participants who consumed three to five servings of vegetables a month (12), $41.7 \%$ was normal weight, $25 \%$ was overweight, $25 \%$ was obese, $0 \%$ was moderately obese, and $8.3 \%$ was morbidly obese. Among participants who consumed more than five servings of vegetables a month (40), 32.5\% was normal weight, $30 \%$ was overweight, $33.3 \%$ was obese, $5 \%$ was moderately obese, and $2.5 \%$ was morbidly obese. 
There is no significant association between BMI/obesity and green vegetable consumption.

Table 18

Cross-Tabulation and Chi-Square Analysis of Association between Diet (Green Vegetables Consumption) Category and BMI/Obesity

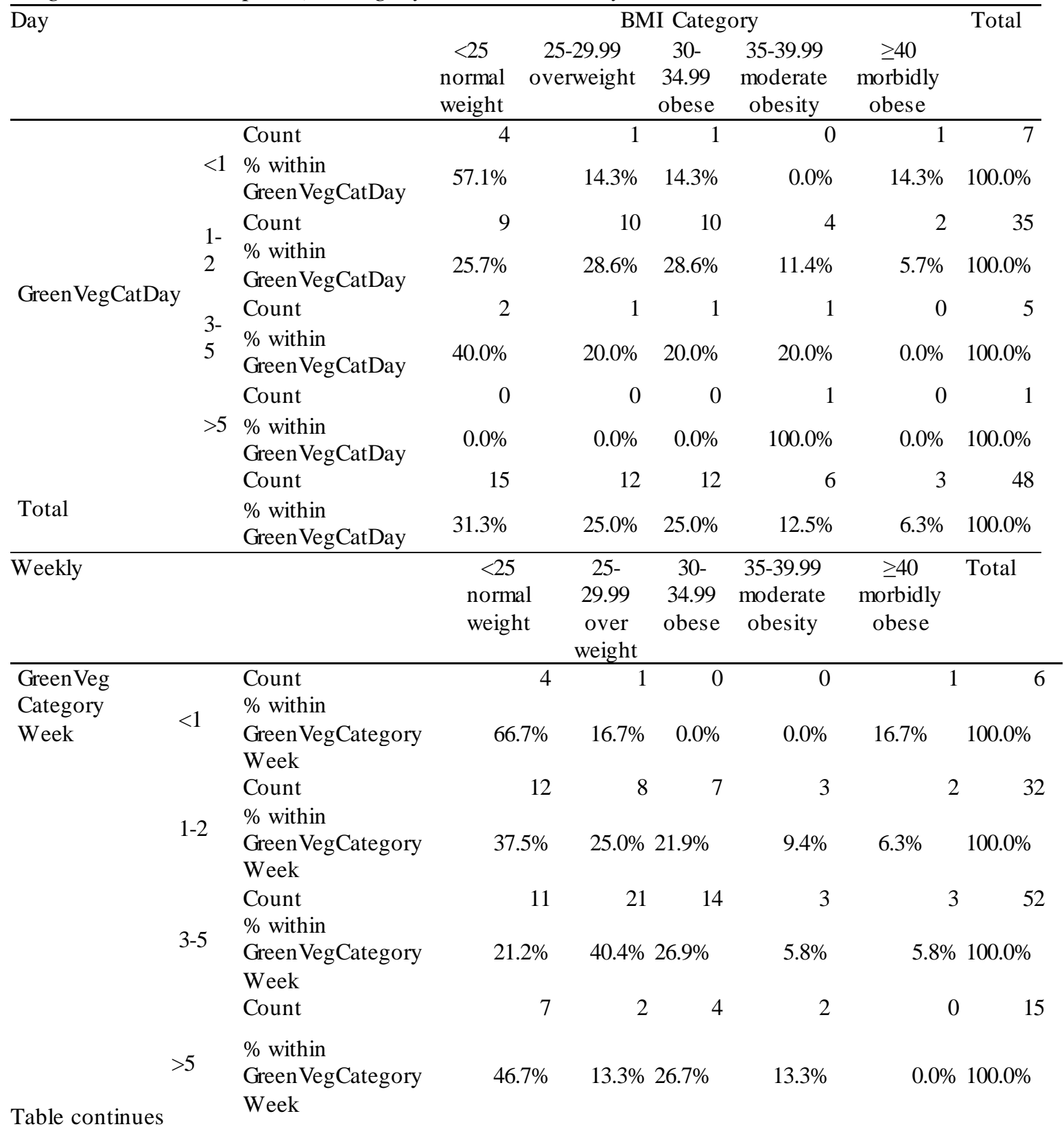




\begin{tabular}{|c|c|c|c|c|c|c|c|c|}
\hline Total & \multicolumn{2}{|c|}{$\begin{array}{l}\text { Count } \\
\% \text { within } \\
\text { Green VegCategory } \\
\text { Week }\end{array}$} & $32.4 \%$ & $30.5 \% \quad 2$ & $3.8 \%$ & $\begin{array}{c}8 \\
7.6 \%\end{array}$ & $5.7 \%$ & $\begin{array}{l}105 \\
100.0 \%\end{array}$ \\
\hline \multirow{2}{*}{ Monthly } & & & \multicolumn{5}{|c|}{ BMI Category } & Total \\
\hline & & & $\begin{array}{c}<25 \\
\text { normal } \\
\text { weight }\end{array}$ & $\begin{array}{c}\text { 25-29.99 } \\
\text { over } \\
\text { weight }\end{array}$ & $\begin{array}{c}30- \\
34.99 \\
\text { obese }\end{array}$ & $\begin{array}{c}35-39.99 \\
\text { moderate } \\
\text { obesity }\end{array}$ & $\begin{array}{c}\geq 40 \\
\text { morbidly } \\
\text { obese }\end{array}$ & \\
\hline \multirow{10}{*}{$\begin{array}{l}\text { Green VegCategory } \\
\text { Month }\end{array}$} & & $\begin{array}{l}\text { Count } \\
\% \text { within }\end{array}$ & 3 & 1 & 0 & 0 & 2 & 6 \\
\hline & $<1$ & $\begin{array}{l}\text { GreenVeg } \\
\text { Category } \\
\text { Month }\end{array}$ & $50.0 \%$ & $16.7 \%$ & $0.0 \%$ & $0.0 \%$ & $33.3 \%$ & $100.0 \%$ \\
\hline & & $\begin{array}{l}\text { Count } \\
\% \text { within }\end{array}$ & 3 & 2 & 0 & 0 & 1 & 6 \\
\hline & $1-2$ & $\begin{array}{l}\text { GreenVeg } \\
\text { Category }\end{array}$ & $50.0 \%$ & $33.3 \%$ & $0.0 \%$ & $0.0 \%$ & $16.7 \%$ & $100.0 \%$ \\
\hline & & Month & & & & & & \\
\hline & & $\begin{array}{l}\text { Count } \\
\% \text { within }\end{array}$ & 5 & 3 & 3 & 0 & 1 & 12 \\
\hline & $3-5$ & $\begin{array}{l}\text { GreenVeg } \\
\text { Category } \\
\text { Month }\end{array}$ & $41.7 \%$ & $25.0 \%$ & $25.0 \%$ & $0.0 \%$ & $8.3 \%$ & $100.0 \%$ \\
\hline & & $\begin{array}{l}\text { Count } \\
\% \text { within }\end{array}$ & 13 & 12 & 12 & 2 & 1 & 40 \\
\hline & $>5$ & $\begin{array}{l}\text { GreenVeg } \\
\text { Category } \\
\text { Month }\end{array}$ & $32.5 \%$ & $30.0 \%$ & $30.0 \%$ & $5.0 \%$ & $2.5 \%$ & $100.0 \%$ \\
\hline & & $\begin{array}{l}\text { Count } \\
\% \text { within }\end{array}$ & 24 & 18 & 15 & 2 & 5 & 64 \\
\hline Total & & $\begin{array}{l}\text { GreenVeg } \\
\text { Category } \\
\text { Month }\end{array}$ & $37.5 \%$ & $28.1 \%$ & $23.4 \%$ & $3.1 \%$ & $7.8 \%$ & $100.0 \%$ \\
\hline
\end{tabular}

Table continues 


\begin{tabular}{lccc}
\hline & Chi-Square Tests Green Vegetables Day & \\
\hline & Value & $\mathrm{df}$ & Asymp. Sig. (2-sided) \\
Pearson Chi-Square & 12.251 & 12 & .426 \\
Likelihood Ratio & 10.193 & 12 & .599 \\
Linear-by-Linear & 1.031 & 1 & .310 \\
Association & & & \\
N of Valid Cases & 48 & df & Asymp. Sig. (2-sided) \\
\hline \multicolumn{4}{l}{} \\
\hline & Chi-Square Tests Green Vegetables Weekly & .267 \\
Pearson Chi-Square & Value & 12 & .160 \\
Likelihood Ratio & 14.557 & 12 & 752 \\
Linear-by-Linear & 16.722 & 1 & \\
Association & .100 & & \\
N of Valid Cases & 105 & & \\
\hline
\end{tabular}

Table continues

Chi-Square Tests Green Vegetables Monthly

\begin{tabular}{lccc}
\hline & Value & $\mathrm{df}$ & Asymp. Sig. (2-sided) \\
Pearson Chi-Square & 13.065 & 12 & .364 \\
Likelihood Ratio & 14.621 & 12 & .263 \\
Linear-by-Linear & .132 & 1 & .717 \\
Association & 64 & & \\
N of Valid Cases & 64 & & \\
\hline
\end{tabular}

\section{BMI by Physical Activity}

Table 19 shows that among participants who exercised for at least 20 minutes less than once a week (45), 31.1\% was normal weight, $24.4 \%$ was overweight, $22.2 \%$ was obese, $8.9 \%$ was moderately obese, and $13.3 \%$ was morbidly obese. Among participants who exercised for at least 20 minutes one to two a week (51), 25.5\% was normal weight, $31.4 \%$ was overweight, $23.5 \%$ was obese, $11.8 \%$ was moderately obese, and $7.8 \%$ was morbidly obese. Among participants who exercised for at least 20 minutes three to five times a week (35), 37.1\% was normal weight, $34.3 \%$ was overweight, $17.1 \%$ was obese, $.6 \%$ was moderately obese, and $2.9 \%$ was morbidly obese. Among participants who 
exercised for at least 20 minutes more than five times a week (4), 50\% was normal weight, $25 \%$ was overweight, $25 \%$ was obese, $100 \%$ was moderately obese, and $0 \%$ was morbidly obese. Table 19 shows that among participants who performed moderate activities for at least 10 minutes at a time in a week (118), 33.9\% was normal weight, $27.1 \%$ was overweight, $22 \%$ was obese, $9.3 \%$ was moderately obese, and $9 \%$ was morbidly obese. Among participants who did not perform moderate activities for at least 10 minutes at a time in a week (36), 22.2\% was normal weight, $33.3 \%$ was overweight, $22.2 \%$ was obese, $13.9 \%$ was moderately obese, and $8.3 \%$ was morbidly obese. Among participants who were unsure of their moderate activity level (3), 66.7\% was normal weight, $33.3 \%$ was overweight, $0 \%$ was obese, $0 \%$ was moderately obese, and $0 \%$ was morbidly obese. Table 19 shows that among participants who performed vigorous activities for at least 10 minutes at a time in a week (76), 32.9\% was normal weight, $30.3 \%$ was overweight, $19.7 \%$ was obese, $7.9 \%$ was moderately obese, and $9.2 \%$ was morbidly obese. Among participants who did not perform vigorous activities for at least 10 minutes at a time in a week (74), 29.7\% was normal weight, $27 \%$ was overweight, $24.3 \%$ was obese, $12.2 \%$ was moderately obese, and $6.8 \%$ was morbidly obese. Among participants who were unsure of their vigorous activity level (6), 50\% was normal weight, $16.7 \%$ was overweight, $16.7 \%$ was obese, $16.7 \%$ was moderately obese, and $0 \%$ was morbidly obese. Overall, statistically, there was no significant association between BMI/obesity and physical activity. 
Table 19

Cross-Tabulation and Chi-Square Analysis of Association between Physical Activity Category and BMI/Obesity

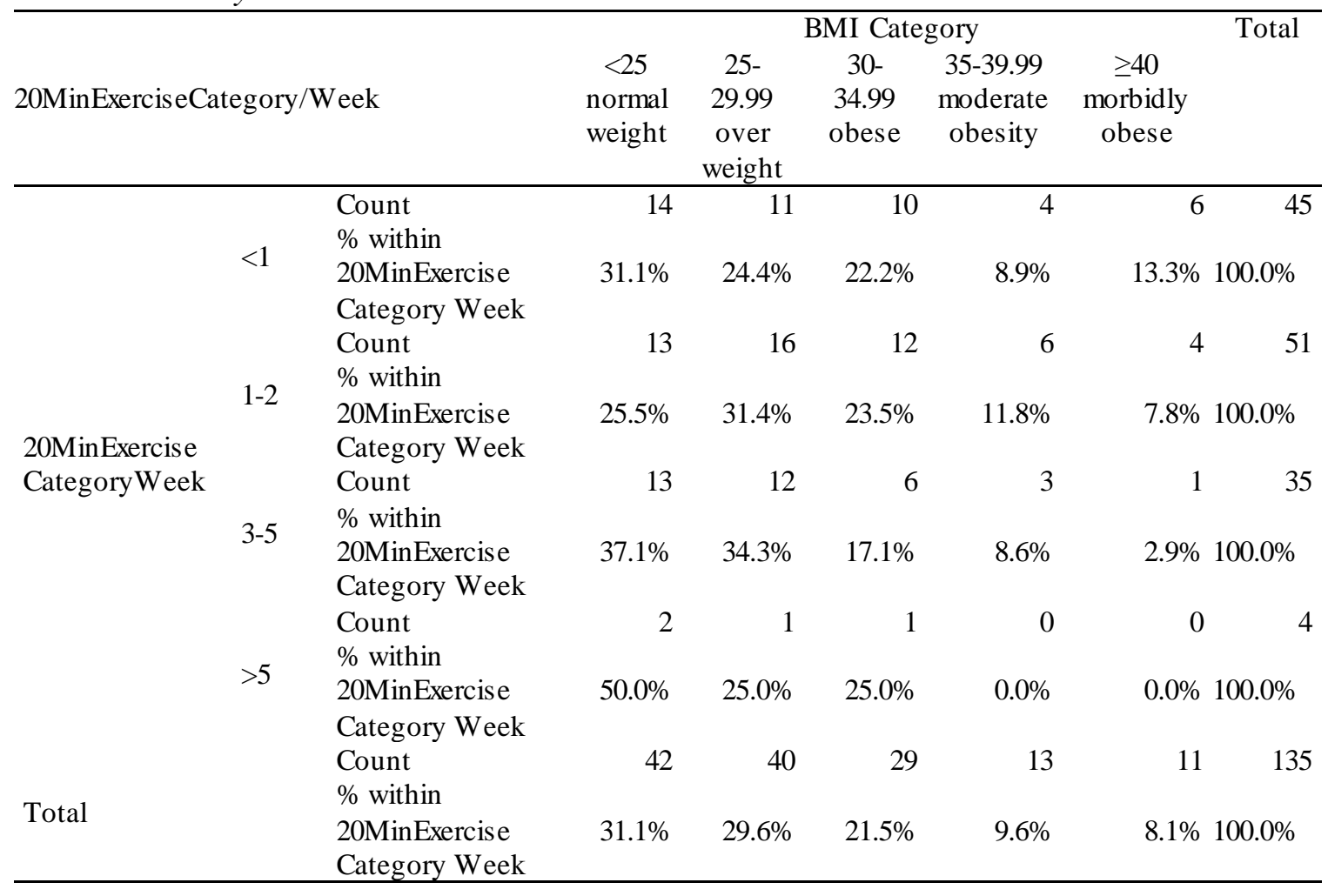

Moderate Activity X 10 Minutes/Week

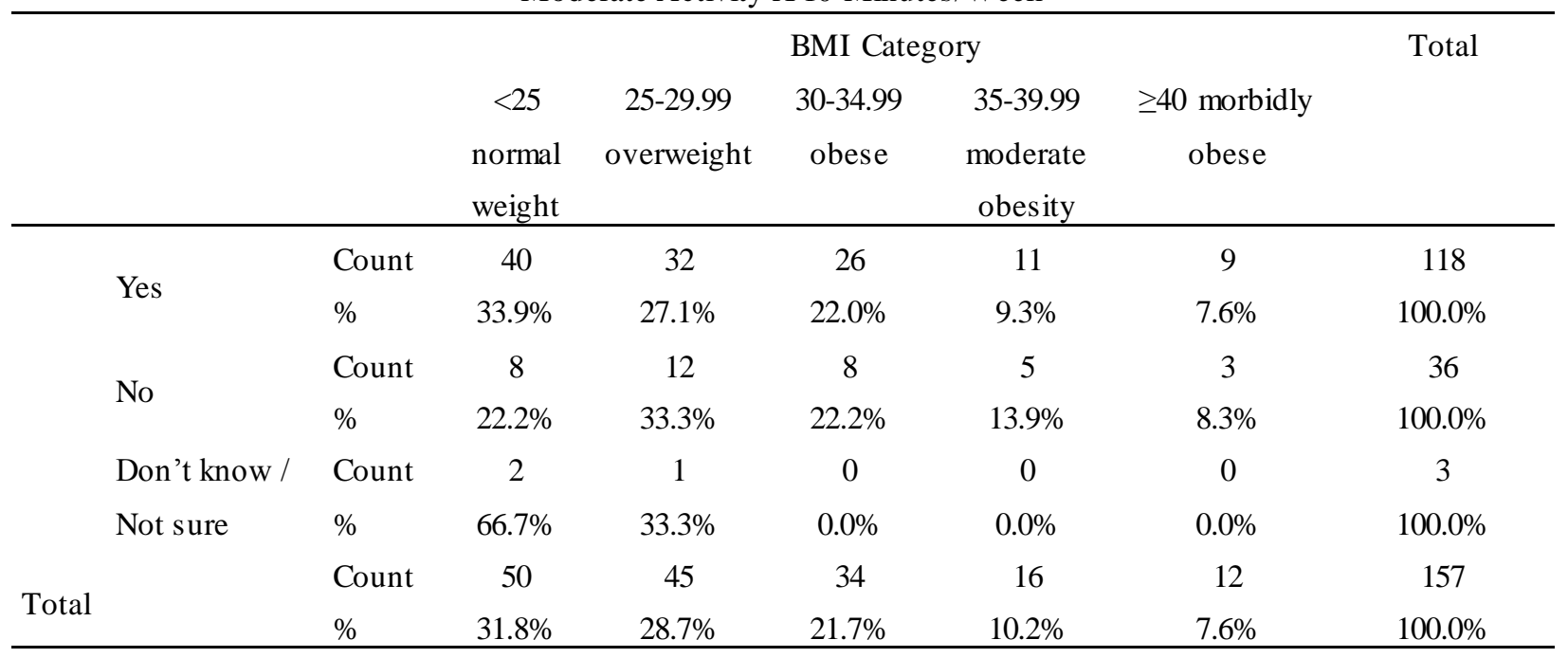

Table continues 
Vigorous Activity X 10 Minutes/Week

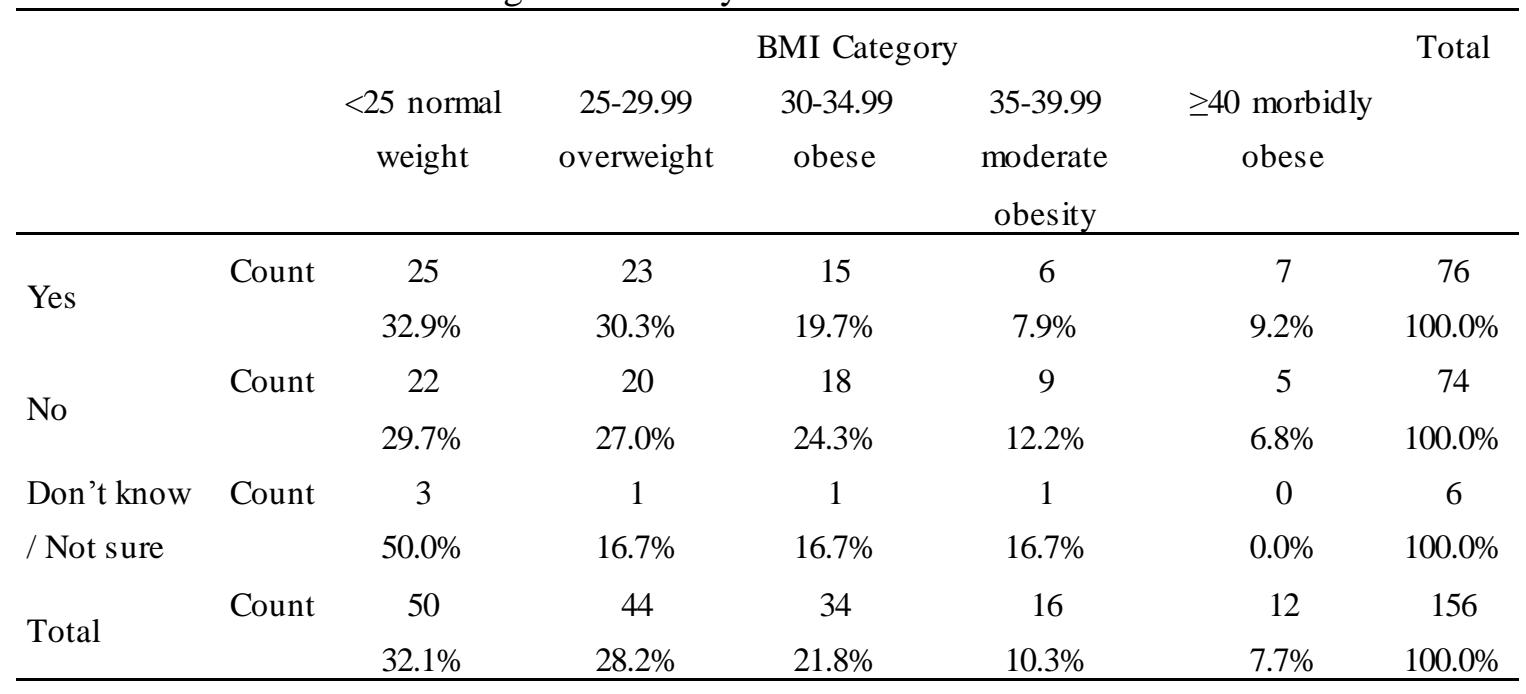

Chi-Square Tests-20Min ExerciseCategoryWeek

\begin{tabular}{|c|c|c|c|}
\hline & Value & $\mathrm{df}$ & Asymp. Sig. (2-sided) \\
\hline Pearson Chi-Square & $6.284^{\mathrm{a}}$ & 12 & .901 \\
\hline Likelihood Ratio & 7.117 & 12 & .850 \\
\hline $\begin{array}{l}\text { Linear-by-Linear } \\
\text { Association }\end{array}$ & 3.076 & 1 & .079 \\
\hline $\mathrm{N}$ of Valid Cases & 135 & & \\
\hline \multicolumn{4}{|c|}{ Chi-Square Tests - Moderate Activity X 10 Minutes/Week } \\
\hline & Value & $\mathrm{df}$ & Asymp. Sig. (2-sided) \\
\hline Pearson Chi-Square & $4.531^{\mathrm{a}}$ & 8 & .806 \\
\hline Likelihood Ratio & 5.500 & 8 & .703 \\
\hline $\begin{array}{l}\text { Linear-by-Linear } \\
\text { Association }\end{array}$ & .021 & 1 & .885 \\
\hline $\mathrm{N}$ of Valid Cases & 157 & & \\
\hline \multicolumn{4}{|c|}{ Chi-Square Tests - Vigorous Activity X 10 Minutes/Week } \\
\hline & Value & df & Asymp. Sig. (2-sided) \\
\hline Pearson Chi-Square & $3.305^{\mathrm{a}}$ & 8 & .914 \\
\hline Likelihood Ratio & 3.703 & 8 & .883 \\
\hline $\begin{array}{l}\text { Linear-by-Linear } \\
\text { Association }\end{array}$ & .001 & 1 & .970 \\
\hline $\mathrm{N}$ of Valid Cases & 156 & & \\
\hline
\end{tabular}




\section{Bivariate Analysis - Logistic Regression}

When gender is considered alone, the logistic regression model showed no statistical significant association between the predictor variable, gender, and obesity, OR $.694(95 \% \mathrm{CI}=.344,1.404), p=.310$. However, the logistic regression model showed statistical significant association between gender and moderate/morbid obesity, OR .247 $(95 \% \mathrm{CI}=.071, .853), p=.027$. This suggests that being male has decreased odds (OR .247) of predicting moderate/morbid obesity than being female in this sample population of Nigerian immigrants (see Table 21). With Spearman correlations, gender showed a weak positive correlation with moderate/morbid obesity, $r_{s}(181)=.175, p=.018$, its $\mathrm{R}^{2}$ indicates that this association is not strong as this variable only accounts for $3 \%$ of the variance thereby providing limiting support for the purpose of prediction. These findings, combined, provide support to reject Null Hypothesis 1 under Research Question 2, which predicted that gender was not a predictor of obesity in this sample of Nigerian immigrants. 
Table 20

Logistic Regression Analysis-Gender

\begin{tabular}{|c|c|c|c|c|c|c|c|c|c|}
\hline \multicolumn{10}{|c|}{ Logistic Regression Analysis-Obesity*Gender Variables in the Equation } \\
\hline & & \multirow[t]{2}{*}{ B } & \multirow[t]{2}{*}{ S.E. } & \multirow[t]{2}{*}{ Wald } & \multirow[t]{2}{*}{ df } & \multirow[t]{2}{*}{ Sig. } & \multirow[t]{2}{*}{$\operatorname{Exp}(B)$} & \multicolumn{2}{|c|}{ 95\% C.I.for $\operatorname{EXP}(B)$} \\
\hline & & & & & & & & Lower & Upper \\
\hline Step & Gender(1) & .365 & .359 & 1.031 & 1 & .310 & .694 & .344 & 1.404 \\
\hline $1^{\mathrm{a}}$ & Constant & -.393 & .176 & 4.980 & 1 & .026 & \multicolumn{2}{|l|}{.675} & \\
\hline \multicolumn{10}{|c|}{ Logistic Regression Analysis-Obesity*Gender Variables in the Equation } \\
\hline & & \multirow[t]{2}{*}{ B } & \multirow[t]{2}{*}{ S.E. } & \multirow[t]{2}{*}{ Wald } & \multirow[t]{2}{*}{ df } & \multirow[t]{2}{*}{ Sig. } & \multirow[t]{2}{*}{$\operatorname{Exp}(B)$} & \multicolumn{2}{|c|}{ 95\% C.I.for $\operatorname{EXP}(B)$} \\
\hline & & & & & & & & Lower & Upper \\
\hline Step & Gender(1) & 1.399 & .633 & 4.892 & 1 & .027 & .247 & .071 & .853 \\
\hline $1^{\mathrm{a}}$ & Constant & 1.287 & .210 & 37.620 & 1 & .000 & .276 & & \\
\hline
\end{tabular}

When level of education is considered alone, the logistic regression model showed that no statistical significant association between level of education and obesity, OR $.828(95 \% \mathrm{CI}=.409,1.677), p=.600$, or between level of education and moderate and morbid obesity, OR $.617(95 \% \mathrm{CI}=.292,1.301), p=.204$ (Table 21). No association was found between level of education and obesity using Spearman correlations, $r_{s}(179)=-$ $.106, p=.156$; level of education, however, showed a weak negative correlation with moderate/morbid obesity, $r_{s}(179)=-.165, p=.027$, its $\mathrm{R}^{2}$ indicates that this association is not strong as this variable only accounts for $2.7 \%$ of the variance thereby providing limited support for the purpose of prediction (Table 29). This combination of findings provided limited support to reject Null Hypothesis 2 under Research Question 2 of this study which predicted that level of education was not a predictor of obesity in the Nigerian immigrant population. 
Table 21

Logistic Regression Analysis-Level of Education

\begin{tabular}{|c|c|c|c|c|c|c|c|c|c|}
\hline \multicolumn{10}{|c|}{ Logistic Regression Analysis-Obesity*Educ Variables in the Equation } \\
\hline & & \multirow[t]{2}{*}{$\mathrm{B}$} & \multirow[t]{2}{*}{ S.E. } & \multirow[t]{2}{*}{ Wald } & \multirow[t]{2}{*}{ df } & \multirow[t]{2}{*}{ Sig. } & \multirow[t]{2}{*}{$\operatorname{Exp}(B)$} & \multicolumn{2}{|c|}{ 95\% C.I.for $\operatorname{EXP}(B)$} \\
\hline & & & & & & & & Lower & Upper \\
\hline \multirow{5}{*}{$\begin{array}{l}\text { Step } \\
1^{\mathrm{a}} \\
\end{array}$} & Educ & -.189 & .360 & .275 & 1 & .600 & .828 & .409 & 1.677 \\
\hline & Constant & .648 & 2.131 & .092 & 1 & .761 & 1.911 & & \\
\hline & \multicolumn{9}{|c|}{ Logistic Regression Analysis - Moderate/Morbid Obesity Variables in the Equation } \\
\hline & & \multirow[t]{2}{*}{ B } & \multirow[t]{2}{*}{ S.E. } & \multirow[t]{2}{*}{ Wald } & \multirow[t]{2}{*}{$\mathrm{df}$} & \multirow[t]{2}{*}{ Sig. } & \multirow[t]{2}{*}{$\operatorname{Exp}(B)$} & \multicolumn{2}{|c|}{ 95\% C.I.for $\operatorname{EXP}(B)$} \\
\hline & & & & & & & & Lower & Upper \\
\hline Step & Educ & -.483 & .381 & 1.612 & 1 & .204 & .617 & .292 & 1.301 \\
\hline $1^{\mathrm{a}}$ & Constant & 1.318 & 2.241 & .346 & 1 & .556 & 3.3737 & & \\
\hline
\end{tabular}

When socio-economic status (annual household income) is considered alone, the logistic regression model showed that no statistical significant association between socioeconomic status (annual household income) and obesity OR .944 (95\% CI= .791, 1.127), $p=.525$, or between socio-economic status and moderate and morbid obesity (OR .870 (95\% CI .708, 1.068), $p=.182$ (Table 22). No association was found between socioeconomic status and obesity using Spearman correlations, $r_{s}(181)=-.072, p=.336$ (Table 29). This result supports Null Hypothesis 3 under Research Question 2 of this study which predicted that socio-economic status was not a predictor of obesity in the Nigerian immigrant population. 
Table 22

Logistic Regression Analysis-Socioeconomic Status

\begin{tabular}{|c|c|c|c|c|c|c|c|c|c|}
\hline \multicolumn{10}{|c|}{ Logistic Regression Analysis - Obesity*SES Variables in the Equation } \\
\hline \multirow[b]{3}{*}{ Step } & \multirow[b]{3}{*}{ Income } & \multirow[t]{2}{*}{ B } & \multirow[t]{2}{*}{ S.E. } & \multirow[t]{2}{*}{ Wald } & \multirow[t]{2}{*}{ df } & \multirow[t]{2}{*}{ Sig. } & \multirow[t]{2}{*}{$\operatorname{Exp}(B)$} & \multicolumn{2}{|c|}{ 95\% C.I.for $\operatorname{EXP}(B)$} \\
\hline & & & & & & & & Lower & Upper \\
\hline & & -.057 & .090 & .403 & 1 & .525 & .944 & .791 & 1.127 \\
\hline $1^{\mathrm{a}}$ & Constant & -.144 & .556 & .067 & 1 & .796 & .866 & & \\
\hline \multicolumn{10}{|c|}{ Logistic Regression Analysis - Moderate/Morbid Obesity Variables in the Equation } \\
\hline & & \multirow[t]{2}{*}{$\mathrm{B}$} & \multirow[t]{2}{*}{ S.E. } & \multirow[t]{2}{*}{ Wald } & \multirow[t]{2}{*}{ df } & \multirow[t]{2}{*}{ Sig. } & \multirow[t]{2}{*}{$\operatorname{Exp}(B)$} & \multicolumn{2}{|c|}{ 95\% C.I.for $\mathrm{EXP}(\mathrm{B})$} \\
\hline & & & & & & & & Lowe & Upper \\
\hline Step & Income & -.140 & .105 & 1.780 & 1 & .182 & .870 & .708 & 1.068 \\
\hline $1^{\mathrm{a}}$ & Constant & -.724 & .628 & 1.329 & 1 & .249 & .485 & & \\
\hline
\end{tabular}

When length of stay in the United States is considered alone, the logistic regression model showed that no statistical significant association between length of stay in the United States and obesity OR $1.024(95 \% \mathrm{CI}=.983,1.067), p=.257$, or between length of stay and moderate and morbid obesity $\mathrm{OR} 1.016(95 \% \mathrm{CI}=.966,1.069), p=$ .539 (Table 23). No association was found between socio-economic status and obesity using Spearman correlations, $r_{s}(164)=.043, p=.587$ (Table 29). This result supports Null Hypothesis 4 under Research Question 2 of this study which predicted that length of stay in the United States was not a predictor of obesity in the Nigerian immigrant population. 
Table 23

Logistic Regression Analysis - Length of Stay in the United States

\begin{tabular}{|c|c|c|c|c|c|c|c|c|c|}
\hline \multicolumn{10}{|c|}{ Logistic Regression Analysis - Obesity*Stay Variables in the Equation } \\
\hline \multirow{3}{*}{ Step } & \multirow[b]{3}{*}{ Stay } & \multirow[t]{2}{*}{ B } & \multirow[t]{2}{*}{ S.E. } & \multirow[t]{2}{*}{ Wald } & \multirow[t]{2}{*}{ df } & \multirow[t]{2}{*}{ Sig. } & \multirow[t]{2}{*}{$\operatorname{Exp}(B)$} & \multicolumn{2}{|c|}{ 95\% C.I.for EXP(B) } \\
\hline & & & & & & & & Lower & Upper \\
\hline & & .024 & .021 & 1.284 & 1 & .257 & 1.024 & .983 & 1.067 \\
\hline \multirow[t]{4}{*}{$1^{\mathrm{a}}$} & Constant & -.822 & .311 & 6.965 & 1 & 008 & .440 & & \\
\hline & \multicolumn{9}{|c|}{ Logistic Regression Analysis - Moderate/Morbid Obesity Variables in the Equation } \\
\hline & & \multirow[t]{2}{*}{ B } & \multirow[t]{2}{*}{ S.E. } & \multirow[t]{2}{*}{ Wald } & \multirow[t]{2}{*}{$\mathrm{df}$} & \multirow[t]{2}{*}{ Sig. } & \multirow[t]{2}{*}{$\operatorname{Exp}(B)$} & \multicolumn{2}{|c|}{ 95\% C.I.for $\operatorname{EXP}(\mathrm{B})$} \\
\hline & & & & & & & & Lower & Upper \\
\hline Step & Stay & .016 & .026 & .377 & 1 & .539 & 1.016 & .966 & 1.069 \\
\hline $1^{\mathrm{a}}$ & Constant & -1.739 & .392 & 19.643 & 1 & .000 & .176 & & \\
\hline
\end{tabular}

When weekly consumption of alcohol is considered alone, the logistic regression model showed that no statistical significant association between weekly consumption of alcohol and obesity OR $1.410(95 \% \mathrm{CI}=.995,1.997), p=.053$. However, the logistic regression model showed statistical significant association between weekly consumption of alcohol and moderate and morbid obesity OR $1.453(95 \% \mathrm{CI}=1.031,2.046), p=.033$ (Table 24). A weak positive correlation was also found between weekly consumption of alcohol and moderate and morbid obesity using Spearman correlations, $r_{s}(127)=.303, p$ $=.001$ (Table 29). These findings, combined, provide support to reject Null Hypothesis 5 under Research Question 2 which predicted that diet (weekly consumption of alcohol) was not a predictor of obesity in this sample of Nigerian immigrants. 
Table 24

Logistic Regression Analysis-Weekly Consumption of Alcohol

Logistic Regression Analysis - Obesity*AlcW Variables in the Equation

$\mathrm{B}$

S.E. Wald df Sig. $\quad \operatorname{Exp}(B)$

95\% C.I.for $\operatorname{EXP}(B)$

Lower Upper

\begin{tabular}{llllllllll} 
Step & $\begin{array}{l}\text { Alcohol } \\
1^{\mathrm{a}}\end{array}$ & .344 & .178 & 4.567 & 1 & .053 & 1.410 & .995 & 1.997 \\
& Constant & -.674 & .202 & 44.834 & 1 & .001 & .510 & & \\
\hline
\end{tabular}

Logistic Regression Analysis - Moderate/Morbid Obesity Variables in the Equation

\begin{tabular}{llcccccccc}
\hline & & B & S.E. & Wald & df & Sig. & Exp(B) & \multicolumn{2}{c}{$95 \%$ C.I.for EXP(B) } \\
& & & & & & & & Lower & Upper \\
\multirow{2}{*}{$\begin{array}{l}\text { Step } \\
1^{\mathrm{a}}\end{array}$} & $\begin{array}{l}\text { Alcohol } \\
\text { Weekly }\end{array}$ & .373 & .175 & 4.567 & 1 & .033 & 1.453 & 1.031 & 2.046 \\
\hline
\end{tabular}

When monthly consumption of alcohol is considered alone, the logistic regression model showed that no statistical significant association between weekly consumption of alcohol and obesity OR $1.029(95 \%=$ CI .956, 1.107), $p=.451$. The logistic regression model also showed no statistical significant association between monthly consumption of alcohol and moderate and morbid obesity OR 1.010 (95\% CI= .945, 1.080), $p=.760$ (Table 25). No association was found between monthly consumption of alcohol and obesity using Spearman correlations, $r_{S}(144)=.114, p=.172$, however, monthly consumption of alcohol was significantly associated with morbid obesity, $r_{s}(144)=.179$, $p=.032$ (Table 29). These findings, combined, provide limited support to reject Null Hypothesis 5 under Research Question 2 which predicted that diet (weekly consumption of alcohol) was not a predictor of obesity in this sample of Nigerian immigrants. 
Table 25

Logistic Regression Analysis-Monthly Consumption of Alcohol

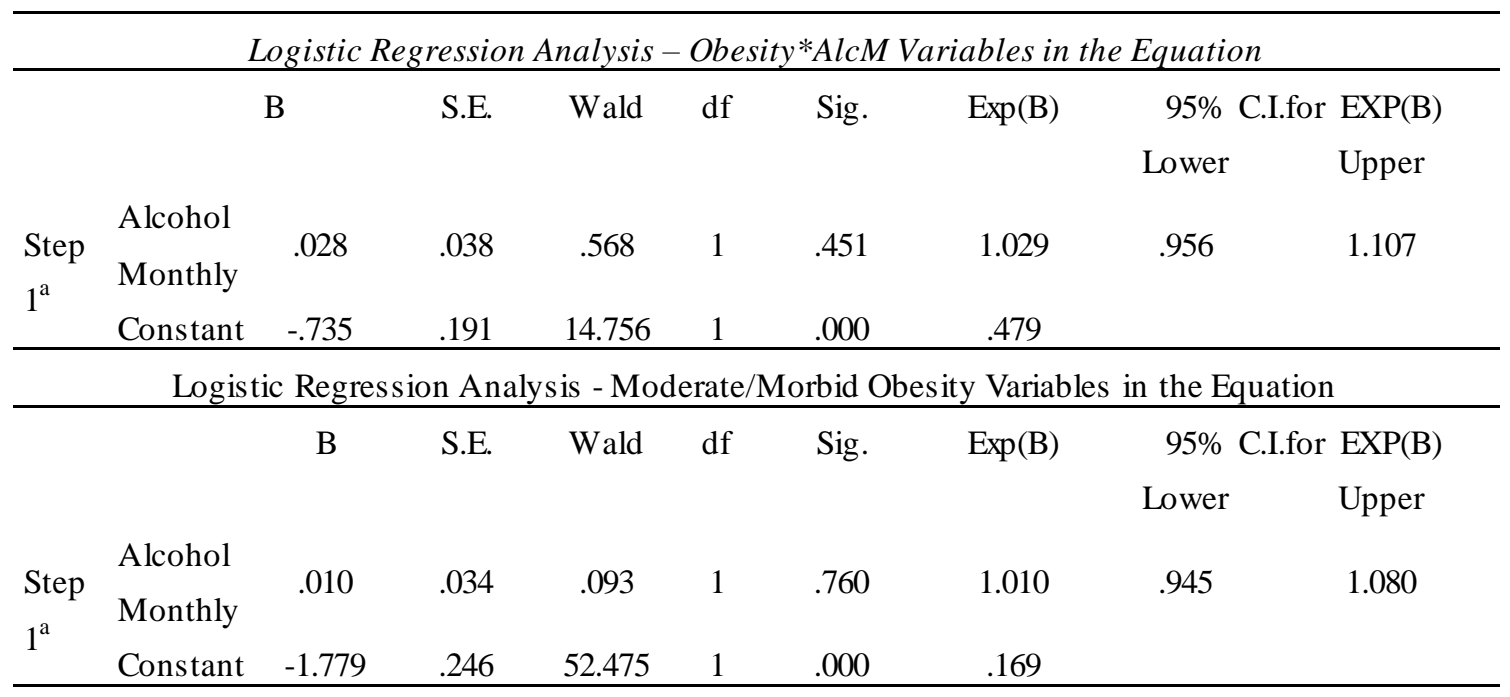

When exercise for at least 20 minutes once a week was considered alone, the logistic regression model showed that no statistical significant association between exercise for at least 20 minutes once a week and obesity, OR .856 (95\% CI =.700, 1.047), $p=.131$. The logistic regression model also showed no statistical significant association between exercise for at least 20 minutes once a week and moderate and morbid obesity, OR $.806(95 \% \mathrm{CI}=.602,1.079), p=.147$ (Table 26). No association was found between exercise for at least 20 minutes once a week and obesity using Spearman correlations, $r_{s}$ (135) =.-121, $p=.164$ (Table 29). These findings, combined, provide support to reject Null Hypothesis 5 under Research Question 2 which predicted that diet (monthly consumption of alcohol) was not a predictor of obesity in this sample of Nigerian immigrants. 
Table 26

Logistic Regression Analysis-Exercise for 20 Minutes

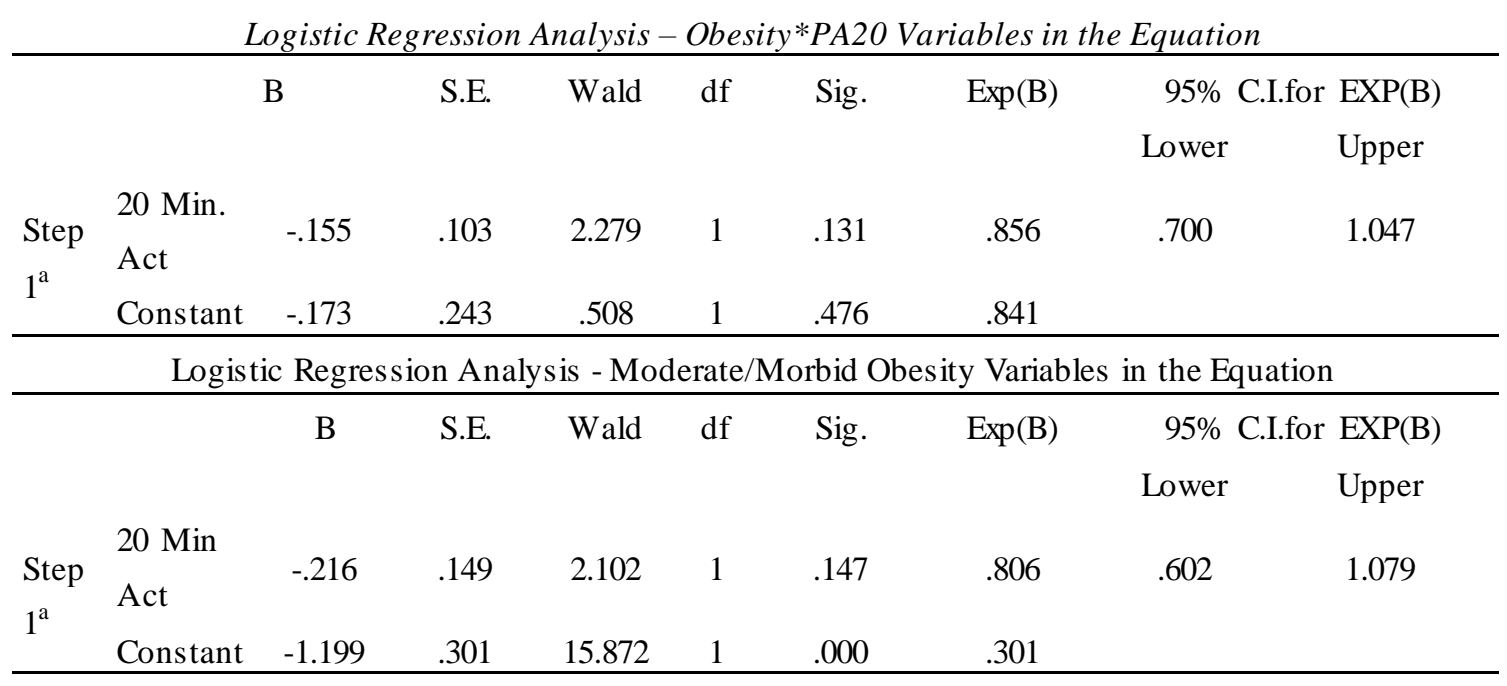

When weekly moderate exercise for at least 10 minutes was considered alone, the logistic regression model showed that no statistical significant association between physical activity and obesity, OR $.935(95 \% \mathrm{CI}=.481,1.819), p=.843$. The logistic regression model also showed no statistical significant association between weekly moderate exercise for at least 10 minutes and moderate and morbid obesity OR 1.097 $(95 \% \mathrm{CI}=.480,2.507), p=.826$ (Table 27$)$. No association was found between weekly moderate exercise for at least 10 minutes and obesity using Spearman correlations, $r_{s}$ $(157)=.009, p=.913$. These findings, combined, support Null Hypothesis 6 under Research Question 2 which predicted that physical activity was not a predictor of obesity in this sample of Nigerian immigrants. 
Table 27

Logistic Regression Analysis-Moderate Exercise for 10 Minute

Logistic Regression Analysis -Obesity* PAMod Variables in the Equation

$\begin{array}{llllll}\text { B } & \text { S.E. Wald df } \quad \text { Sig. } & \text { Exp(B) } & \begin{array}{c}95 \% \\ \text { Lower }\end{array} & \text { C.I.for } & \text { EXP(B) }\end{array}$

10 Min.

\begin{tabular}{llllllllll} 
Step & Mod. & -.067 & .339 & .039 & 1 & .843 & .935 & .481 & 1.819 \\
$1^{\mathrm{a}}$ & Act & & & & & & & & \\
& Constant & -.342 & .459 & .555 & 1 & .456 & .710 & & \\
\hline
\end{tabular}

Logistic Regression Analysis - Moderate/Morbid Obesity Variables in the Equation

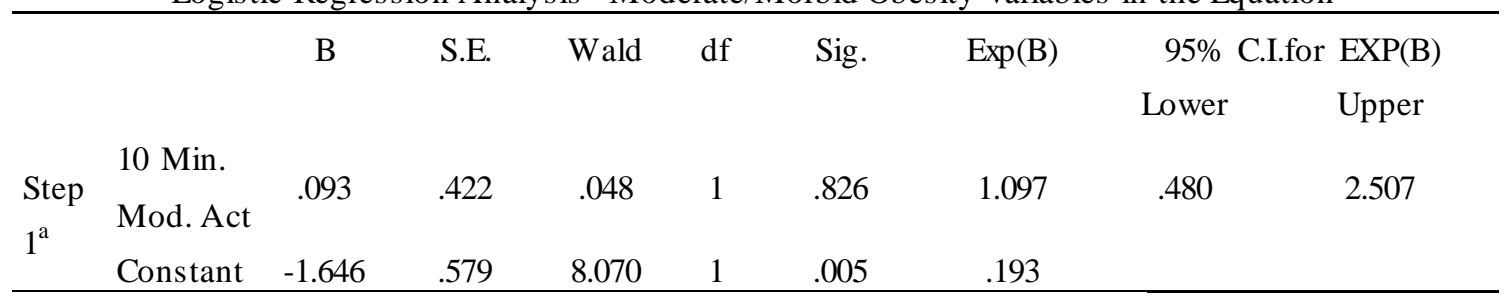

When weekly vigorous exercise for at least 10 minutes was considered alone, the logistic regression model showed that no statistical significant association between physical activity and obesity OR $1.162(95 \% \mathrm{CI}=.662,2.038), p=.601$. The logistic regression model also showed no statistical significant association between weekly vigorous exercise for at least 10 minutes and moderate and morbid obesity OR 1.078 (95\% CI =.528, 2.202), $p=.836$ (Table 28). No association was found between weekly vigorous exercise for at least 10 minutes and obesity using Spearman correlations, $r_{s}$ $(156)=.049, p=.540$ (Table 29). These findings, combined, support the Null Hypothesis 6 under Research Question 2, which predicted that physical activity was not a predictor of obesity in this sample population. 
Table 28

Logistic Regression Analysis-Vigorous Exercise for 10 Minutes

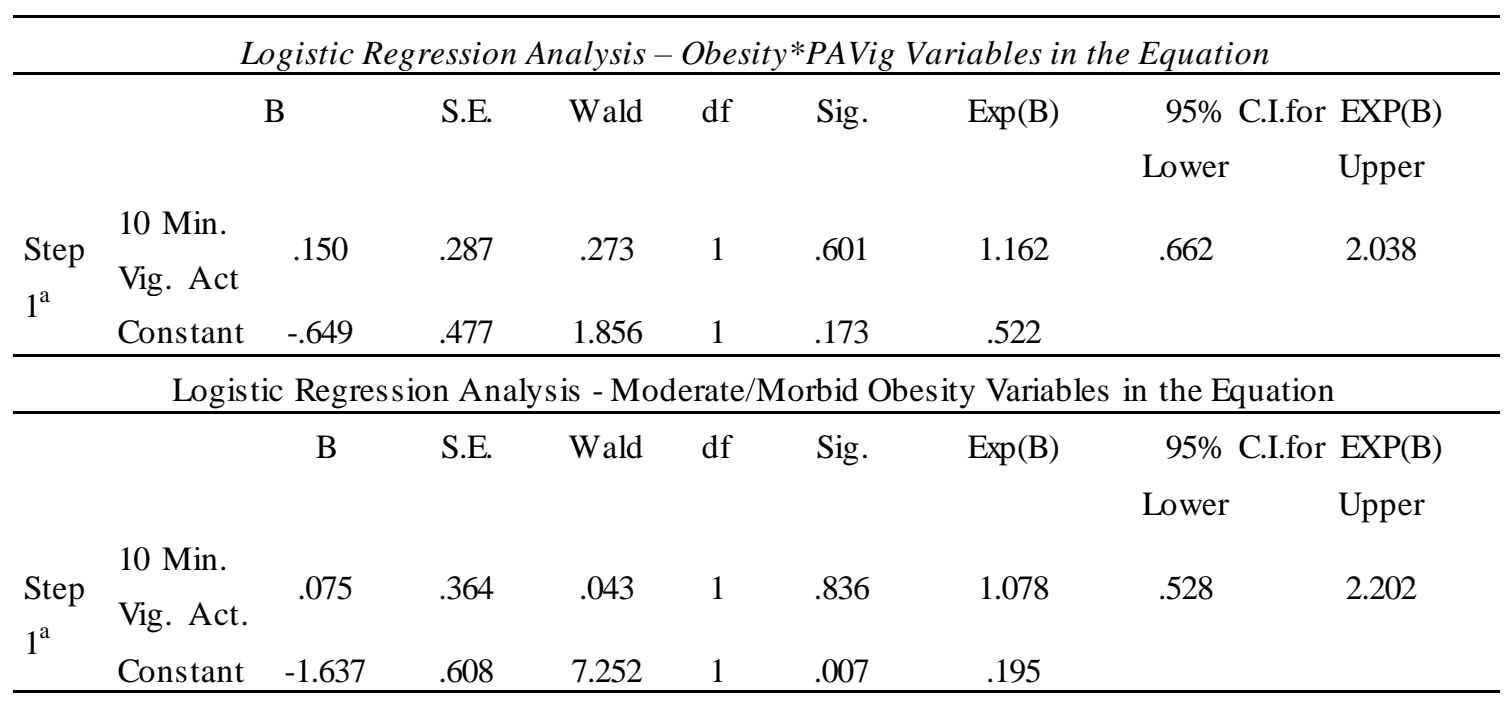

\section{Multivariate Analysis}

\section{Predictors for Obesity}

A multivariate logistic regression model simultaneously analyzed the effect of gender, level of education, socio-economic status, length of stay, diet (weekly consumption of alcohol) and moderate and vigorous level of physical activity on the likelihood of obesity compared to nonobesity in the sample population $(N=181$, Female $=0$, Male $=1$ ). The logistic regression model showed no statistical significance when all five predictor variables were considered and obesity; however significance at $p<0.05$ level was demonstrated for diet (weekly consumption of alcohol) and obesity, adjusted OR $1.784(95 \% \mathrm{CI}=1.091,2.919), p=.021($ Table 30$)$. 
Table 29

$\underline{\text { Spearman Correlations }}$

\begin{tabular}{|c|c|c|c|c|c|}
\hline & & & BMI & $\begin{array}{l}\text { Obese/Not } \\
\text { Obese BMI } \\
\text { Category }\end{array}$ & $\begin{array}{l}\text { M/M } \\
\text { Obesity } \\
\text { BMI } \\
\text { Category }\end{array}$ \\
\hline & & $\begin{array}{l}\text { Correlation } \\
\text { Coefficient }\end{array}$ & .001 & .076 & 175 \\
\hline & Gender & Sig. (2-tailed) & .991 & .311 & .018 \\
\hline & & $\mathrm{N}$ & 181 & 181 & 181 \\
\hline & What is the highest grade or year of & $\begin{array}{l}\text { Correlation } \\
\text { Coefficient }\end{array}$ & -.126 & -.106 & -.165 \\
\hline & schoolyou completed? & Sig. (2-tailed) & .093 & .156 & .027 \\
\hline & & $\mathrm{N}$ & 179 & 179 & 179 \\
\hline & Is your annual household income & $\begin{array}{l}\text { Correlation } \\
\text { Coefficient }\end{array}$ & .054 & -.072 & -.092 \\
\hline & from all sources? & Sig. (2-tailed) & .467 & .336 & .219 \\
\hline & & $\mathrm{N}$ & 181 & 181 & 181 \\
\hline & Length of stay & $\begin{array}{l}\text { Correlation } \\
\text { Coefficient } \\
\text { Sig. (2-tailed) } \\
\text { N }\end{array}$ & $\begin{array}{l}.080 \\
.306 \\
164\end{array}$ & $\begin{array}{l}.043 \\
.587 \\
164\end{array}$ & $\begin{array}{l}.022 \\
.780 \\
164\end{array}$ \\
\hline Spearman's & & $\begin{array}{l}\text { Correlation } \\
\text { Coefficient }\end{array}$ & .287 & 237 & .303 \\
\hline Rho & Alconol days per week & Sig. (2-tailed) & .001 & .007 & .001 \\
\hline & & $\mathrm{N}$ & 127 & 127 & 127 \\
\hline & Alcohol days in past 30 days & $\begin{array}{l}\text { Correlation } \\
\text { Coefficient }\end{array}$ & .105 & .114 & 179 \\
\hline & & Sig. (2-tailed) & .210 & 172 & .032 \\
\hline & & $\mathrm{N}$ & 144 & 144 & 144 \\
\hline & Physical activity times in the last & $\begin{array}{l}\text { Correlation } \\
\text { Coefficient }\end{array}$ & -.059 & -.121 & -.120 \\
\hline & week & Sig. (2-tailed) & .500 & 164 & 166 \\
\hline & & $\mathrm{N}$ & 157 & 157 & 157 \\
\hline & Moderate activities/week/for at least & $\begin{array}{l}\text { Correlation } \\
\text { Coefficient }\end{array}$ & .051 & .009 & .034 \\
\hline & 10 minutes & Sig. (2-tailed) & .524 & .913 & .670 \\
\hline & & $\mathrm{N}$ & 157 & 157 & 157 \\
\hline & Vigorous activities you/week/ 10 & $\begin{array}{l}\text { Correlation } \\
\text { Coefficient }\end{array}$ & -.007 & .049 & .019 \\
\hline & minutes & Sig. (2-tailed) & .931 & .540 & .815 \\
\hline & & $\mathrm{N}$ & 156 & 156 & 156 \\
\hline
\end{tabular}


Table 30

Multivariate Logistic Regression Results-Predictors of Obesity Variables in the Equation $(N=103)$

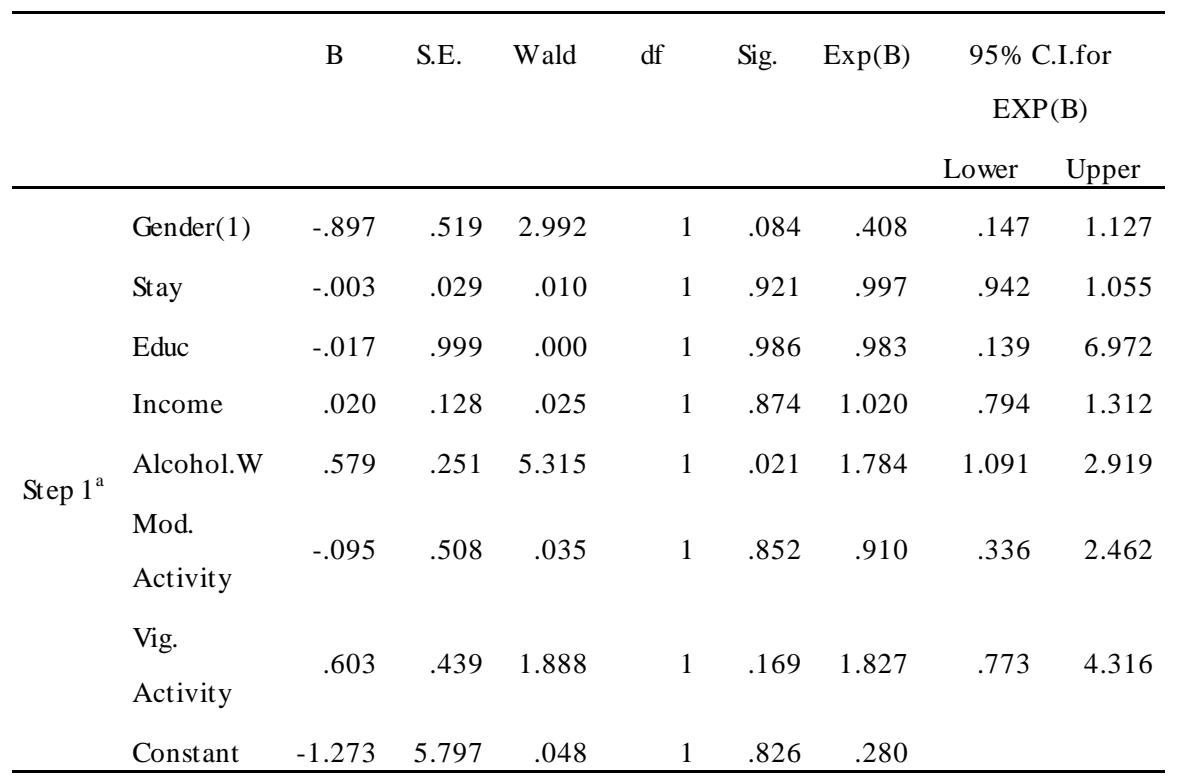

\section{Predictors for Moderate/Morbid Obesity}

A multivariate logistic regression model simultaneously analyzed the effect of gender, level of education, socio-economic status, and length of stay (independent variables) on the likelihood of moderate and morbid obesity compared to non- moderate and morbid obesity in the sample population $(\mathrm{N}=181$, [Reference Category- Female $=0$, Male=1). The logistic regression model showed no statistical significance between four predictor variables and moderate and morbid obesity; however significance at $p<0.05$ level was demonstrated for gender and obesity OR $3.30(95 \% \mathrm{CI}=.001, .733), p=.031$, and, diet (weekly consumption of alcohol) and obesity, OR 2.462 (95\% CI= 1.213, 
4.999), $p=.013$ (Table 31). These results provide support for Null Hypotheses 2, 3, 4, and 6 under Research Question 2 which predicted that level of education, socio-economic status, length of stay, and level of physical activity were not predictors of obesity in Nigerian immigrants within this sample population.

Table 31

Multivariate Logistic Regression Results—Predictors of Moderate/Morbid Obesity Variables in the Equation $(N=103)$

\begin{tabular}{|c|c|c|c|c|c|c|c|c|c|}
\hline & & \multirow[t]{2}{*}{ B } & \multirow[t]{2}{*}{ S.E. } & \multirow[t]{2}{*}{ Wald } & \multirow[t]{2}{*}{ df } & \multirow[t]{2}{*}{ Sig. } & \multirow[t]{2}{*}{$\operatorname{Exp}(B)$} & \multicolumn{2}{|c|}{$\begin{array}{l}\text { 95\% C.I.for } \\
\operatorname{EXP}(B)\end{array}$} \\
\hline & & & & & & & & Lower & Upper \\
\hline & Gender(1) & -3.503 & 1.629 & 4.626 & 1 & .031 & .030 & .001 & .733 \\
\hline & Stay & .008 & .036 & .045 & 1 & .833 & 1.008 & .938 & 1.082 \\
\hline & Educ & -.265 & 1.227 & .047 & 1 & .829 & .767 & .069 & 8.502 \\
\hline & Income & -.054 & .162 & .112 & 1 & .738 & .947 & .690 & 1.301 \\
\hline Step $1^{\mathrm{a}}$ & Alcohol.W & .901 & .361 & 6.217 & 1 & .013 & 2.462 & 1.213 & 4.999 \\
\hline & $\begin{array}{l}\text { Mod. } \\
\text { Activity }\end{array}$ & .471 & .721 & .427 & 1 & .513 & 1.602 & .390 & 6.580 \\
\hline & $\begin{array}{l}\text { Vig. } \\
\text { Activity }\end{array}$ & -.068 & .646 & .011 & 1 & .916 & .934 & .263 & 3.316 \\
\hline & Constant & -.229 & 7.073 & .001 & 1 & .974 & .796 & & \\
\hline
\end{tabular}

\section{Conclusion}

This study focused on investigating the prevalence of obesity and its predictors in a sample of 205 Nigerian immigrants in the United States. Six main predictor variables, gender, level of education, socio-economic status, length of stay, diet, and level of 
physical activity, were tested against obesity in a binary logistic regression model and Spearman's correlation model. Diet (weekly consumption of alcohol) was the only predictor variable with statistical significant association with obesity and moderate and morbid obesity; gender, however, had a statistical significant association with moderate and morbid obesity. These results support the hypotheses that gender and diet are predictors of obesity. In Chapter 5, I interpret these results, and provide recommendations for future research and implications for social change based on the findings of this study. 
Chapter 5: Discussions, Recommendations, Conclusions and Summary.

This research was driven by the need to examine the overgeneralization of obesity predictors in the immigrant population. While the generalization of specific risk factors for obesity allows public health researchers to infer what is already known to draw a conclusion that can then be generally applied to all populations, this practice of overgeneralization minimizes the need to identify new obesity predictors that either occur in isolation or through an interaction with one another, and is unique to each specific immigrant population (Harvard School of Public Health, 2014a; Singh et al., 2011; Zheng \& Yang, 2012). Obesity is a significant public health problem in the United States and the continued surge in the obese status of many populations indicates a need to obtain a better perspective on what exists in certain populations to identify what increases their susceptibility to being obese (CCDC, 2014; Finkelstein et al., 2012). Because obesity has been associated with increased prediction of being at-risk for certain diseases, health conditions, medical complications, and poor quality of life, a need exists to examine possible associations of obesity to different variables, and if a level of influence at specific levels of interaction exists that should be targeted (International Risk Governance Council, 2010; Mackenbach et al., 2014; Ogden et al., 2014). The identification of substantial heterogeneity in the obesity predictors in the different immigrant populations of the United States is a critical element of the public health plan to prevent and address obesity (Florez, 2011; Oza-Frank \& Narayan, 2010). Evidence exists that although obesity is a problem in all ethnic populations; its prevalence is 
significantly higher in minority/immigrant groups. Moreover, the complex interaction between demographic statuses, culture, dietary, physical activity patterns, and environment, and their influence on one another remains unrecognized and unidentified in different immigrant populations (Averett et al., n.d.; Barrington et al., 2010; Blanchard, 2009; Caprio, Daniels, Drewnowski, Kaufman, Palinkas, Rosenbloom, \& Schwimmer, 2008; Castellanos et al., 2011; Drummond et al., 2011; Gele \& Mbalilaki, 2013; Harvard School of Public Health, 2014a; Jasti et al., 2011; Martinez et al., 2012; McCubbin \& Antonio, 2012; Oza-Frank \& Narayan, 2010; Sharkey et al., 2011; Wen et al., 2013; Zheng \& Yang, 2012).

Data were exported from Survey Monkey to SPSS for data analysis. This study used Spearman's correlation to test the association between each independent variable, gender, level of education, socio-economic status, length of stay, diet, and level of physical activity, and obesity outcomes. Binomial logistic regression 'enter' method was used to investigate the effect of gender, level of education, socio-economic status, length of stay, diet, and level of physical activity on the predictive likelihood of obesity outcomes in the sample population (see Table 32). The logistic regression analysis results showed no statistically significant association between level of education, socioeconomic status, length of stay, and level of physical activity on obesity outcomes in the sample population. Gender and diet (weekly consumption of alcohol), however, showed statistical associations with moderate and morbid obesity. 


\section{Interpretation of the Findings}

This research was carried out to identify the prevalence of obesity in a sample of Nigerian immigrant population in the United States, and to investigate whether gender, level of education, socio-economic status, length of stay, diet, and level of physical activity were predictors of obesity outcomes in the sample population of Nigerian immigrants who have lived in the United States two or more years. The primary purpose of this research was to fill a gap about possible heterogeneity in obesity predictors in the immigrant populations in the United States. The general Nigerian adult immigrant population in the United States was specifically chosen because it has never before been studied alone. This population has always been studied alongside the general African American population (Ade et al., 2011). The research questions and hypotheses that guided this study were developed to provide baseline information of what actually exists in a sample population of Nigerian immigrants, and what basic predictors of obesity explained any prevalence of obesity.

This study identified an obesity prevalence of $38.1 \%$ in this sample population of 205 Nigerian immigrants living in the United States. This prevalence is lower than the obesity prevalence identified in the non-Hispanic black population (47.8\%) and the Hispanic population $(42.5 \%)$. This prevalence is, however, higher than the obesity

prevalence identified in the general adult obesity in the United States (34.9\%) and nonHispanic Asian population (10.8\% [CDC, 2014]). 
Logistic regression was performed to ascertain the effects of gender, level of education, socio-economic status, and length of stay on the likelihood that participants will be obese. While the result did not show any effect between the four predictor variables and obesity, it identified an effect between gender and moderate/morbid obesity. Gender had decreased odds (OR 3.30) of predicting moderate/morbid obesity in this sample population. This result was consistent with other studies that found gender was a significant predictor of obesity in certain populations. The study by Borders, Rohrer, and Cardarelli (2006) found a higher odds of obesity in male participants compared to female participants $(\mathrm{OR}=1.63, \mathrm{CI}=1.36,1.96)$. Similarly, the study by Zeigler-Johnson, Weber, Glanz, Spangler, and Rebbeck (2013) concluded that significant gender differences exist in the prevalence of obesity among eight ethnic groups $(\mathrm{p}<.001)$, with an increase odds of obesity noted in males African-American males, Hispanic males, and European American males. Asian females had a higher prevalence of obesity compared with Asian males. Another study by Choi (2011) found similar results, which found a higher prevalence of obesity in female immigrants and a higher prevalence of overweight status in male immigrants in their research sample. The result of this study, however, contradicts the findings of Ade et al.(2011) who found that no significant statistical association exists between gender and both obesity and morbidly obese status in African immigrants.

This study found no statistical significance between level of education and moderate and morbid obesity in the sample of Nigerian immigrants. Similarly, Borders et 
al. (2006) found no significant association between educational status and obesity status. The study by Ade et al. (2011), however, concluded differently when their study found that while education did not increase the risk of obesity, it did increase the risk for morbid obesity $(\mathrm{OR}=0.0569, p=0.0000)$. Barrington et al. $(2010)$ arrived at a similar conclusion when their study found obesity disparity in males with higher levels of education and females with lower level of education.

This study found no statistical significant association between socio-economic status (annual household income) and obesity status. This result was consistent with Salsberry and Reagan (2009) who found that although disadvantaged socio-economic status was associated with an increased risk for midlife obesity in Mexican American women and White women, no association was found in African American women. Ade et al. (2011) also found a similar finding when the results of their study showed no significant association between socio-economic status (measured by income level) and the risk of morbid obesity. However, Obayashi, Bianchi, Houang, and Song (2007) came to a different conclusion. They found that with consideration for age, the risk for obesity increased in low-income women $(\mathrm{OR}=2.21)$ and middle-income women $(\mathrm{OR}=1.71)$ in comparison to high-income women. The study did not find a similar association in males (Obayashi et al., 2007). The same conclusion was reached by Choi (2011) whose study found that the prevalence of overweight was higher in immigrants who lived above the United States indicated poverty level. 
This study found no statistical significant association between length of stay in the United States and obesity status, $\chi^{2}(1)=1.286, p=.257$. Again, this was similar to the findings by Ade et al. (2011) that showed that length of stay did not increase the risk of obesity in African immigrants in the United States. This, however, contradicted the findings by Goel (2004) who found that having lived in the United States for more than 10 years was associated with a higher BMI. Choi (2011) also reached a similar conclusion with study results that showed an association between having lived in the United States for a longer period and the prevalence of obesity in immigrants.

This study found statistical significant association between diet and obesity. This study identified an association between weekly consumption of alcohol, and obesity, and moderate and morbid obesity. This result is consistent with the finding of Ade et al. (2011), which found an association between alcohol consumption and morbid obesity. This conclusion was, however, not consistent with the finding of earlier studies, which have reported an association between decreased consumption of vegetables and weight gain (Castellanos et al., 2011; He et al., 2004; Sartorelli, Franco, \& Cardoso, 2008; Vioque, Weinbrenner, Castelló, Asensio, \& Garcia de la Hera, 2008). If this observation was valid, it could be explained by the study by Whybrow, Harrison, Mayer, and Stubbs (2006) that found no association between the increased consumption of fruits and vegetables and weight loss when study participants did not decrease their total fat or calorie consumption. This study found no association between physical activity and obesity. This result contradicted the findings of other studies that suggested participation 
in physical activity might attenuate the weight gain, which indicates that an association exists between physical activity and obesity (Gordon-Larsen et al., 2008; Hemmings son \& Ekelund, 2006; Ladabaum, Mannalithara, Myer, \& Singh, 2014).

This research was guided by two theoretical frameworks, the socio-ecological model, and the segmented assimilation theory. This research's findings do align with the construct of both theories that postulate that certain factors exist at individual and societal levels in socio-ecological environment that contribute or do not contribute to obesity outcomes in the Nigerian immigrant population. The findings of this study suggest that in the Nigerian immigrant population, consideration should be given to other extenuating circumstances that contribute to the lack of association between socio-economic status and length of stay and obesity outcomes, which several studies have identified as predictors of obesity. Socio-ecological theory may be extended to include socialecological resilience to explain how specific characteristics in Nigerian immigrants increase their resilience to obesity, despite possessing certain risks for obesity (Ball et al., 2011; Brogan et al., 2012).

\section{Limitations of the Study}

A need exists to take the limitations of this study into consideration in interpreting its findings. Although evidence exists that the BRFSS has moderate to substantial reliability, the possibility of under-reporting or over-reporting of self-report data from participants is a significant limitation for this study. Many of the survey questions depended heavily on the ability of the participants to recall their patterns of diet and 
physical activities precisely. A lack of objective and direct measurement of weight and height, and subsequently calculated BMI may result in an inaccurate report on the prevalence of obesity in the sample population. This is a significant limitation to an accurate analysis of data. This study used the BRFSS. No changes were made to the detailed questions in this survey to allow for the evaluation of other potential predictive obesity variables, such as religion and acculturation.

The use of a cross-sectional study was appropriate in investigating the prevalence of obesity in the sample population and the factors that contribute to its prevalence. This was, however, limited in its ability to conclude that there are temporal cause and effect relationships between gender, level of education, socio-economic status, length of stay, diet, socio-economic status, and level of physical activity, and obesity outcomes in the sample population (Carlson, \& Morrison, 2009). This distinction between prevalence and incidence is what hinders the ability to state with precision that gender, level of education, socio-economic status, length of stay, diet, and level of physical activity definitely caused obesity outcomes in the sample population (Carlson, \& Morrison, 2009).

The use of a convenience sample is also a significant limitation for this study. Even though the research focused on and collected data from only Nigerian immigrants who migrated from Nigeria to the United States, the sample population was limited to only Nigerian immigrants who belonged to the Nigerian community Facebook groups and who had the available time or Internet access to complete the survey. Because this 
sample population may not have been representative of the Nigerian immigrant population, this limits the generalization of results to just the sample population and not the larger population of Nigerian immigrants in the United States. This sample population was comprised of more female participants than of male participants. This could also have contributed to the higher prevalence of moderate/morbid obesity identified in the female participants. Despite the identification of these limitations, this study is beneficial because it demonstrates an association between gender and moderate/morbid obesity, which indicates a need to develop targeted obesity screening and prevention intervention programs in partnership with local organizations and agencies that specifically serve the Nigerian immigrant population.

\section{Recommendations}

Given what existing literature says and what this study has found, predictors of obesity exist that are not applicable to all populations in the United States. However, there are still things unknown. In specific immigrant populations: Are there specific variables or unique interactive clusters that increase the susceptibility to obesity after immigration, beside well- known predictors of obesity? Is obesity a temporary phenomenon in this population and does it change as socio-economic status improve or as people move from one geographical location to another, within the United States? Is

there a need to investigate socio-cultural dynamics and to investigate how these increase BMI? 
Because questions remain unanswered, future research should, therefore, include longitudinal investigations that provide more than snapshot information of what exists in the Nigerian immigrant population living in the United States. By carrying out longitudinal studies, researchers can track obesity outcomes in relation to different predictive factors, which influence variable clusters. For example, a longitudinal study can track obesity outcomes in relation to length of stay and change in socio-economic status. Researchers can also carry out future research by using a randomized sample of Nigerian immigrant population living in the United States, instead of a convenience sample, which may comprise of only Nigerians who share similar cultural characteristics. A randomized study will allow for a more generalized result that could be applied to a larger population of Nigerian immigrants in the United States. Because several participants were disqualified because they were not born in Nigeria, even though they had returned and lived in Nigeria for many years before migrating again, future research may focus on investigating any potential differences between Nigerian immigrants who were born in the Nigeria, and those who were born in the United States, had returned to Nigeria, and then migrated again to the United States later in adulthood. Future researchers should also consider increasing the length of time for data collection, which would allow more participants to access the survey. The use of qualitative research, especially interviews, may be necessary to obtain an in-depth understanding of what participants consider to increase their risk for obesity. It is also important to investigate 
participants' perception of the roles that participation in social and cultural events and gatherings play in their risk for obesity.

\section{Implications for Social Change}

This study has provided new information that suggests heterogeneous predictors of obesity in the Nigerian immigrant population. This information is of interest to health professionals and organizations that serve this population. Because the results of this study indicate that certain predictors of obesity that exist in certain immigrant populations may not apply to the Nigerian immigrant population, public health professionals can use this this information to screen for other underlying predictors of obesity or the identification of specific demographic or socio-ecological factors that should be targeted when developing obesity prevention interventions in this population. In identifying a lack of association between commonly known predictors of obesity and obesity outcomes, this study may have identified protective psychosocial factors that are unique to this population. Health professionals who work with this population may, therefore, have the opportunity to develop appropriate interventions that promote and strengthen these factors, as well as other known general factors, such as level of physical activity and dietary patterns. Because this study has identified that a higher prevalence of moderate and morbid obesity exists in female Nigerian immigrants, health organizations who serve this population may use this information to develop culturally appropriate health education programs, as well as to screen for the risk for obesity-related chronic diseases 
and health conditions, which include depression in Nigerian women (Markowitz, Friedman, \& Arent, 2008).

This study used the BRFSS core modules to assess dietary patterns. Health professionals who wish to screen for this predictor in this population may benefit more from a culturally sensitive food frequency questionnaire. An identification of the foods consumed in this population may be useful in guiding community-based interventions that focus on food preparation methods and suggestions for healthier ingredient substitutions or recipes that are appropriate for the Nigerian cultural dietary preferences. What makes this a positive social change is the dietary transition from alcohol consumption and what may possibly be an unhealthy food preparation method and portion size to methods of food preparation that incorporate healthier fat, carbohydrate, overall caloric content, and portion size (Hu, 2009, 2011; Swinburn, Caterson, Seidell, \& James, 2004). This study also brings awareness to an association between weekly consumption of alcohol and moderate/morbid obesity in the Nigerian immigrant population, which alerts public health professionals to the need to screen for alcohol use in this population and how this increases their risk for moderate/morbid obesity.

\section{Conclusion}

This study investigated the prevalence of obesity in the Nigerian immigrant population in the United States and the predictors of obesity in the sample population, specifically gender, level of education, socio-economic status, length of stay, and level of physical activity. The results showed that an association exists between diet (weekly 
consumption of alcohol) and obesity, and diet (weekly consumption of alcohol) and moderate and morbid obesity. The results also showed an association between gender and moderate and morbid obesity. These results suggest that well-known predictors of obesity may not be homogeneous in all populations and may not specifically apply to this sample population. The overgeneralization of obesity factors in minority and immigrant populations may hide diverse, unique, and significant predictors of obesity that remain unrecognized and unknown. This could result in blanket interventions that may or may not address the increasing prevalence of obesity in specific populations. 
References

Acheampong, I., \& Haldeman, L. (2013). Are nutrition knowledge, attitudes, and beliefs associated with obesity among low-income Hispanic and African American women caretakers? Journal of Obesity, 2013, 1-8. doi:10.1155/2013/123901

Ade, J., Rohrer, J., \& Rea, N. (2011). Immigration, income, drinking and obesity in African American adults. Journal of Immigrant and Minority Health/Center for Minority Public Health, 13, 659-663. doi:10.1007/s10903-010-9431-8

Adedoyin, R. A., Mbada, C. E., Balogun, M. O., Adebayo, R. A., Martins, T., \& Ismail, I. S. (2010). Obesity prevalence in adult residents of Ile-Ife, Nigeria. Nigerian Quarterly Journal of Hospital Medicine, 19(1), 63-68. doi:10.4314/nqjhm.v19i1.50211

Adefule, A. K., Adu, T. O., Ogundahunsi, O.A., Caxton-Martins, E. A., Otulana, O. J., \& Adesanya, O. A. (2014). Prevalence of overweight and central obesity among south western Nigerian young adults. Nova Journal of Medical and Biological Sciences, 2(3), 1-10. Retrieved from http://novaexplore.com/NJMBS/wpcontent/uploads/sites/4/2014/05/S2292793X1400012-2.pdf

Akarolo-Anthony, S., Willett, W., Spiegelman, D., \& Adebamowo, C. (2014). Obesity epidemic has emerged among Nigerians. BMC Public Health, 14, 455-470. doi:10.1186/1471-2458-14-455 
Albrecht, S., \& Gordon-Larsen, P. (2013). Ethnic differences in body mass index trajectories from adolescence to adulthood: A focus on Hispanic and Asian subgroups in the United States. Plos One, 8(9), e72983. doi:10.1371/journal.pone.0072983

American Heart Association. (2014). Obesity information. Retrieved from http://www.heart.org/HEARTORG/GettingHealthy/WeightManagement/Obesity/ Obesity-Information_UCM_307908_Article.jsp

American Immigration Council. (2012). African immigrants in America: A demographic overview. Retrieved from http://immigrationpolicy.org/just-facts/africanimmigrants-america-demographic-overview

American Psychological Association. (2014). Socioeconomic status. Retrieved from http//www.apa.org/topics/socioeconomic-status/

Ani, P. N., Uvere, P. O., \& Ene-Obong, H. N. (2013). Prevalence of overweight, obesity and thinness among adolescents in rural and urban areas of Enugu State, Nigeria. International Journal of Basic and Applied Sciences, 3(1), 1-7. doi:10.14419/ijbas.v3i1.1171

Association for Psychological Science. (2011). 'Fatting in': Immigrant groups eat highcalorie American meals to fit in. Retrieved from http://www.psychologicalscience.org/index.php/news/releases/fatting-inimmigrant-group s-eat-high-calorie-american- meals-to-fit-in.html 
Averett, S. L., Argys, L. M., \& Kohn, J. L. (2012). Immigration, obesity and labor market outcomes in the UK. Retrieved from http//ftp.iza.org/dp6454.pdf

Averett, S. L., Argys, L. M., \& Kohn, J. L. (n.d.). Immigrants, wages and obesity: The weight of the evidence. Retrieved from http://www.iza.org/MigrationHandbook/13_Averett_Argys_Kohn_im_wages_obe sity.pdf

Aschengrau, A., \& Seage, G. R., III (2008). Essentials of epidemiology in public health (2nd ed.). Sudbury, MA: Jones and Bartlett.

Babey, S., Hastert, T., Wolstein, J., \& Diamant, A. (2010). Income disparities in obesity trends among California adolescents. American Journal of Public Health, 100, 2149-2155. doi:10.2105/AJPH.2010.192641

Ball, K., Abbott, G., Cleland, V., Timperio, A., Thornton, L., Mishra, G., ... Crawford, D. (2011). Resilience to obesity among socioeconomically disadvantaged women: the READI study. International Journal of Obesity, 36, 855-865. doi:10.1038/ijo.2011.183

Barrington, D., Baquero, M., Borrell, L., \& Crawford, N. (2010). Racial/ethnic disparities in obesity among US-born and foreign-born adults by sex and education. Obesity, 18, 422-424. doi:10.1038/oby.2009.212

Bewick, V., Cheek, L., \& Ball, J. (2005). Statistics review 14: Logistic regression. Critical Care, 9(1), 112-118. doi:10.1186/cc3045 
Blanchard, S. A. (2009). Variables associated with obesity among African-American women in Omaha. American Journal of Occupational Therapy, 63(1), 58-68. doi:10.5014/ajot.63.1.58

Bodea, T. D., Garrow, L. A., Meyer, M. D., \& Ross, C. L. (2009). Socio-demographic and built environment influences on the odds of being overweight or obese: The Atlanta experience. Transportation Research Part A: Policy and Practice, 43, 430-444. doi:10.1016/j.tra.2008.11.009

Borders, T. F., Rohrer, J. E., \& Cardarelli, K. M. (2006). Gender-specific disparities in obesity. Journal of Community Health, 31(1), 57-68. doi:10.1007/s10900-0058189-8

Brogan, K., Idalski Carcone, A., Jen, K. C., Ellis, D., Marshall, S., \& Naar-King, S. (2012). Factors associated with weight resilience in obesogenic environments in female African-American adolescents. Journal of the Academy of Nutrition and Dietetics, 112, 718-724. doi:10.1016/j.jand.2012.02.004

Brown, S. K. \& Bean, F. D. (2006). Assimilation models, old and new: Explaining a long-term process. Retrieved from http://www.migrationpolicy.org/article/assimilation-models-old-and-newexplaining-long-term-process

Buowari, Y. (2010). Obesity among students attending a tertiary institution in Nigeria. International Journal of Technology Management, 7(1). doi:10.5580/12d9 
Burns, N., \& Grove, S.K. (2007). Understanding nursing research (4th ed.). St. Louis, Mo: Saunders Elsevier

Caprio, S., Daniels, S., Drewnowski, A., Kaufman, F., Palinkas, L., Rosenbloom, A., \& Schwimmer, J. (2008). Influence of race, ethnicity, and culture on childhood obesity: Implications for prevention and treatment. Obesity, 16, 2566-2577. doi:10.1038/oby.2008.398.

Caramota, S. A. (2012). Immigrants in the United States, 2010: A profile of America's foreign-born population. Retrieved from http://cis.org/2012-profile-of-americasforeign-born-population\#f1

Carlson, M. D. A., \& Morrison, R. S. (2009). Study design, precision, and validity in observational studies. Journal of Palliative Medicine, 12(1), 77-82. doi:10.1089/jpm.2008.9690

Castellanos, D., Connell, C., \& Lee, J. (2011). Factors affecting weight gain and dietary intake in Latino males residing in Mississippi: a preliminary study. Hispanic Health Care International, 9(2), 91-98. doi:10.1891/1540-4153.9.2.91

Castro, F., Marsiglia, F., Kulis, S., \& Kellison, J. (2010). Lifetime segmented assimilation trajectories and health outcomes in Latino and other community residents. American Journal of Public Health, 100, 669-676.

doi:10.2105/AJPH.2009.167999 
Centers for Disease Control and Prevention. (2010). Vital signs: State-specific obesity prevalence among adults - United States, 2009. Retrieved from http://www.cdc.gov/mmwr/preview/mmwrhtml/mm59e0803a1.htm?s_cid=mm59 e0803a1_e\%0D\%0A

Centers for Disease Control and Prevention. (2012). Defining overweight and obesity. Retrieved from http://www.cdc.gov/obesity/adult/defining.html Centers for Disease Control and Prevention. (2013a). One in five adults meet overall physical activity guidelines. Retrieved from http://www.cdc.gov/media/releases/2013/p0502-physical-activity.html

Centers for Disease Control and Prevention. (2013b). The social-ecological model: A framework for prevention. Retrieved from http://www.cdc.gov/violenceprevention/overview/social-ecologicalmodel.html Centers for Disease Control and Prevention. (2014). Adult obesity facts. Retrieved from http://www.cdc.gov/obesity/data/adult.html

Chapman, B. P., Fiscella, K., Duberstein, P., Coletta, M., \& Kawachi, I. (2009). Can the influence of childhood socioeconomic status on men's and women's adult body mass be explained by adult socioeconomic status or personality? Findings from a national sample. Health Psychology, 28, 419-427. doi:10.1037/a0015212

Check, R., \& Schutt, R.K. (2012). Research methods in education. Thousand Oaks, CA: Sage. 
Chircop, A., Shearer, C., Pitter, R., Sim, M., Rehman, L., Flannery, M., \& Kirk, S. (2013). Privileging physical activity over healthy eating: 'Time' to choose?. Health Promotion International, 1-9. doi: 10.1093/heapro/dat056

Choi, J. Y. (2011). Prevalence of overweight and obesity among US immigrants: Results of the 2003 New Immigrant Survey. Journal of Immigrant and Minority Health, 14, 1112-1118. doi:10.1007/s10903-011-9560-8

Cohen, L., Chávez, V., \& Chehimi, S. (2010). Prevention is primary: Strategies for community well-being (2nd ed.). San Francisco, CA: Jossey-Bass

Creswell, J. (2013). Research design: Qualitative, quantitative, and mixed methods approaches (4th ed.). Thousand Oaks, CA: Sage.

Delavari, M., Sønderlund, A., Swinburn, B., Mellor, D., \& Renzaho, A. (2013). Acculturation and obesity among migrant populations in high income countries--a systematic review. BMC Public Health, 13, 458-460. doi:10.1186/1471-2458-13458

Drummond, P., Mizan, A., Burgoyne, A., \& Wright, B. (2011). Knowledge of cardiovascular risk factors in West African refugee women living in Western Australia. Journal of Immigrant \& Minority Health, 13(1), 140-148. doi:10.1007/s10903-010-9322-z

Ellis, P. D. (2010). The essential guide to effect sizes: Statistical power, meta-analysis, and the interpretation of research results. Cambridge, NY: Cambridge University Press. 
El-Sayed, A., Scarborough, P., \& Galea, S. (2012). Unevenly distributed: A systematic review of the health literature about socioeconomic inequalities in adult obesity in the United Kingdom. BMC Public Health, 12, 18-24. doi:10.1186/1471-2458-1218

Engel, R. J., \& Schutt, R. K. (2009). Fundamentals of social work research. Thousand Oaks, CA: Sage.

Evenson, K., \& McGinn, A. (2005). Test-retest reliability of adult surveillance measures for physical activity and inactivity. American Journal of Preventive Medicine, 28, 470-478. doi: http//dx.doi.org/10.1016/j.amepre.2005.02.005

Field, A. (2009). Discovering statistics using IBM SPSS statistics (3rd ed.). London, England: Sage.

Finkelstein, E. A., Khavjou, O. A., Thompson, H., Trogdon, J. G., Pan, L., Sherry, B., \& Dietz, W. (2012). Obesity and severe obesity forecasts through 2030. American Journal of Preventive Medicine, 42, 563-570. doi:10.1016/j.amepre.2011.10.026

Florez, K. (2011). Segmented assimilation patterns and obesity among Latino adults in the United States. Paper presented at the APHA 139th Annual Meeting and Exposition, October 29-November 2, 2011. Washington, DC. Retrieved from https $/ /$ apha.confex.com/apha/139am/webprogram/Paper237723.html 
Food Research and Action Center. (2010). Why low-income and food insecure people are vulnerable to overweight and obesity. Retrieved from http://frac.org/initiatives/hunger-and-obesity/why-are-low-income-and-foodinsecure-people- vulnerable-to-obesity/

Frankfort-Nachmias, C. \& Nachmias, D. (2008). Research methods in the social sciences (7th ed.). New York, NY: Worth.

Fuller, D. (2004). Web based surveys, social epidemiology and Internet freedom. Retrieved from http://ijph.blogs.springer.com/food-for-thought/rnestudents-denweb-based-surveys-social-epidemiology-and-intet-freedom/

Gele, A. A., \& Mbalilaki, A. J. (2013). Overweight and obesity among African immigrants in Oslo. BMC Research Notes, 6(1), 1-6. doi:10.1186/1756-0500-6119

Gentile, D. A., Welk, G., Eisenmann, J. C., Reimer, R. A., Walsh, D. A., Russell, D. W., . . Fritz, K. (2009). Evaluation of a multiple ecological level child obesity prevention program: Switch what you do, view, and chew. BMC Medicine, 7(1), 49-55. doi:10.1186/1741-7015-7-49

Gerstman, B. (2008). Basic biostatistics: Statistics for public health practice. Sudbury, MA: Jones and Bartlett

Goel, M. S. (2004). Obesity among US immigrant subgroups by duration of residence. The Journal of the American Medical Association (JAMA), 292, 2860-2871. doi:10.1001/jama.292.23.2860 
Goldstein, H. (2009). Translating research into public policy. Journal of Public Health Policy, 30, S16-20. doi:10.1057/jphp.2008.49.

Gordon-Larsen, P., Hou, N., Sidney, S., Sternfeld, B., Lewis, C. E., Jacobs, D. R., \& Popkin, B. M. (2008). Fifteen-year longitudinal trends in walking patterns and their impact on weight change. American Journal of Clinical Nutrition, 89(1), 1926. doi:10.3945/ajcn.2008.26147

Guendelman, S., Ritterman-Weintraub, M., Fernald, L., \& Kaufer-Horwitz, M. (2013). Weight status of Mexican immigrant women: a comparison with women in Mexico and with US-born Mexican American women. American Journal of Public Health, 103, 1634-1640. doi:10.2105/AJPH.2012.301171

Hao, L., \& Kim, J. J. H. (2009), Immigration and the American obesity epidemic. International Migration Review, 43, 237-262. doi: 10.1111/j.17477379.2009.00764.x

Harley, A. (2009). Social support and companionship among active African American women. American Journal of Health Behavior, 33, 673-685 doi:10.5993/ajhb.33.6.5

Harvard School of Public Health. (2014a). Ethnic differences in BMI and disease risk. Retrieved from http://www.hsph.harvard.edu/obesity-prevention-source/ethnicdifferences-in-bmi-and-disease-risk/ 
Harvard School of Public Health. (2014b). Toxic food environment. Retrieved from http://www.hsph.harvard.edu/obesity-prevention-source/obesity-causes/foodenvironment-and-obesity/

He, K., Hu, F. B., Colditz, G. A., Manson, J. E., Willett, W. C., \& Liu, S. (2004). Changes in intake of fruits and vegetables in relation to risk of obesity and weight gain among middle-aged women. International Journal of Obesity, 28, 15691574. doi:10.1038/sj.ijo.0802795

Hemmingsson, E., \& Ekelund, U. (2006). Is the association between physical activity and body mass index obesity dependent? International Journal of Obesity. 31. 663671. doi:10.1038/sj.ijo.0803458

Holsten, J. E. (2009). Obesity and the community food environment: A systematic review. Public Health Nutrition, 12, 397-405. doi: 10.1017/S1368980008002267.

Hu, F. B. (2009). Diet and physical activity in the prevention of obesity. In C. Mantzoros (Ed.), Nutrition and metabolism: Underlying mechanism and clinical consequences (pp. 135-173). New York City, NY: Humana Press.

Hunte, H., \& Williams, D. (2009). The association between perceived discrimination and obesity in a population-based multiracial and multiethnic adult sample. American Journal of Public Health, 99, 1285-1292. doi:10.2105/AJPH.2007.128090 
Iloh, G., Amadi, A., Nwankwo, B., \& Ugwu, V. (2011). Obesity in adult Nigerians: A study of its pattern and common primary co-morbidities in a rural Mission General Hospital in Imo State, South-Eastern Nigeria. Nigerian Journal of Clinical Practice, 14, 212-218. doi:10.4103/1119-3077.84019

International Risk Governance Council. (2010). The obesity epidemic. Retrieved from http://irgc.org/wp-content/uploads/2012/04/Emerging_risks_Obesity.pdf

Jasti, S., Chang Hyun, L., \& Doak, C. (2011). Gender, acculturation, food patterns, and overweight in Korean immigrants. American Journal of Health Behavior, 35, 734-745. Retrieved from http://www.ncbi.nlm.nih.gov/pubmed/22251764

Kandala, N.-B., \& Stranges, S. (2014). Geographic variation of overweight and obesity among women in Nigeria: A case for nutritional transition in Sub-Saharan Africa. PLoS ONE, 9(6), e101103. doi:10.1371/journal.pone.0101103

Kayode, J., Olayinka, A., Sola, A., \& Steven, A. (2011). Underweight, overweight and obesity in adults Nigerians living in rural and urban communities of Benue State. Annals of African Medicine, 10, 139-145. doi:10.4103/1596-3519.82081

Kellou, N., Sandalinas, F., Copin, N., \& Simon, C. (2014). Prevention of unhealthy weight in children by promoting physical activity using a socio-ecological approach: What can we learn from intervention studies?. Diabetes \& Metabolism, 40, 258-274. .doi:10.1016/j.diabet.2014.01.002 
Kershaw, K. N., \& Albrecht, S. S. (2014). Metropolitan-level ethnic residential segregation, racial identity, and body mass index among U.S. Hispanic adults: a multilevel cross-sectional study. BMC Public Health, 14, 283-290. doi:10.1186/1471-2458-14-283

Kish, L. (1990). Weighting: Why, when, and how? Retrieved from www.amstat.org/sections/srms/Proceedings/papers/1990_018.pdf

Korn, E. L., \& Graubard, B. I. (2011). Analysis of health surveys. San Francisco, CA: John Wiley \& Sons.

Knoblock-Hahn, A., \& LeRouge, C. (2014). A qualitative, exploratory study of predominantly female parental perceptions of consumer health technology use by their overweight and/or obese female adolescent participating in a fee-based 4week weight-management intervention. Journal of the Academy of Nutrition And Dietetics, 114, 570-577. doi:10.1016/j.jand.2013.11.021

Ladabaum, U., Mannalithara, A., Myer, P. A., \& Singh, G. (2014). Obesity, abdominal obesity, physical activity, and caloric intake in US adults: 1988 to 2010. The American Journal of Medicine, 127, 717-727. doi:10.1016/j.amjmed.2014.02.026

Layton, K., Parker, S., Hermann, J., \& Williams, S. (2009). Comparison of socioecologic factors affecting overweight and obesity among limited income African American, Native American and White women. Journal of Nutrition Education and Behavior, 41(4), S43-49. doi:10.1016/j.jneb.2009.03.014 
Leadership Paradigms, Inc. (n. d.). What is social change? Retrieved from http://www.leadershipparadigms.com/docs/SOCIAL.pdf

Lind, D. A., Marchal, W. G. \& Wathen, S. A. (2008). Basic statistics for business and economics (6th ed.). New York, NY: McGraw-Hill/Irwin.

Lund Research, Ltd. (2012). Convenience sampling. Retrieved from http://dissertation.laerd.com/convenience-sampling.php

Lytle, L. A. (2009a). Examining the etiology of childhood obesity: The IDEA study. American Journal of Community Psychology, 44, 338-349. doi:10.1007/s10464009-9269-1

Lytle, L. A. (2009b). Measuring the food environment: State of the science. American Journal of Preventive Medicine, 36, S134-1344. doi:10.1016/j.amepre.2009.01.018.

Mackenbach, J. D., Rutter, H., Compernolle, S., Glonti, K., Oppert, J., Charreire, H.,. . . Lakerveld, J. (2014). Obesogenic environments: a systematic review of the association between the physical environment and adult weight status, the SPOTLIGHT project. BMC Public Health, 14(1), 1-28. doi:10.1186/1471-2458$14-233$

Markowitz, S., Friedman, M. A., \& Arent, S. M. (2008). Understanding the relation between obesity and depression: Causal mechanisms and implications for treatment. Clinical Psychology: Science and Practice, 15(1), 1-20. doi:10.1111/j.1468-2850.2008.00106.x 
Martinez, J., Powell, J., Agne, A., Scarinci, I., \& Cherrington, A. (2012). A focus group study of Mexican immigrant men's perceptions of weight and lifestyle. Public Health Nursing, 29, 490-498. doi:10.1111/j.1525-1446.2012.01026.x

McCubbin, L., \& Antonio, M. (2012). Discrimination and obesity among Native Hawaiians. Hawai'i Journal of Medicine \& Public Health: A Journal of Asia Pacific Medicine \& Public Health, 71, 346-352. Retrieved from http://www.ncbi.nlm.nih.gov/pmc/articles/PMC3525333/

McKenzie, J. F., Neiger, B. L., \& Thackeray, R. (2008). Planning, implementing and evaluating health promotion programs: A primer (5th ed.). San Francisco, CA: Pearson Benjamin Cumming.

Mokdad, A. (2009). The behavioral risk factors surveillance system: Past, present, and future. Annual Review of Public Health, 30, 43-54. doi:10.1146/annurev.publhealth.031308.100226

Mudge, J. F., Baker, L. F., Edge, C. B., \& Houlahan, J. E. (2012). Setting an optimal $\alpha$ that minimizes errors in null hypothesis significance tests. PLoS ONE 7, e32734. doi:10.1371/journal.pone.0032734

National Obesity Observatory. (2011). Obesity and ethnicity. Retrieved from http://www.noo.org.uk/uploads/doc/vid_9444_Obesity_and_ethnicity_270111.pdf National Collaborative on Childhood Obesity Research. (2010). Behavioral risk factor surveillance system (BRFSS). Retrieved from http:/tools.nccor.org/css/system/28/ 
New Hampshire Department of Health and Human Services. (2010). Obesity prevention. Retrieved from http://www.dhhs.nh.gov/dphs/nhp/obesity.htm

National Institutes of Health. (2005). Theory at a glance: A guide for health promotion practice (2nd.ed.). Retrieved from www.cancer.gov/cancertopics/cancerlibrary/theory.pdf

Obayashi, S., Bianchi, L., Houang, R., \& Song, W. O. (2007). Obesity predictors differentiating subgroups by gender and income in the U.S. The FASEB Journal, 21, 527-537. Retrieved from http://www.fasebj.org/cgi/content/meeting_abstract/21/5/A302

Ocean University of China. (n.d.). Major strengths and weaknesses. Retrieved from http:/gwxy.sysu.edu.cn/lxbx/english/epidemiologic\%20knowled ge/Analytic\%20 Ecological\%20and\%20Cross-Sectional\%20Studies/Cross/Major.html\# Office of the Surgeon General. (2010). The Surgeon General's vision for a healthy and fit nation. Retrieved from http://www.ncbi.nlm.nih.gov/books/NBK44656/

Ogden, C. L., Carroll, M. D., Kit, B. K., \& Flegal, K. M. (2014). Prevalence of childhood and adult obesity in the United States, 2011-2012. Journal of American Medical Association, 311, 806-814. doi:10.1001/jama.2014.732 
Ogunjimi, L. O., Ikorok, M. M., \& Yusuf, O. O. (2010). Prevalence of obesity among Nigeria nurses: The Akwa Ibom State experience. International NGO Journal, 5(2), 45-49. Retrieved from http://www.academicjournals.org/article/article1381821731_Ogunjimi\%20et\%20 al.pdf

Olatunbosun, S., Kaufman, J., \& Bella, A. (2011). Prevalence of obesity and overweight in urban adult Nigerians. Obesity Reviews: An Official Journal of the International Association for the Study of Obesity, 12, 233-241. doi:10.1111/j.1467-789X.2010.00801.x

Oster, A., \& Yung, J. (2010). Dietary acculturation, obesity, and diabetes among Chinese immigrants in New York City. Diabetes Care, 33(8), e109-e109. doi:10.2337/dc09-2291

Oza-Frank, R., \& Narayan, K. (2010). Overweight and diabetes prevalence among US immigrants. American Journal of Public Health, 100, 661-668. doi:10.2105/AJPH.2008.149492

Pan, L., Freedman, D., Gillespie, C., Park, S., \& Sherry, B. (2011). Incidences of obesity and extreme obesity among US adults: Findings from the 2009 behavioral risk factor surveillance system. Population Health Metrics, 9(1), 56-62. doi:10.1186/1478-7954-9-56 
Piedra, L., \& Engstrom, D. (2009). Segmented assimilation theory and the life model: An integrated approach to understanding immigrants and their children. Social Work, 54, 270-277. Retrieved from http//www.ncbi.nlm.nih.gov/pubmed/19530574

Pierannunzi, C., Hu, S. S., \& Balluz, L. (2013). A systematic review of publications assessing reliability and validity of the behavioral risk factor surveillance system (BRFSS), 2004-2011. BMC Medical Research Methodology, 13(1), 49-55. doi:10.1186/1471-2288-13-49.

Rothe, E., Holt, C., Kuhn, C., McAteer, T., Askari, I., O’Meara, M., ... Dexter, W. (2010). Barriers to outdoor physical activity in wintertime among Somali youth. Journal of Immigrant \& Minority Health, 12, 726-736. doi:10.1007/s10903-0099287

Salsberry, P. J., \& Reagan, P. B. (2009). Comparing the influence of childhood and adult economic status on midlife obesity in Mexican American, White, and African American women. Public Health Nursing, 26(1), 14-22. doi:10.1111/j.15251446.2008.00751.x

Sartorelli, D. S., Franco, L. J., \& Cardoso, M. A. (2008). High intake of fruits and vegetables predicts weight loss in Brazilian overweight adults. Nutrition Research, 28, 233-238. doi:10.1016/j.nutres.2008.02.004

Schneider, M. J. (2006). Introduction to public health (2nd ed.). Sudbury, MA: Jones and Bartlett. 
Schutt, R. K. (2011). Investigating the social world: The process and practice of research (7th ed.). Thousand Oaks, CA: Sage.

Sharkey, J., Johnson, C., \& Dean, W. (2011). Nativity is associated with sugar-sweetened beverage and fast-food meal consumption among Mexican-origin women in Texas border colonies. Nutrition Journal, 10, 101-115. doi:10.1186/1475-2891$10-101$

Sim, J., \& Wright, C. (2005). The kappa statistic in reliability studies: Use, interpretation, and sample size requirements. Physical Therapy, 85, 257-268. Retrieved from http://ptjournal.apta.org/content/85/3/257.full

Simons-Morten, B., McLeroy, K. R., \& Wendel, M. L. (2012). Behavior theory in health promotion practice and research. Burlington, MA: Jones \& Bartlett Learning.

Singh, G., Siahpush, M., Hiatt, R., \& Timsina, L. (2011). Dramatic increases in obesity and overweight prevalence and body mass index among ethnic-immigrant and social class groups in the United States, 1976-2008. Journal of Community Health, 36(1), 94-110. doi:10.1007/s10900-010-9287-9

Sola, A., Steven, A., Kayode, J., \& Olayinka, A. (2011). Underweight, overweight and obesity in adults Nigerians living in rural and urban communities of Benue State. Annals of African Medicine, 10, 139-143. doi:10.4103/1596-3519.82081

Sutherland, M. E. (2013). Overweight and obesity among African American Women: An Examination of predictive and risk factors and weight-reduction 
recommendations. Journal of Black Studies, 44, 846-869.

doi:10.1177/0021934713511639.

Swinburn, B. A., Caterson, I., Seidell, J. C., \& James, W. P. (2004). Diet, nutrition and the prevention of excess weight gain and obesity. Public Health Nutrition, 7(1A), 123-146. doi:10.1079/phn2003585

Szklo, M., \& Nieto, F. J. (2014). Epidemiology: Beyond the basics (3rd ed.). Sudbury, MA: Jones and Bartlett.

Tekkel, M., Veideman, T., \& Rahu, M. (2010). Changes over fourteen years in adult obesity in Estonia: Socioeconomic status and use of outpatient health services. Central European Journal of Public Health, 18, 186-191. Retrieved from http://www.ncbi.nlm.nih.gov/pubmed/21361100

Thomas, J. (2009). Support needs of overweight African American women for weight loss. American Journal of Health Behavior, 33(4), 339-352. doi:10.5993/ajhb.33.4.1

Thompson, B. (1994). The concept of statistical significance testing. Retrieved from http://PAREonline.net/getvn.asp? v=4\&n=5

Townsend, N., \& Foster, C. (2013). Developing and applying a socio-ecological model to the promotion of healthy eating in the school. Public Health Nutrition, 16, 11011108. doi:10.1017/S1368980011002655 
Trochim, W. (2006). Types of surveys. Retrieved from http://www.socialresearchmethods.net/kb/survsel.php

Tseng, M., \& Fang, C. (2011). Stress is associated with unfavorable patterns of dietary intake among female Chinese immigrants. Annals of Behavioral Medicine: A Publication of the Society of Behavioral Medicine, 41, 324-332. doi:10.1007/s12160-010-9259-4

United States Department Of Health And Human Services. (n.d.) Physical activity and health: A report of the surgeon general executive summary. Retrieved from http://www.fitness.gov/ execsum/execsum.htm\#3

van Gelder, M. M., Bretveld, R. W., \& Roeleveld, N. (2010). Web-based questionnaires: The future in epidemiology? American Journal of Epidemiology, 172, 1292-1300. doi:10.1093/aje/kwq291.

Vals, K., Kiivet, R., \& Leinsalu, M. (2013). Alcohol consumption, smoking and overweight as a burden for health care services utilization: A cross-sectional study in Estonia. BMC Public Health, 13, 772-790. doi:10.1186/1471-2458-13-772

Vioque, J., Weinbrenner, T., Castelló, A., Asensio, L., \& Garcia de la Hera, M. (2008). Intake of fruits and vegetables in relation to 10-year weight gain among Spanish adults. Obesity, 16, 664-670. doi:10.1038/oby.2007.121 
Wahab, K. W., Sani, M. U., Yusuf, B. O., Gbadamosi, M., Gbadamosi, A., \& Yandutse, M. I. (2011). Prevalence and determinants of obesity - a cross-sectional study of an adult Northern Nigerian population. International Archives of Medicine, 4(1), 10-16. doi:10.1186/1755-7682-4-10

Wändell, P. E. (2013). Population groups in dietary transition. Food \& Nutrition Research, 57, 216-268. http://dx.doi.org/10.3402/fnr.v57i0.21668.

Waters, M. C., Tran, V. C., Kasinitz, P., \& Mollenkopf, J. H. (2010). Segmented assimilation revisited: Types of acculturation and socioeconomic mobility in young adulthood. Ethnic and Racial Studies, 1-26. doi:10.1080/01419871 003624076

Wen, M., Kowaleski-Jones, L., \& Fan, J. X. (2013). Ethnic-immigrant disparities in total and abdominal obesity in the US. American Journal of Health Behavior, 37, 807818. doi:10.5993/AJHB.37.6.10

Whybrow, S., Harrison, C. L. S., Mayer, C., \& Stubbs, R. J. (2006). Effects of added fruits and vegetables on dietary intakes and body weight in Scottish adults. British Journal of Nutrition, 95, 496-502. doi:10.1079/bjn20051489

World Health Organization. (2011). Stop the global epidemic of chronic diseases. Retrieved from https://apps. who.int/infobase/Index.aspx

World Health Organization. (2014a). Obesity. Retrieved from http://www.who.int/topics/obesity/en/ 
World Health Organization. (2014b). Obesity and overweight. Retrieved from http://www.who.int/mediacentre/factsheets/fs311/en/

Wu, H. W., \& Sturm, R. (2013). What's on the menu? A review of the energy and nutritional content of US chain restaurant menus. Public Health Nutrition, 16(1), 87-96. doi:10.1017/S136898001200122X

Xie, Y., \& Greenman, E. (2005). Segmented assimilation theory: A reformulation and empirical test. Retrieved from http//www.psc.isr.umich.edu/pubs/pdf/rr05581.pdf

Yeary, K., Cornell, C., Turner, J., Moore, P., Bursac, Z., Prewitt, T., \& West, D. (2011). Feasibility of an evidence-based weight loss intervention for a faith-based, rural, African American population. Preventing Chronic Disease, 8, A146-152. Retrieved from http://www.cdc.gov/pcd/issues/2011/nov/10_0194.htm

YoonMyung, K., \& SoJung, L. (2009). Physical activity and abdominal obesity in youth. Applied Physiology Nutrition \& Metabolism 34, 571-581. doi:10.1139/H09-066.

Yore, M., Ham, S., Ainsworth, B., Kruger, J., Reis, J., Kohl, H., \& Macera, C. (2007). Reliability and validity of the instrument used in BRFSS to assess physical activity. Medicine and Science in Sports and Exercise, 39, 1267-1274. Retrieved from http://www.ncbi.nlm.nih.gov/pubmed/17762359 
Zeigler-Johnson, C., Weber, A., Glanz, K., Spangler, E., \& Rebbeck, T. R. (2013).

Gender- and ethnic-specific associations with obesity: individual and neighborhood-level factors. Journal of the National Medical Association, 105, 173-182. Retrieved from http://www.ncbi.nlm.nih.gov/pubmed/24079218

Zheng, H., \& Yang, Y. (2012). Population heterogeneity in the impact of body weight on mortality. Social Science \& Medicine, 75, 990-996.

doi:10.1016/j.socscimed.2012.05.013

Zive, M., \& Rhee, K. (2014). Call to action: Continuum of care for females of reproductive age to prevent obesity and ensure better health outcomes of offspring through nutrition. Clinical Obstetrics and Gynecology, 57(3), 446-455 doi:10.1097/grf.0000000000000046 
Appendix A: Invitation Flyer

\section{Invitation Flyer}

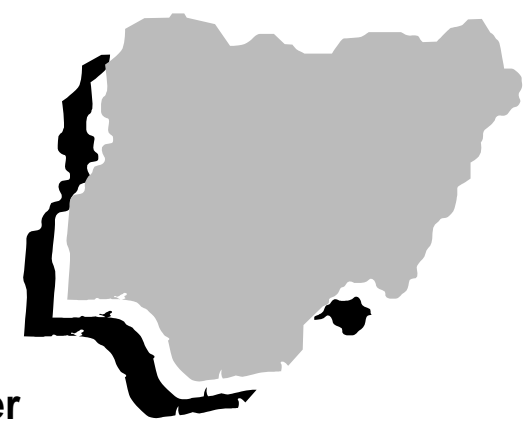

If you are 18 years or older and a Nigerian-born immigrant who has lived in the United States for two years or more, you might be interested in participating in a voluntary research study on obesity among Nigerian immigrants in the United States. Obesity is a health condition characterized by a body mass index (BMI) of $\geq 30 \mathrm{~kg} / \mathrm{m} 2$, and has been identified as a risk factor for the development of chronic diseases such as diabetes, coronary artery diseases and certain cancers.

To participate in this study, please go to https://www.surveymonkey.com/s/obesity-in-Nigerian-immigrants. Please know that participation in this survey is voluntary and you are not obligated to submit this survey, even if you change your mind after beginning the survey.

This survey does not contain any identifying information allowing for confidentiality and protection of your privacy. This data will also be transmitted electronically and stored on a password-protected computer to safeguard your data.

Please only complete this survey if you are 18 years or older, a Nigerianborn immigrant, and have lived in the United States for two years or more. To obtain an accurate measurement of the prevalence of obesity in the Nigerian Immigrant population in the United States, please do not complete this survey if you are pregnant and not mentally-capable of consenting.

This process will take 15 to 20 minutes. If you have any questions, please call Olawunmi Obisesan at $(\mathrm{XXX}) \mathrm{XXX}-\mathrm{XXXX}$ 


\section{Appendix B: Consent Form}

Hello everyone!

My name is Olawunmi Obisesan, a Public Health (Epidemiology) doctoral student from Walden University. I am conducting a research on obesity among Nigerian immigrants, ages 18 years and older, in the United States. Obesity is a health condition characterized by a body mass index (BMI) of $\geq 30 \mathrm{~kg} / \mathrm{m}^{2}$, and has been identified as a risk factor for the development of chronic diseases such as diabetes, coronary artery diseases and certain cancers.

This letter serves as a formal invitation to you to participate in my research survey which contains questions about the demographic characteristics, as well as length of stay, diet, and level of physical activity of Nigerian immigrants in the United States. This survey will take between 10 to 15 minutes of your time and your participation is voluntary; there is no penalty for refusing to participate or submit your survey. There is also no risk or penalty associated with participating in this survey, and each survey contains no identifying information that can directly link you to the survey submitted. The data obtained from this survey will also be stored on a password-protected computer to safeguard your information.

Your participation is very important as this research may provide information on predictors of obesity in the Nigerian immigrant population; this could provide insight into how to tailor public health interventions that target these unique predictors of obesity and subsequently prevent obesity-associated chronic diseases. Please only complete this 
survey if you are 18 years or older, a Nigerian-born immigrant, and have lived in the United States for two years or more. To obtain an accurate measurement of the prevalence of obesity in the Nigerian Immigrant population in the United States, please do not complete this survey if you are pregnant and not mentally-capable of consenting.

By submitting this survey, you indicate you understand the questions being asked in the survey, provide your consent to voluntarily participate in this research anonymously, and are not under any pressure to participate. Please direct any questions or concerns about this research process to me at $\mathrm{XXX}-\mathrm{XXX}-\mathrm{XXXX}$ or at olawunmi.obisesan@waldenu.edu. If you have any questions or concerns about your rights as a participant in this research, please call Dr. Leilani Endicott, the Walden University research representative, at XXX-XXX-XXXX. My Walden University's approval number for this study is 11-26-14-0160632; this expires on November 25, 2015. Please feel free to keep/print a copy of this consent form for your records. 
Appendix C: Modified BRFSS Questionnaire

Are you a Nigerian immigrant? _ Yes _ No

Gender

Male

Female

What is your age? _-

How long have you lived in the United States?

Months

Years

What is the highest grade or year of school you completed?

1 Never attended school or only attended kindergarten

2 Grades 1 through 8 (Elementary)

3 Grades 9 through 11 (Some high school)

4 Grade 12 or GED (High school graduate)

5 College 1 year to 3 years (Some college or technical school)

6 College 4 years or more (College graduate)

Are you currently...?

1 Employed for wages

2 Self -employed

3 Out of work for 1 year or more

4 Out of work for less than 1 year

5 A Homemaker

6 A Student

7 Retired

8 Unable to work

9 Refused

Is your annual household income from all sources

_ $\$ 20,000$ to less than $\$ 25,000$

_ $\$ 15,000$ to less than $\$ 20,000$ 
_ $\$ 10,000$ to less than $\$ 15,000$

- $\$ 25,000$ to less than $\$ 35,000$

_ $\$ 35,000$ to less than $\$ 50,000$

_ $\$ 50,000$ to less than $\$ 75,000$

_ $\$ 75,000$ or more

Do you own or rent your home?

1 Own

2 Rent

3 Other arrangement

7 Don't know / Not sure

About how much do you weigh without shoes?

$\overline{\text { Weight }}$ (pounds/kilograms)

7777

Don't know / Not sure

About how tall are you without shoes?

Round fractions up

- I _ -

Height (ft/inches/meters/centimeters)

$77 / 77$

Don't know / Not sure

\section{Alcohol and Sugar-Sweetened Fruit Drinks/Soda Consumption}

During the past 30 days, how many days per week or per month did you have at least one drink of any alcoholic beverage such as beer, wine, a malt beverage or liquor?

1 _ _ Days per week

$2 \ldots$ Days in past 30 days

888 No drinks in past 30 days

777 Don't know / Not sure

999 Refused

One drink is equivalent to a 12 ounce beer, a 5-ounce glass of wine, or a drink with one shot of liquor. During the past 30 days, on the days when you drank, about how many drinks did you drink on the average?

NOTE: A 40 ounce beer would count as 3 drinks, or a cocktail drink with 2 shots would count as 2 drinks. 
- Number of drinks

$\overline{7} \overline{7}$ Don't know / Not sure

99 Refused

During the past 30 days, how often did you drink regular soda or pop that contains sugar? Do not include diet soda or diet pop.

1 _ Times per day

2 _ - Times per week

3 _ Times per month

777 Don't know / Not sure

During the past 30 days, how often did you drink sugar-sweetened fruit drinks (such as Kool-aid and lemonade), sweet tea, and sports or energy drinks (such as Gatorade and Red Bull)? Do not include 100\% fruit juice, diet drinks, or artificially sweetened drinks. $1_{-}$_ Times per day

2 _- Times per week

3 _ Times per month

777 Don't know / Not sure

\section{Fruits and Vegetables}

During the past month, how many times per day, week or month did you drink $100 \%$ PURE fruit juices? Do not include fruit-flavored drinks with added sugar or fruit juice you made at home and added sugar to. Only include $100 \%$ juice.

1 __Per day

2 __Per week

3 _ Per month

555 Never

777 Don't know / Not sure

999 Refused

During the past month, not counting juice, how many times per day, week, or month did you eat fruit? Count fresh, frozen, or canned fruit

1 __Per day

2 __ Per week

3 _ - Per month

555 Never

777 Don't know / Not sure 
999 Refused

During the past month, how many times per day, week, or month did you eat cooked or canned beans, such as refried, baked, black, garbanzo beans, beans in soup, soybeans, edamame, tofu or lentils. Do NOT include long green beans.

1 __Per day

2 __Per week

3 __Per month

555 Never

777 Don't know / Not sure

999 Refused

During the past month, how many times per day, week, or month did you eat dark green vegetables for example broccoli or dark leafy greens including romaine, chard, collard greens or spinach?

1 _ Per day

2__Per week

3 _ Per month

555 Never

777 Don't know / Not sure

999 Refused

During the past month, how many times per day, week, or month did you eat orangecolored vegetables such as sweet potatoes, pumpkin, winter squash, or carrots?

1 __Per day

2 __Per week

3 _ - Per month

555 Never

777 Don't know / Not sure

999 Refused

Not counting what you just told me about, during the past month, about how many times per day, week, or month did you eat OTHER vegetables? Examples of other vegetables include tomatoes, tomato juice or V-8 juice, corn, eggplant, peas, lettuce, cabbage, white potatoes that are not fried such as baked or mashed potatoes, corn, peas, tomatoes, okra, beets, cauliflower, bean sprouts, avocado, cucumber, onions, peppers (red, green, yellow, orange); all cabbage including American-style cole-slaw; mushrooms, snow peas, snap peas, broad beans, string, wax-, or pole-beans. 
1 __Per day

2 __Per week

3 _ - Per month

555 Never

777 Don't know / Not sure

999 Refused

\section{Physical Activity}

In the last week, how many times did you exercise at least 20 minutes hard enough to breathe fast, speed up your heart rate, or work up a sweat?

times in the last week

When you are at work, which of the following best describes what you do? Would you say:

1 Mostly sitting or standing

2 Mostly walking

3 Mostly heavy labor or physically demanding work

Now, thinking about the moderate activities you do, when you are not working, in a usual week, do you do moderate activities for at least 10 minutes at a time, such as brisk walking, bicycling, vacuuming, gardening, or anything else that causes some increase in breathing or heart rate?

Yes

2 No

7Don't know / Not sure

How many days per week do you do these moderate activities for at least 10 minutes at a time?

_- Days per week

88 Do not do any moderate physical activity for at least 10 minutes at a time?

77 Don't know / Not sure

Now, thinking about the vigorous activities you do, when you are not working, in a usual week, do you do vigorous activities for at least 10 minutes at a time, such as running, aerobics, heavy yard work, or anything else that causes large increases in breathing or heart rate?

1 Yes

2 No 
7 Don't know / Not sure

How many days per week do you do these vigorous activities for at least 10 minutes at a time?

- - Days per week

88 Do not do any vigorous physical activity for at least 10 minutes at a time

77 Don't know / Not sure

During the past month, how many times per week or per month did you do physical activities or exercises to STRENGTHEN your muscles? Do NOT count aerobic activities like walking, running, or bicycling. Count activities using your own body weight like yoga, sit-ups or push-ups and those using weight machines, free weights, or elastic bands. 1__ Times per week

2__Times per month

888 Never

777 Don't know / Not sure

\section{Social Context}

How often in the past 12 months would you say you were worried or stressed about having enough money to pay your rent/mortgage? Would you say you were worried or stressed:

1 Always

2 Usually

3 Sometimes

4 Rarely

5 Never

How often in the past 12 months would you say you were worried or stressed about having enough money to buy nutritious meals? Would you say you were worried or stressed:

1 Always

2 Usually

3 Sometimes

4 Rarely

5 Never

How often do you get the social and emotional support you need from any source?

1 Always

2 Usually

3 Sometimes 
4 Rarely

5 Never 